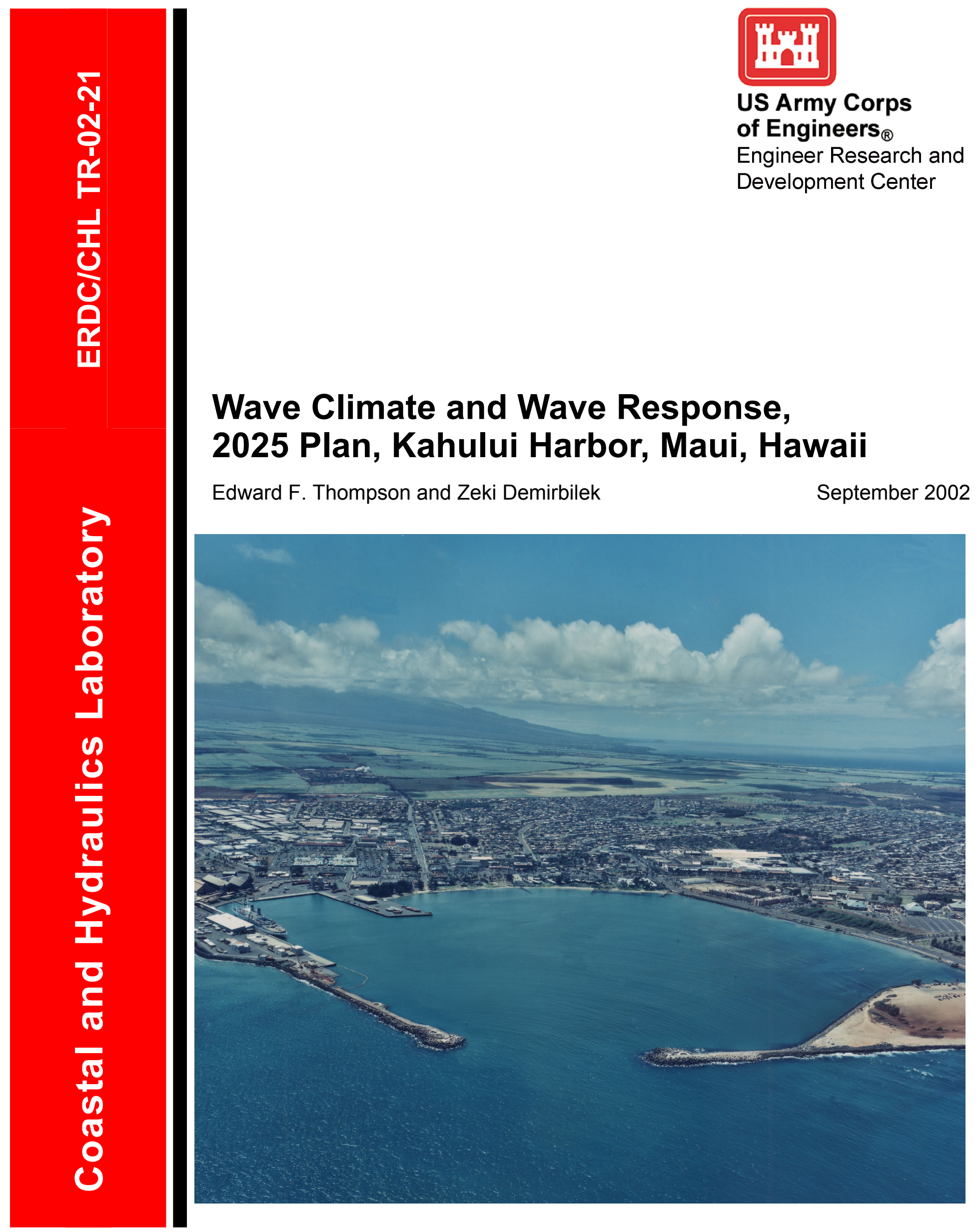


The contents of this report are not to be used for advertising, publication, or promotional purposes. Citation of trade names does not constitute an official endorsement or approval of the use of such commercial products.

The findings of this report are not to be construed as an official Department of the Army position, unless so designated by other authorized documents. 


\section{Wave Climate and Wave Response, 2025 Plan, Kahului Harbor, Maui, Hawaii}

by Edward F. Thompson, Zeki Demirbilek

Coastal and Hydraulics Laboratory

U.S. Army Engineer Research and Development Center 3909 Halls Ferry Road

Vicksburg, MS 39180-6199

Final report

Approved for public release; distribution is unlimited

Prepared for U.S. Army Engineer District, Honolulu

Ft. Shafter, HI 96858-5440 


\section{Contents}

Preface for

SF 298 


\section{List of Figures}

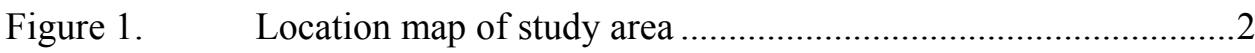

Figure 2. Kahului Harbor aerial photo (from State of Hawaii 2000) ..........................................................................2

Figure 3. Kahului Harbor aerial photo, commercial piers

(from State of Hawaii 2000)........................................................

Figure 4. Kahului Harbor, existing plan ..................................................4

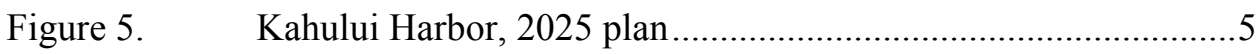

Figure 6. Kahului Harbor entrance plans for modeling ..............................

Figure 7. Location map for wave climate study ......................................

Figure 8. Wave height roses, annual, NDBC buoy $51026 \ldots \ldots \ldots \ldots \ldots \ldots \ldots . . . . . . .10$

Figure 9. Wave period roses, annual, NDBC buoy $51026 \ldots \ldots \ldots \ldots \ldots \ldots \ldots \ldots . . . . . . . . . .10$

Figure 10. Wave height roses, winter, NDBC buoy $51026 \ldots \ldots \ldots \ldots \ldots \ldots \ldots . . . . . . . . . . .12$

Figure 11. Wave period roses, winter, NDBC buoy $51026 \ldots \ldots \ldots \ldots \ldots \ldots \ldots \ldots . . . . . . . . .12$

Figure 12. Wave height roses, summer, NDBC buoy $51026 \ldots \ldots \ldots \ldots \ldots \ldots \ldots . . . . .13$

Figure 13. Wave period roses, summer, NDBC buoy $51026 \ldots \ldots \ldots \ldots \ldots \ldots . . . . .13$

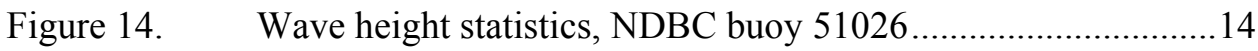

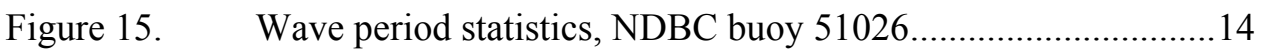

Figure 16. Map showing exposure to deepwater waves ............................15

Figure 17. Wave height roses, Kahului array ...........................................16

Figure 18. Wave period roses, Kahului array ..........................................16

Figure 19. Wave height statistics, Kahului array …...................................17

Figure 20. Wave period statistics, Kahului array...................................... 17

Figure 21. Percent occurrence, significant wave height vs. direction, Kahului array, 1994................................................18

Figure 22. Percent occurrence, peak wave period vs. direction, Kahului array, 1994................................................18

Figure 23. Percent occurrence, peak wave period vs. significant height, Kahului array, 1994. 
Figure 24. SHOALS coverage: year 2000 points and contours in color, year 1999 points in background

Figure 25. SHOALS 2000 bathymetry .23

Figure 26. SHOALS bathymetry in vicinity of Kahului Harbor, merged 1999 and 2000 data ......................................23

Figure 27. Depth contours affecting navigation ......................................24

Figure 28. Model bathymetry, existing harbor .........................................25

Figure 29. Model wave reflection coefficients, short waves,

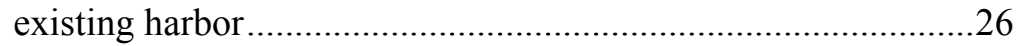

Figure 30. Model bathymetry, 2025 plan ….............................................2

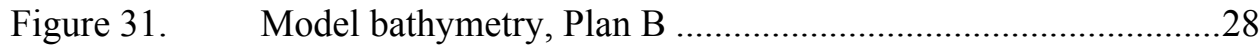

Figure 32. Model bathymetry, Plan C ….............................................28

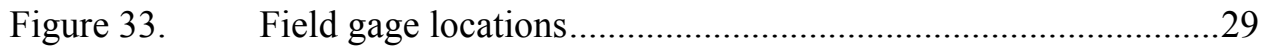

Figure 34. Model short wave calibration to four storm

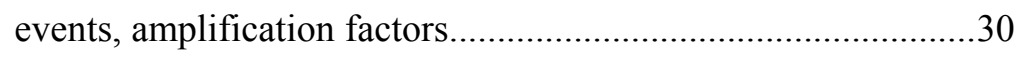

Figure 35. Incident short wave directions modeled ....................................32

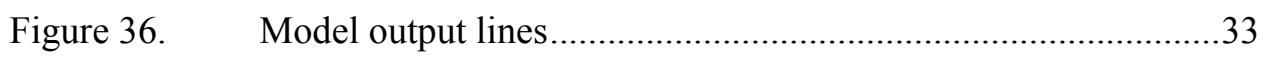

Figure 37. Wave height amplification factor, storm event of 3 Jan. 1994. 35

Figure 38. Wave height amplification factor, storm event of 20 Jan. 1994

Figure 39. Wave height amplification factor, storm event of 31 Jan. 1994. .36

Figure 40. Wave height amplification factor, storm event of 13 Mar. 1994

Figure 41. Comparison of $H_{s}$ exceeded 10 percent of time in entrance channel. .38

Figure 42. Comparison of $H_{s}$ exceeded 1 percent of time in entrance channel.

Figure 43. Comparison of $H_{s}$ exceeded 10 percent of time at piers .39

Figure 44. Comparison of $H_{s}$ exceeded 1 percent of time at piers .40

Figure 45. Harbor oscillation definitions 42 
Figure 46. Long wave response, existing harbor

Figure 47. Resonant long wave amplification factor contours, existing harbor

Figure 48. Resonant long wave phase contours, existing harbor

Figure 49. Long wave response, 2025 plan

.46

Figure 50. Resonant long wave amplification factor contours, 2025 plan

Figure 51. Resonant long wave phase contours, 2025 plan.........................48

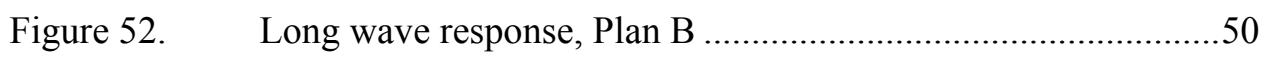

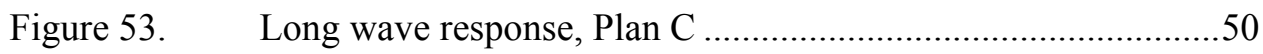

Figure 54. Resonant long wave amplification factor

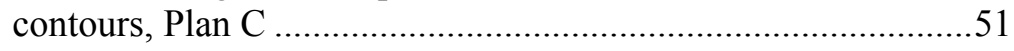

Figure 55. Resonant long wave phase contours, Plan C ...........................52

Figure 56. Percent occurrence of $H_{\text {slong }} \geq 10 \mathrm{~cm}$ at piers, $T$

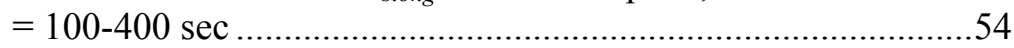

Figure 57. Percent occurrence of $H_{\text {slong }} \geq 10 \mathrm{~cm}$ at piers, $T$

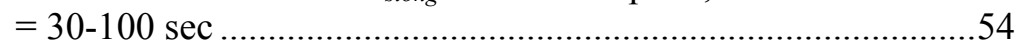

Figure 58. Resonant long wave velocity contours, existing

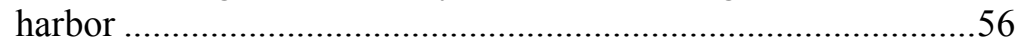

Figure 59. Resonant long wave velocity contours, 2025

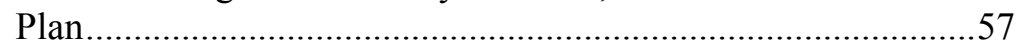

Figure 60. Resonant long wave velocity contours, Plan C .........................58

\section{List of Tables}

Table 1. Sources for Wave Climate Information......................................

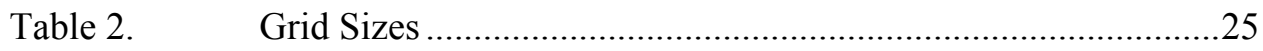

Table 3. Parameter Values Used in CGWAVE .......................................26

Table 4. Field Cases for Short Wave Model Calibration,

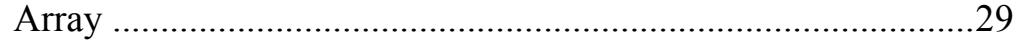

Table 5. Summary of Incident Short Wave Conditions ...........................31

Table 6. Summary of Incident Long Wave Conditions..............................32 
Table 7. Plans with $H_{s}>1 \mathrm{ft}$ Less than 1 Percent of Time.

Table 8. Plans with $A_{\text {amp }, l}$ Along Piers Comparable to or Less than Existing Harbor Piers ..

Table 9. Plans With Percent $H_{\text {slong }} \geq 10 \mathrm{~cm}$ Along Piers Comparable to or Less than Existing Harbor Piers, 100- to 400-sec Periods.

Table 10. Plans With Percent $H_{\text {slong }} \geq 10 \mathrm{~cm}$ Along Piers

Comparable to or Less than Existing Harbor

Piers, 30- to 100-sec Periods .........................................................61

Table 11. Plans with Maximum Long Wave Velocity

Along Piers Comparable to or Less than Existing

Harbor Piers. 


\section{Preface}

This report describes procedures and results of a wave climate and wave response study for Kahului Harbor, Maui, HI. The study was performed in support of long-range planning for the Kahului Commercial Harbor, as reflected in the Kahului Commercial Harbor 2025 Master Plan. The study was performed by the U.S. Army Engineer Research and Development Center (ERDC), Coastal and Hydraulics Laboratory (CHL), for the U.S. Army Engineer District, Honolulu, in coordination with Harbors Division, Department of Transportation (HDOT), State of Hawaii. The study was conducted during the period May 2001 through April 2002.

Mr. Stan Boc, U.S. Army Engineer District, Honolulu, and Mr. Dean Watase, HDOT, were the study managers and points of contact. Meetings at critical points in the study were the preproject review on 17-18 October 2001 at CHL, and the final review on 18 March 2002 at HDOT.

The investigation reported herein was conducted by Drs. Edward F. Thompson and Zeki Demirbilek, both of the Coastal Harbors and Structures Branch, CHL. The final report was prepared by Dr. Thompson.

This study was performed under the general supervision of Mr. Thomas W. Richardson, Director, CHL. Direct supervision of this project was provided by Mr. Dennis G. Markle, Chief, Coastal Harbors and Structures Branch.

At the time of publication of this report, Dr. James R. Houston was Director of ERDC, and COL John W. Morris III, EN, was Commander and Executive Director.

The contents of this report are not to be used for advertising, publication, or promotional purposes. Citation of trade names does not constitute an official endorsement or approval of the use of such commercial products. 


\section{Conversion Factors, Non-SI to SI Units of Measurement}

Non-SI units of measurement used in this report can be converted to SI units as follows:

\begin{tabular}{||l|c|l||}
\hline \hline Multiply & By & To Obtain \\
\hline \hline degrees (angle) & 0.01745329 & radians \\
\hline feet & 0.3048 & meters \\
\hline miles (U.S. nautical) & 1.852 & kilometers \\
\hline tons (2,000 pounds, mass) & 907.1847 & kilograms \\
\hline
\end{tabular}




\section{Summary}

\section{Introduction}

Because of present and projected commercial activities in Kahului Harbor, the needs and concerns of community, private business, and government are periodically reviewed under the State of Hawaii planning process. New berths for barge and passenger ship operations are an expected future requirement. Space for related land-based facilities will be needed.

The new facilities would require expansion of harbor operations into areas not presently used, particularly areas west of the existing commercial piers. These areas are more exposed to wave energy passing through the entrance gap between breakwaters. During 1993-96, field wave measurements and numerical (computer) model studies to evaluate the technical feasibility of alternative modifications were conducted by the U.S. Army Corps of Engineers (USACE) at the U.S. Army Engineer Research and Development Center (ERDC), Coastal and Hydraulics Laboratory (CHL), Vicksburg, MS. Eleven alternative harbor plans were studied along with the existing harbor. The present study extends the earlier study to include three harbor alternatives based on updated planning, described in the State of Hawaii's Kahului Commercial Harbor 2025 Master Plan (see tabulation).

\begin{tabular}{||l|l|l|l|l|l||}
\hline \multicolumn{2}{|||}{ Summary of Kahului Harbor Plans and Wave Response } \\
\hline $\begin{array}{l}\text { Harbor } \\
\text { Plan }\end{array}$ & Distinctive Features & $\begin{array}{l}\text { Wind Waves } \\
\text { and Swell }\end{array}$ & $\begin{array}{l}\text { Surge } \\
\text { Oscillations }\end{array}$ & Remarks & $\begin{array}{l}\text { See } \\
\text { Figure }\end{array}$ \\
\hline $\begin{array}{l}2025 \\
\text { Plan }\end{array}$ & $\begin{array}{l}\text { Reoriented entrance channel; } \\
900 \text {-ft seaward stub on east } \\
\text { breakwater }\end{array}$ & 1 & 1 & $\begin{array}{l}\text { Higher wind waves and } \\
\text { swell at pier 5 than at } \\
\text { existing pier 1 }\end{array}$ & 5 \\
\hline Plan B & $\begin{array}{l}\text { Realigned 900-ft seaward stub } \\
\text { on east breakwater }\end{array}$ & 1 & 1 & $\begin{array}{l}\text { Higher wind waves and } \\
\text { swell at pier 5 than at } \\
\text { existing pier 1 }\end{array}$ & 6 \\
\hline Plan C & $\begin{array}{l}\text { 450-ft seaward stub on east } \\
\text { breakwater; 600-ft landward } \\
\text { stub on west breakwater }\end{array}$ & 1 & 2 & $\begin{array}{l}\text { Increased oscillations at } \\
\text { piers 1 and 2 as well as } \\
\text { pier 5 }\end{array}$ & 6 \\
\hline
\end{tabular}




\section{Study Results}

\section{Harbor basin}

Wind waves and swell in the harbor are affected by distance from the entrance, directional exposure, and bottom depths. Wave approach directions at the entrance are consistently aimed at the southwest part of the harbor. Facilities in the western harbor and located closer to the entrance are prone to increased wind wave and swell conditions. Stubs added to the east and west breakwater tips in harbor plans help shelter the harbor from wind waves and swell. Changes in the western harbor have no significant impact on wind waves and swell at existing facilities in the eastern harbor.

All of the proposed harbor plans have comparable or increased surge (or oscillation) activity relative to the existing harbor. The dredged access areas, straight piers, and interior breakwater stub added in alternative plans can facilitate surge motions. Changes in the western harbor can potentially worsen surge conditions at the existing commercial piers.

\section{Ship surge response}

Kahului Harbor experiences natural resonance modes, which cause standing waves in the harbor. These waves are commonly present in the harbor, but their height varies considerably according to incident wave conditions. High standing waves can cause operational difficulties such as excessive ship motion and high mooring line forces. Areas of greatest horizontal motion (nodal areas) are most likely to experience problems. Possible actions to remedy effects of the surge include proper ballasting as ships are offloaded, adjustment to mooring line tensions, and modifications to mooring line configuration.

\section{Piers 1-4}

Wind wave and swell activity at existing piers 1-3 and proposed pier 4 is not appreciably changed in any of the alternative plans. Surge level is increased in Plan C. A nodal area between the seaward end of pier 2 and the middle of pier 1 is visible in all plans, including the existing harbor.

\section{Barge facility}

Wind wave and swell heights at pier $2 \mathrm{C}$, extending southwest along the end of pier 2, are similar (though slightly higher) to the more seaward parts of existing piers 1 and 2. Surge activity is substantially lower than at existing facilities.

\section{Passenger ship pier}

Wind wave and swell protection varies greatly between plans, ranging from protection nearly as good as existing facilities to much worse. Surge activity is similar to or higher than the present pier 1. 


\section{Boat ramp}

Most plans have the added benefit of helping to shelter the boat ramp from wind waves and swell. Overall surge levels are generally similar to the existing harbor.

\section{Model performance}

The final numerical model behaved realistically when compared to field observations at Kahului Harbor. There is a high level of confidence in the predictions made by the model, especially those involving comparisons between harbor alternatives.

\section{Limitations}

There are inherent limits on the numerical model representations of the harbor response. Modeling did not include breaking waves or currents. Wave climate information used to evaluate each plan was based mainly on 12 months of field data. (Although 19 months of field data were collected, most analyses are based on a representative 12-month subset so that seasonal variations are properly weighted in statistical summaries.) Ship and mooring system responses, the ultimate operational concern, were not explicitly studied.

\section{Recommendations}

Recommended modifications to Kahului Harbor include dredging and a new pier for fuel barges between piers 1 and 3, a new barge facility along the southwest end of pier 2, and a new passenger ship pier located in the western harbor. Wave response of the plans considered in this study is summarized in the tabulation. The tolerance of passenger ship operations to wind wave and swell activity should be better established so that the significance of increased wave energy along pier 5 can be evaluated. Plan $\mathrm{C}$ is not recommended due to the potential for increased harbor oscillations at the main existing piers as well as proposed pier 5.

Results of this study should be combined with operational experience at existing facilities to define a most-promising general plan. A final optimized plan should be determined with the aid of a physical model. The numerical model should be validated against the physical model studies and insure that the final plan is free of problem surge response in existing pier areas and new facilities. Effects of future modifications to the harbor should be evaluated using the validated numerical model. 


\section{Introduction}

\section{Background}

Kahului Harbor is the only deep-draft harbor on the Island of Maui and the busiest port in Hawaii outside of the Island of Oahu. The harbor is approximately 94 miles $^{1}$ southeast of Honolulu and is conveniently located on Maui's north shore (Figure 1). Because of Kahului Harbor's size and commercial importance, the Harbors Division, Department of Transportation, State of Hawaii (HDOT), has devoted special care to long-range planning. Plans and concerns are described in the Kahului Commercial Harbor 2025 Master Plan (State of Hawaii 2000). The present study analyzes wave response of harbor alternatives in support of the 2025 master plan. This study is an extension of a previous, similar study (Thompson et al. 1996) based on the 2010 master plan for Kahului Harbor (State of Hawaii 1994).

Kahului Harbor is exposed to wind and waves from the north and northeast. The northwest end of Maui shelters the harbor from waves arriving from the northwest. The harbor is protected by two large breakwaters. High energy waves generated by intense winter storms in the north Pacific Ocean routinely attack the breakwaters. Hurricanes can also create large waves incident to the harbor. The breakwaters have a long history of construction and repair (Markle and Boc 1994; Sargent, Markle, and Grace 1988). Breakwaters are armored with molded concrete armor units of up to 35 tons on the trunk and 50 tons on the head. The harbor entrance is a $660-\mathrm{ft}$ opening between the breakwaters.

Commercial piers are located in the eastern part of the harbor (Figures 2 and 3). Piers are used by a variety of vessels including barges, container ships, passenger cruise ships, and tug boats. Pier 1 accommodates the larger overseas vessels and barges. Water depth in the Federal entrance channel, harbor basin, and commercial pier areas is $35 \mathrm{ft}$.

Two canoe clubs are located along the shore immediately southwest of pier 2. A large coral stockpile has been placed inside the harbor, adjacent to the west breakwater. This area, under the jurisdiction of the County of Maui, is being considered for park development. A public boat ramp is located near the landward end of the stockpile (Figure 4). The southern shore of the harbor, between the boat ramp and canoe clubs, includes a revetment along Kahului Beach Road and several rock groins further east.

\footnotetext{
${ }^{1}$ A table of factors for converting non-SI units of measurement to SI units is presented on page ix.
} 


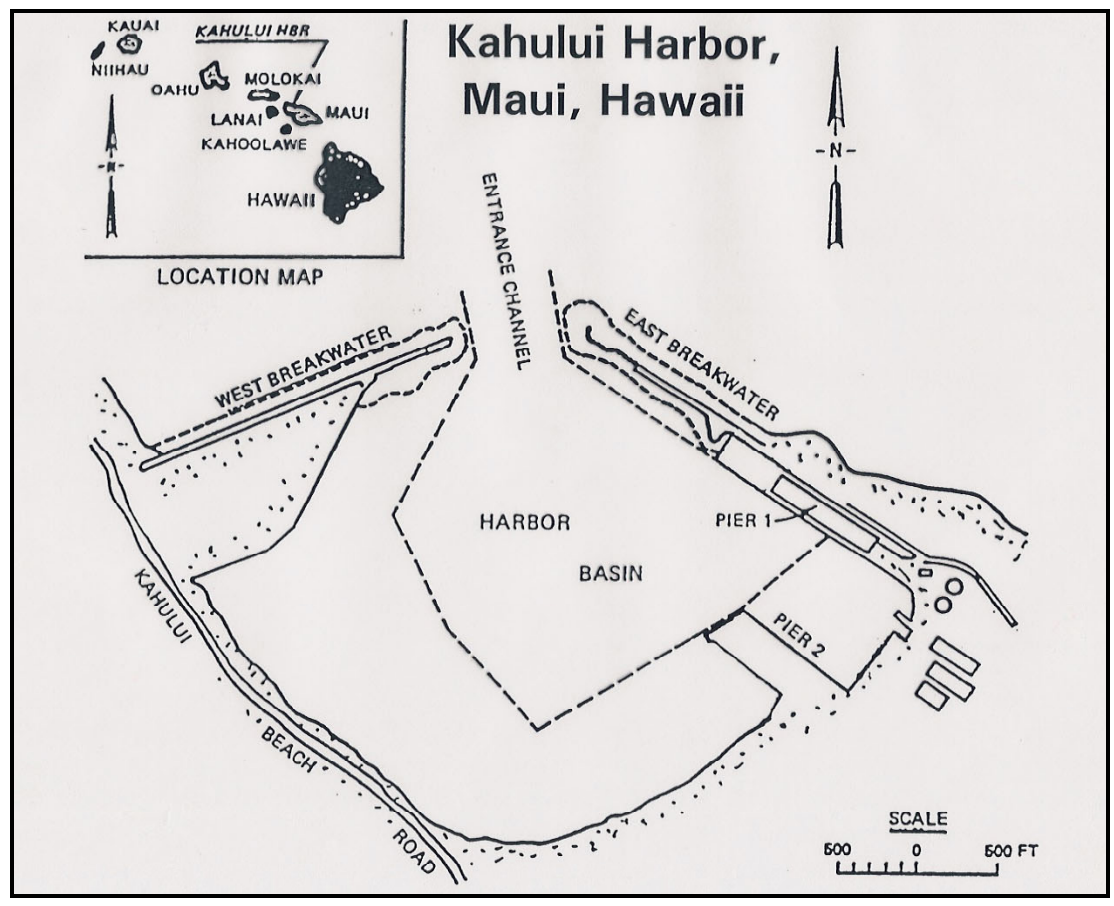

Figure 1. Location map of study area

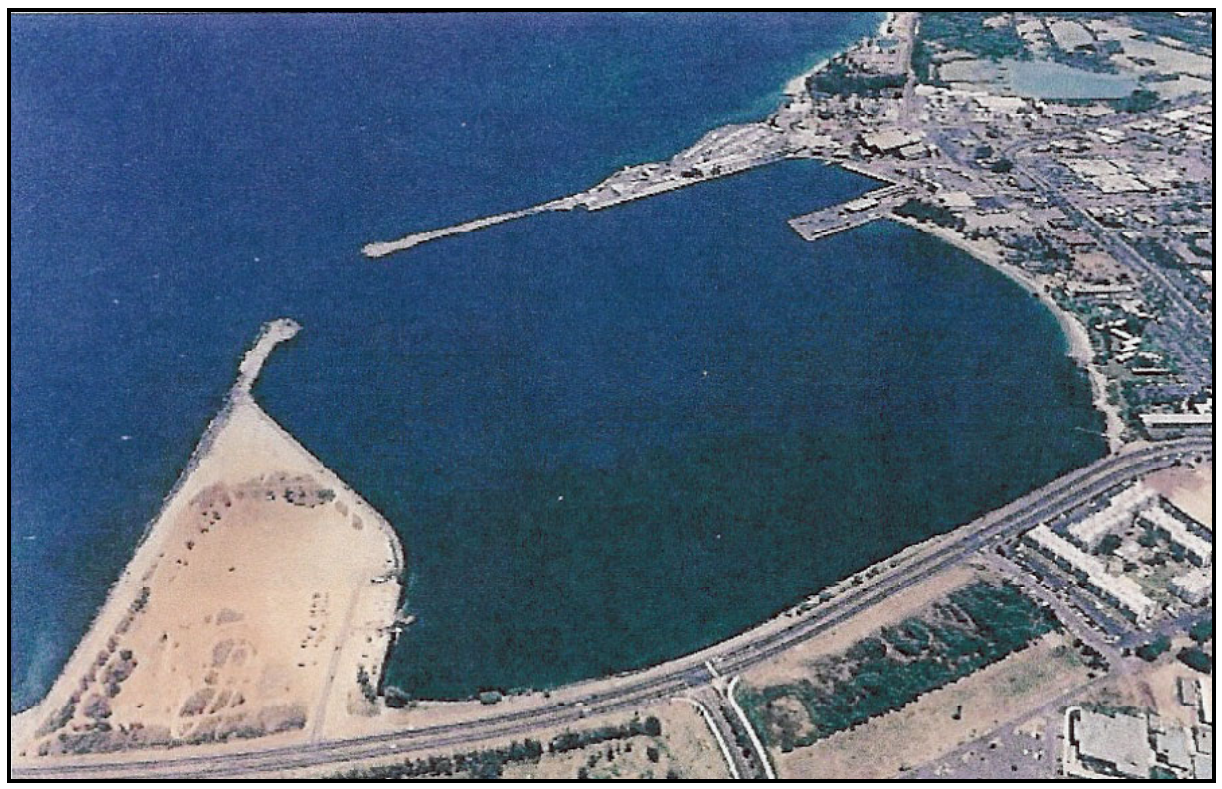

Figure 2. Kahului Harbor aerial photo (State of Hawaii 2000) 


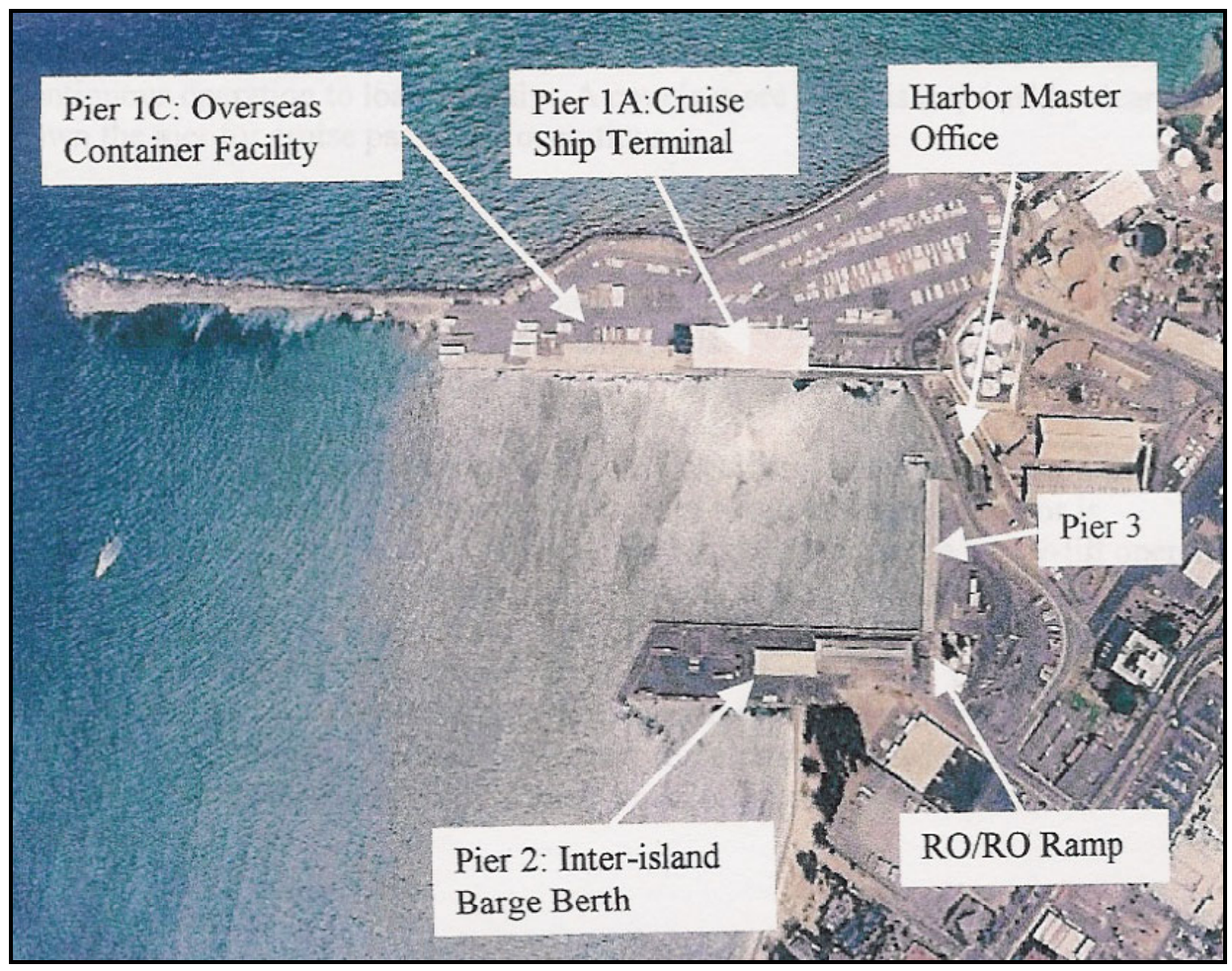

Figure 3. Kahului Harbor aerial photo, commercial piers (State of Hawaii 2000)

\section{Study Approach}

The study described in this report was performed by the U.S. Army Engineer Research and Development Center (ERDC), Coastal and Hydraulics Laboratory (CHL), in support of the 2025 master plan for Kahului Harbor. The approach consisted of the following components:

a. Develop annual and seasonal incident wave climate summaries from available gage data.

$b$. Use gage data to calibrate and validate numerical wave model CGWAVE.

c. Use the numerical model to investigate alternative harbor modification plans.

As part of the previous CHL study, field wave gages were installed outside the harbor entrance and at four locations inside the harbor (Thompson et al. 1996). The outside gage was an array of pressure sensors capable of providing directional wave data. The inside gages were single, nondirectional pressure sensors. As in the previous study, data from these gages were a valuable component of the present study. 


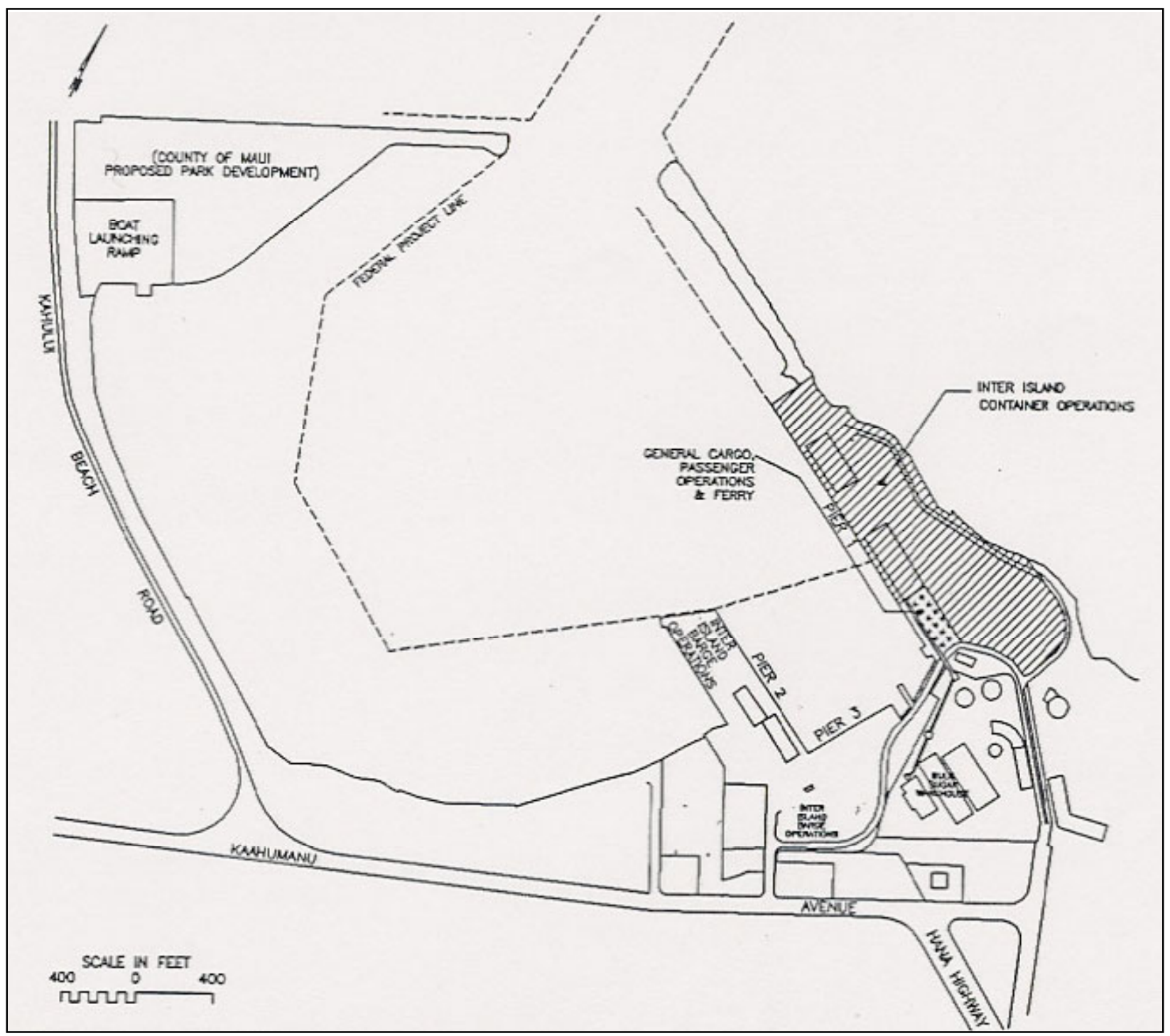

Figure 4. Kahului Harbor, existing plan

Wind wave and swell climate was investigated primarily with data from National Data Buoy Center (NDBC) buoy 51026, located offshore in deep water north of the island of Molokai. Over 4 years of directional wave data are available. Statistics from the array gage outside the harbor entrance were evaluated relative to the multiyear offshore climate. The wave climate study is presented in Chapter 2.

Numerical wave model CGWAVE, the present state-of-the-art CHL model for harbor wave response studies, was set up to cover the entire harbor and the area outside the harbor extending beyond the array wave gage. The model was tested, calibrated, and validated, mainly using the field data. Two alternative harbor plans, variations of the 2025 master plan (Figure 5), were defined as part of the preproject review meeting. Thus, with the 2025 master plan, the study 


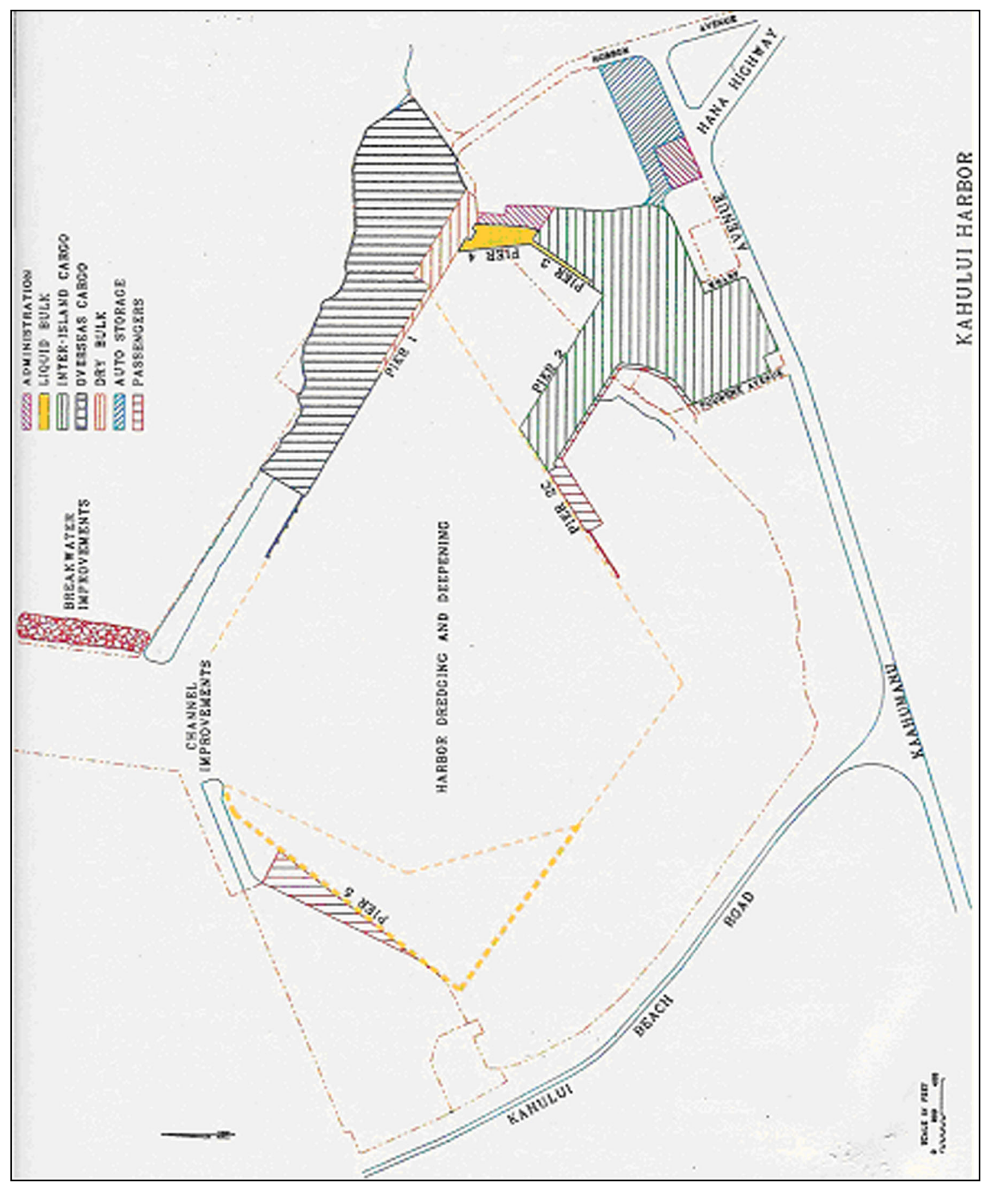

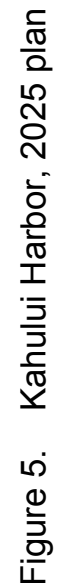


included a total of three plans and the existing harbor. All plans included the following features:

a. New, solid-fill cruise passenger pier adjacent to the coral stockpile (tentatively named pier 5).

b. Pile-supported extension of the seaward end of pier 2 toward the southwest (pier 2C).

c. Expanded turning basin to provide $35-\mathrm{ft}$ depth to pier 5 .

d. Dredged area in the vicinity of piers 3 and 4 to provide 25 - $\mathrm{ft}$ depth for fuel barges.

Plans selected for study differ only in the length and placement of stub extensions to the tips of existing breakwaters and in the orientation of the entrance channel. Special features of each plan are (Figure 6):

a. 2025 master plan. Realigned entrance channel to approximately 6 deg azimuth; 900 -ft stub extending seaward from tip of east breakwater, oriented parallel to realigned entrance channel.

b. Plan B. 900-ft stub extending seaward from tip of east breakwater, oriented parallel to existing entrance channel.

c. Plan C. 450- $\mathrm{ft}$ stub extending seaward from tip of east breakwater, oriented parallel to existing entrance channel; 600 -ft stub extending landward from tip of west breakwater, oriented parallel to existing entrance channel.

Development and calibration of the numerical model and test procedures is described in Chapter 3.

Response of the alternative harbor plans to wind waves and swell (short waves) is presented in Chapter 4. Harbor oscillation characteristics (response to long waves) are presented in Chapter 5. For both short and long waves, the harbor response is related to wave climate and to relevant operational criteria at commercial piers.

Conclusions and recommendations are given in Chapter 6. This chapter is followed by references. 


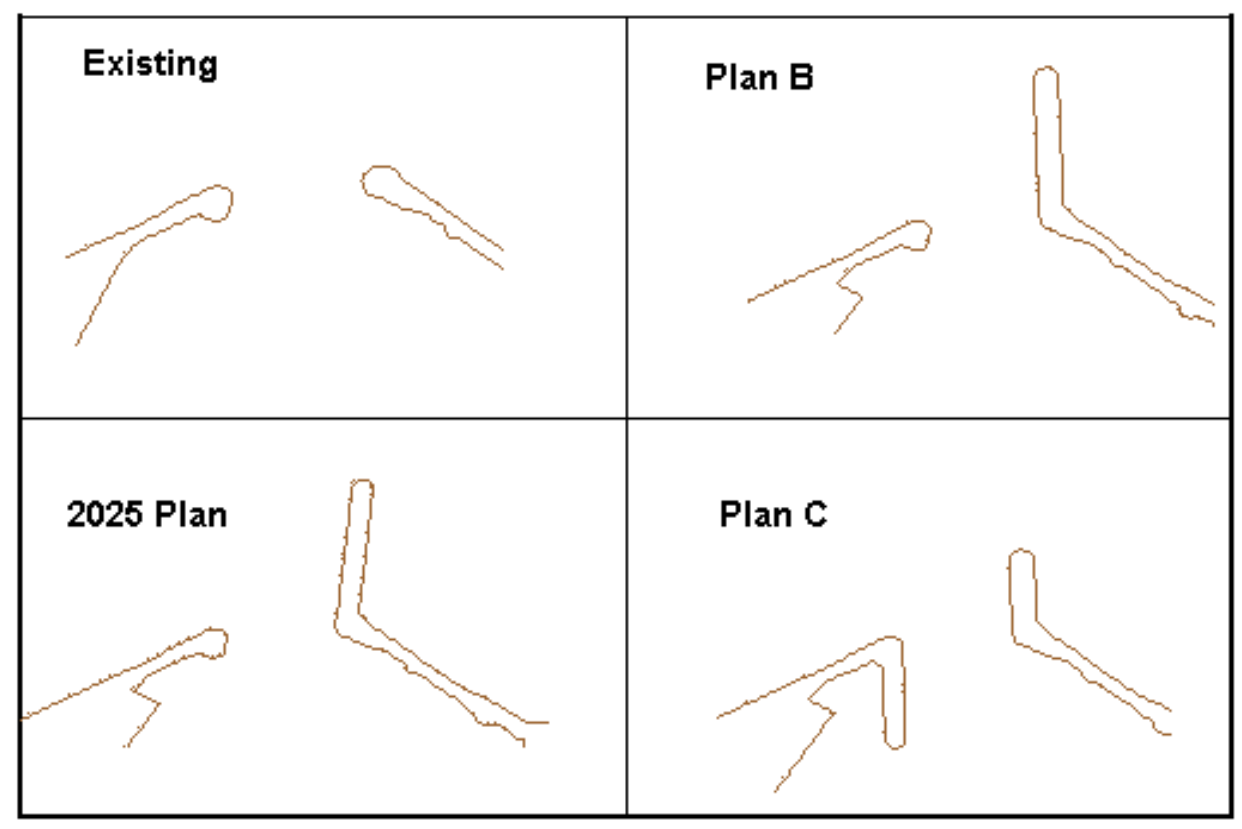

Figure 6. Kahului Harbor entrance plans for modeling 


\section{Wind Wave and Swell Climate}

\section{Sources}

Two sources of wind wave and swell field data were available to develop wave climate outside the harbor entrance (Table 1 and Figure 7). The first was the directional array gage in $14.5-\mathrm{m}(47.6-\mathrm{ft})$ depth just outside the harbor entrance, part of the Coastal Data Information Program (CDIP), a joint effort of the U.S. Army Corps of Engineers (USACE) and the California Department of Boating and Waterways (CDIP Gage 77). The CDIP is a network of gages operated by the Scripps Institution of Oceanography (SIO). Data from November 1993 through May 1995 were available from the Kahului array.

The second source of wind wave and swell data was the directional buoy north of Molokai (NDBC buoy 51026) with data from January 1993 through November 1996, except for a gap in May-September 1994. The objectives were to summarize offshore and nearshore incident wave climate, and to use the longer term offshore data record to establish whether the shorter term array gage record is sufficiently representative of the general wave climate. A similar wave climate analysis was required in the previous study, but at that time only hindcast information was available in sufficient quantity to document the multiyear offshore wave climate. This analysis was repeated in the present study because sufficient NDBC buoy data are now available for climate analysis and they are expected to be significantly more accurate than available hindcasts.

The NDBC buoy is in deeper water than the Kahului array. Also, it is exposed to a wider range of incident wave directions. The buoy has a wide open exposure to directions from northwest to south of east. The buoy is somewhat sheltered from waves approaching the Hawaiian Islands from west, principally by the Island of Oahu. In contrast, the Island of Maui provides considerably more shelter to the Kahului array and the entrance to Kahului Harbor.

\begin{tabular}{||l|l|l|l||}
\hline \hline \multicolumn{4}{|l||}{$\begin{array}{l}\text { Table } 1 \\
\text { Sources for Wave Climate Information }\end{array}$} \\
\hline \hline Source & Years & Latitude (deg N) & Longitude (deg W) \\
\hline \hline CDIP Gage 77 (Kahului array) & $1993-95$ & 20.90 & 156.47 \\
\hline NDBC Buoy 51026 (N. Molokai) & $1993-96$ & 21.37 & 156.96 \\
\hline \hline
\end{tabular}




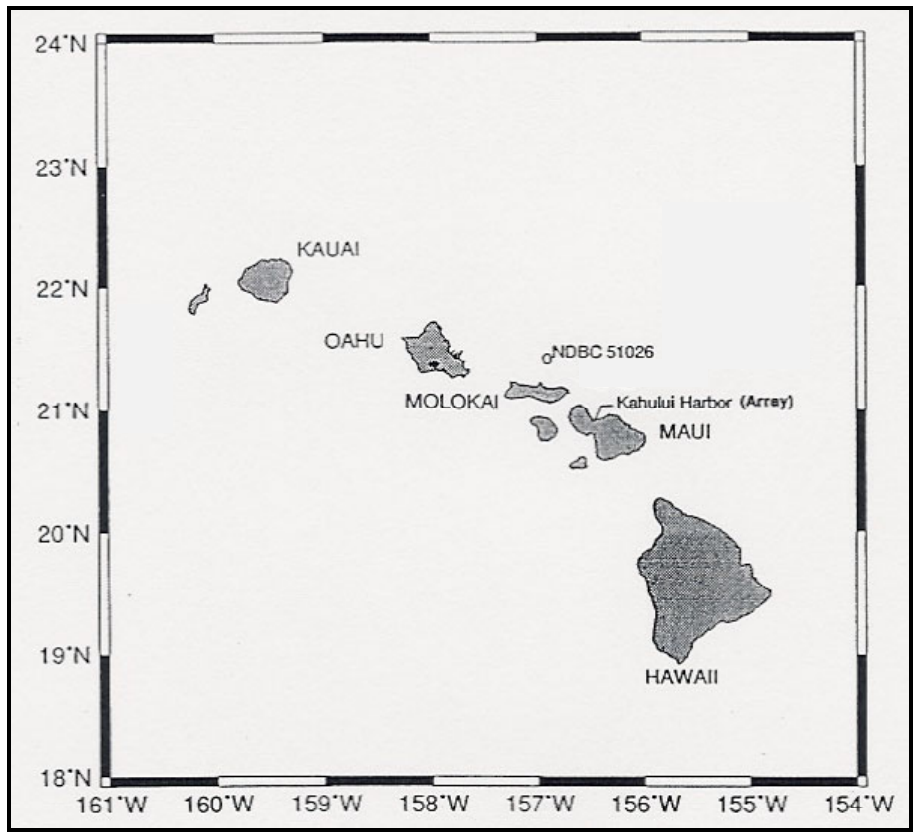

Figure 7. Location map for wave climate study

\section{Deepwater Wave Climate}

NDBC buoy 51026 provides four reasonably complete years of wave data, following calendar years 1993-1996. Wave climate was summarized for each year. Roses of significant wave height, $H_{s}$, show the percentage of wave measurements coming from different directions (Figure 8). The length of the radial bar in each direction shows the percentage from that direction. In each of the four years, the most common wave direction was from the east (23-33 percent of the measurements, depending on the year). Although wave directions are spread between northwest and east, two principal direction concentrations are consistently shown in every year: northwest to north-northwest and eastnortheast to east.

The width of the radial bars indicates significant wave height band. The lowest wave height bands are shown nearest the center of the rose. The radial bars become more narrow toward the outer end of each bar, indicating increasing wave heights. Bar width begins increasing again for the highest wave height bands (significant heights greater than $18 \mathrm{ft}$ ), but significant heights in this range are rare, as indicated by a few very short, wider sections at the outer end of some bars. A tendency for waves from the northwest sector to be higher than those from the east is shown. Although details of the significant height climate vary from year to year, general features of wave climate seem consistent in all four years.

Roses of peak wave period, $T_{p}$, are shown in Figure 9. Directional characteristics are the same as for significant heights. A strong tendency toward 


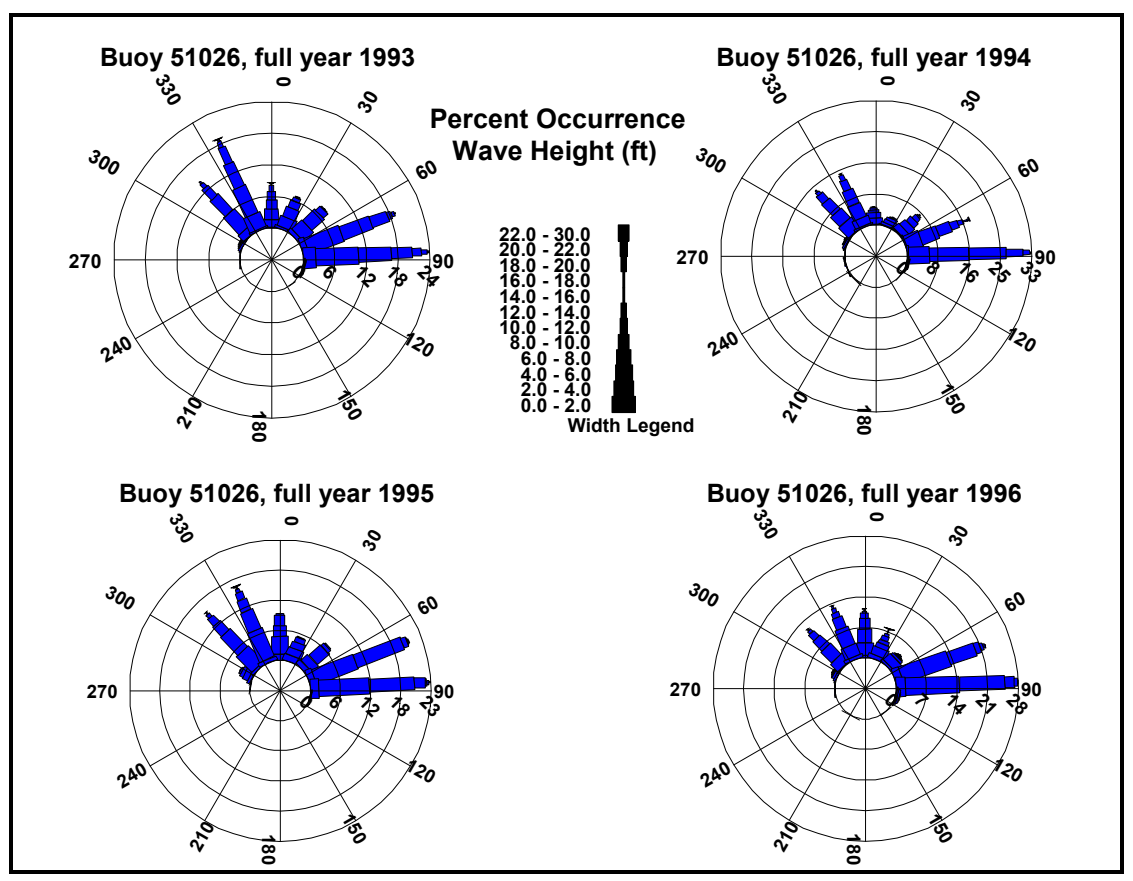

Figure 8. Wave height roses, annual, NDBC buoy 51026

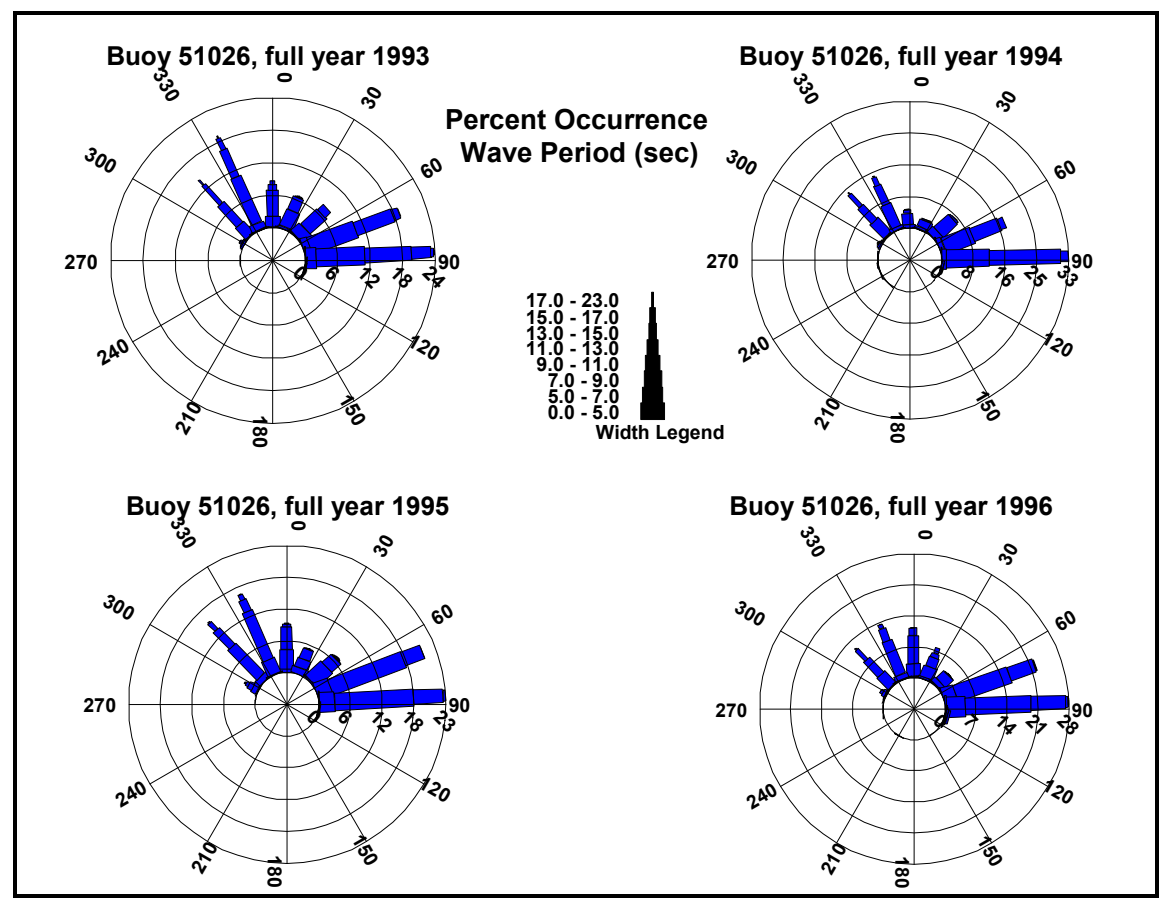

Figure 9. Wave period roses, annual, NDBC buoy 51026

relatively long wave periods from the northwest and shorter periods from the east is evident. 
Wave climate at most locations, including Kahului Harbor, has distinct seasonal characteristics. It is important that seasonal characteristics, especially storms, are included in the Kahului Harbor incident wave climate. To investigate seasonal wave climate, monthly mean wave parameters from NDBC buoy 51026 were reviewed to determine appropriate monthly groupings for seasons. Two distinct seasons were evident, a high wave energy (winter) season (October through April) and a low wave energy (summer) season (May through September).

The NDBC buoy record can provide four independent winters of data (three continuous winters and a fourth represented by October through December 1996 joined with January through April 1993). Significant wave height and peak wave period roses are given in Figures 10 and 11. These roses reveal that waves from northwesterly directions are more dominant in the winter climate than in the annual climate.

Only three summers are available from the NDBC buoy data, since the buoy was out of service during most of the summer of 1994. Wave roses show a very strong dominance of waves coming from easterly directions and very few wave events coming from the northwest (Figures 12 and 13).

Annual and seasonal $H_{s}$ statistics for NDBC buoy 51026 are given in Figure 14. Mean annual $H_{s}$ is about 7-8 ft with standard deviation of about $2.5 \mathrm{ft}$. Mean $H_{s}$ in the four winters is a little higher than the annual mean and lower in the three summers. Maximum $H_{s}$ during the winters is about $18-24 \mathrm{ft}$ versus about 13-15 ft during the summers.

Annual and seasonal $T_{p}$ statistics for NDBC buoy 51026 are given in Figure 15. Annual mean $T_{p}$ values are about 10-11 sec. Seasonal mean $T_{p}$ values tend to be one or two seconds longer than the annual mean during winter and correspondingly shorter during summer.

These offshore wave climate summaries show a reasonably strong consistency in both the annual and seasonal climate during the four years of measurement. In particular, the time period during which the Kahului array operated (October 1993 through May 1995) appears to be representative of the general climate and does not contain any noticeably unusual wave activity.

\section{Wave Climate at Kahului Harbor}

The deepwater wave climate analysis suggests that data from the array would reasonably characterize wave climate immediately incident to Kahului Harbor. The array measurements incorporate local effects of sheltering and bathymetry. The Island of Maui helps to block wave energy from both the northwest and east (Figure 16). In addition, fringing reefs extend from the Maui coast both east and west of the harbor entrance and serve to further restrict the directional exposure of the entrance.

The Kahului array provided sufficient data to give annual and summer information for 1 year and winter information for 2 years. Significant wave 


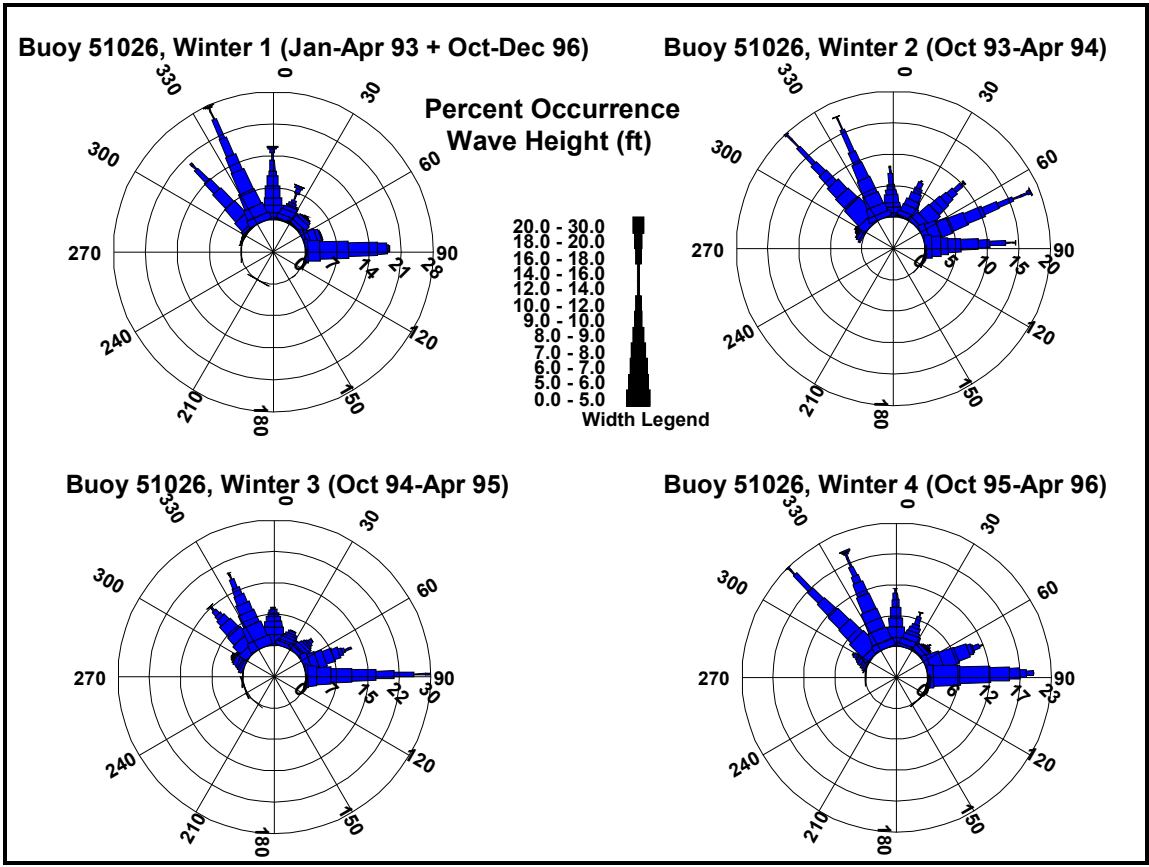

Figure 10. Wave height roses, winter, NDBC buoy 51026

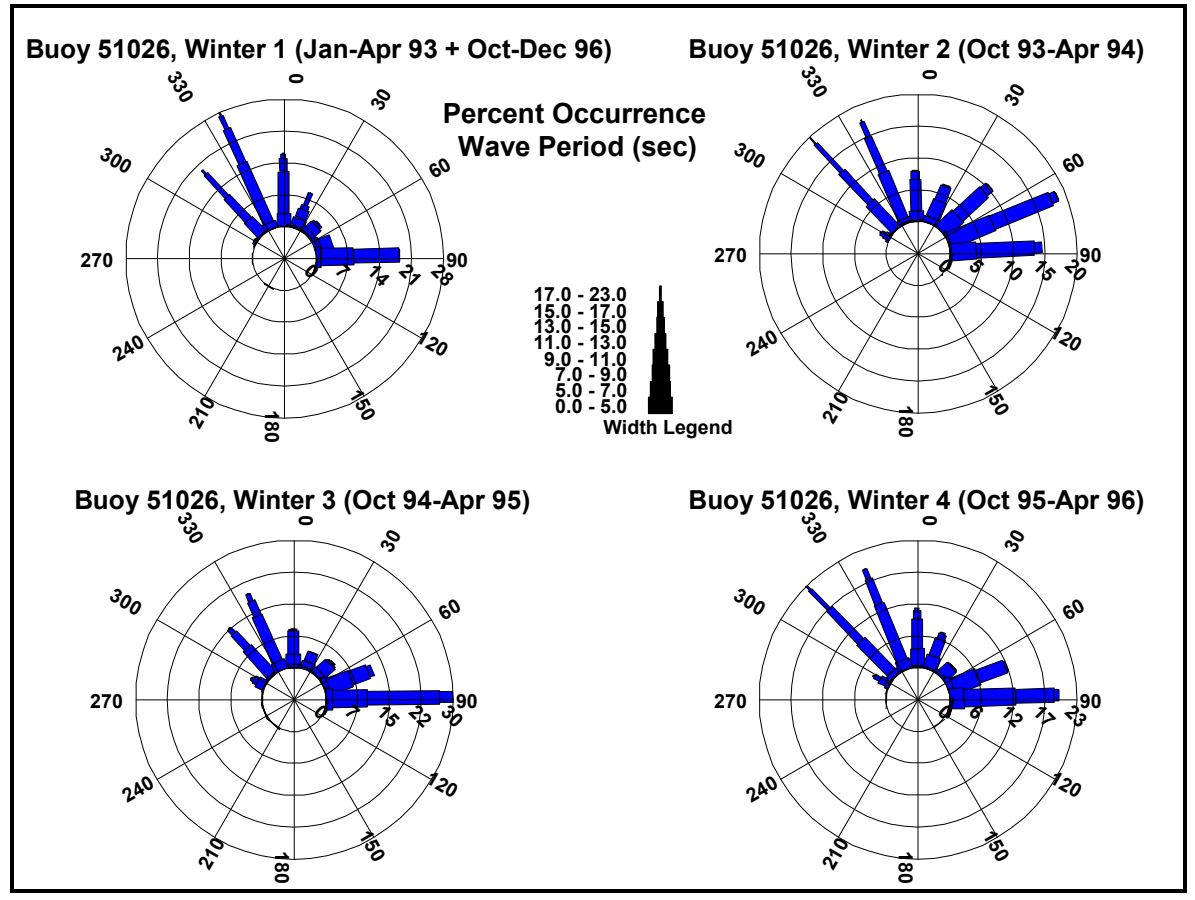

Figure 11. Wave period roses, winter, NDBC buoy 51026 


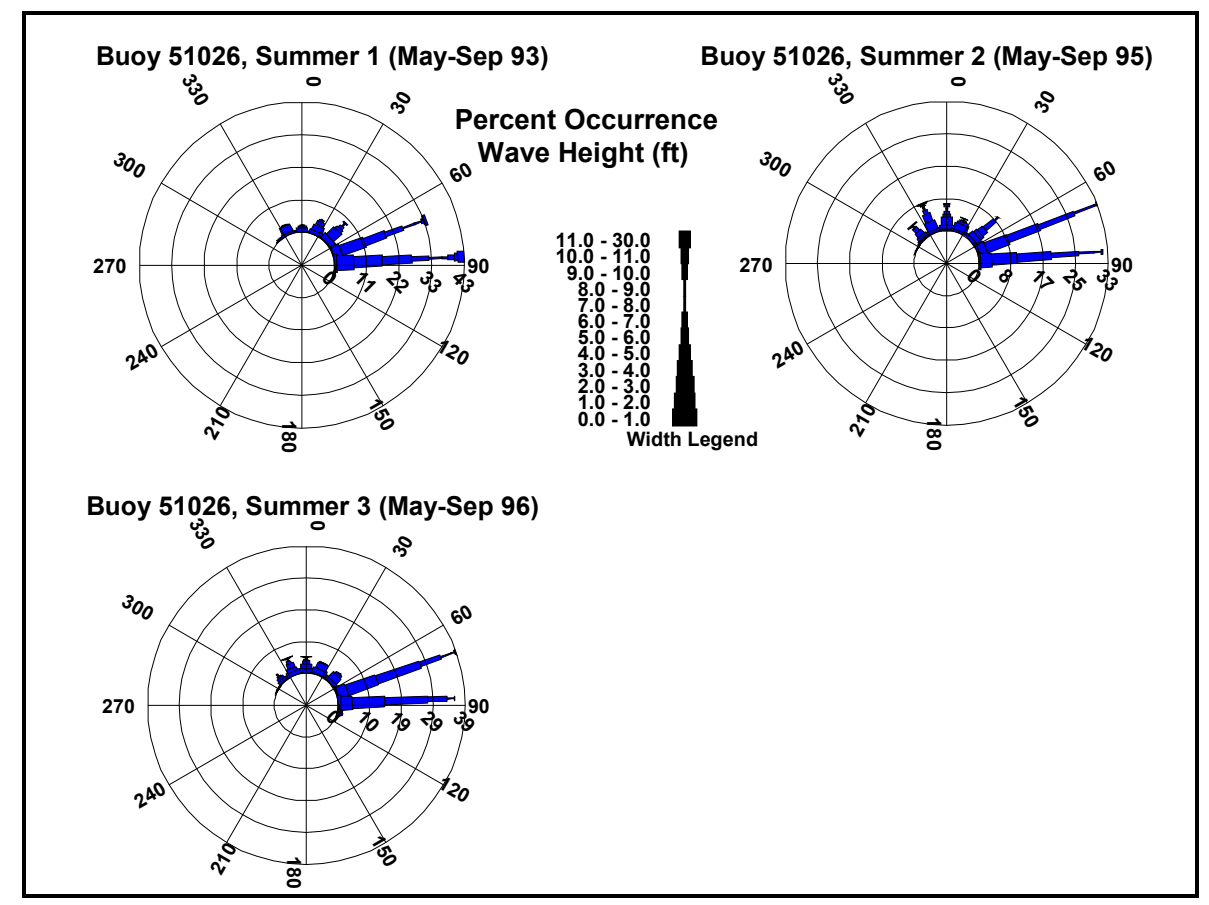

Figure 12. Wave height roses, summer, NDBC buoy 51026

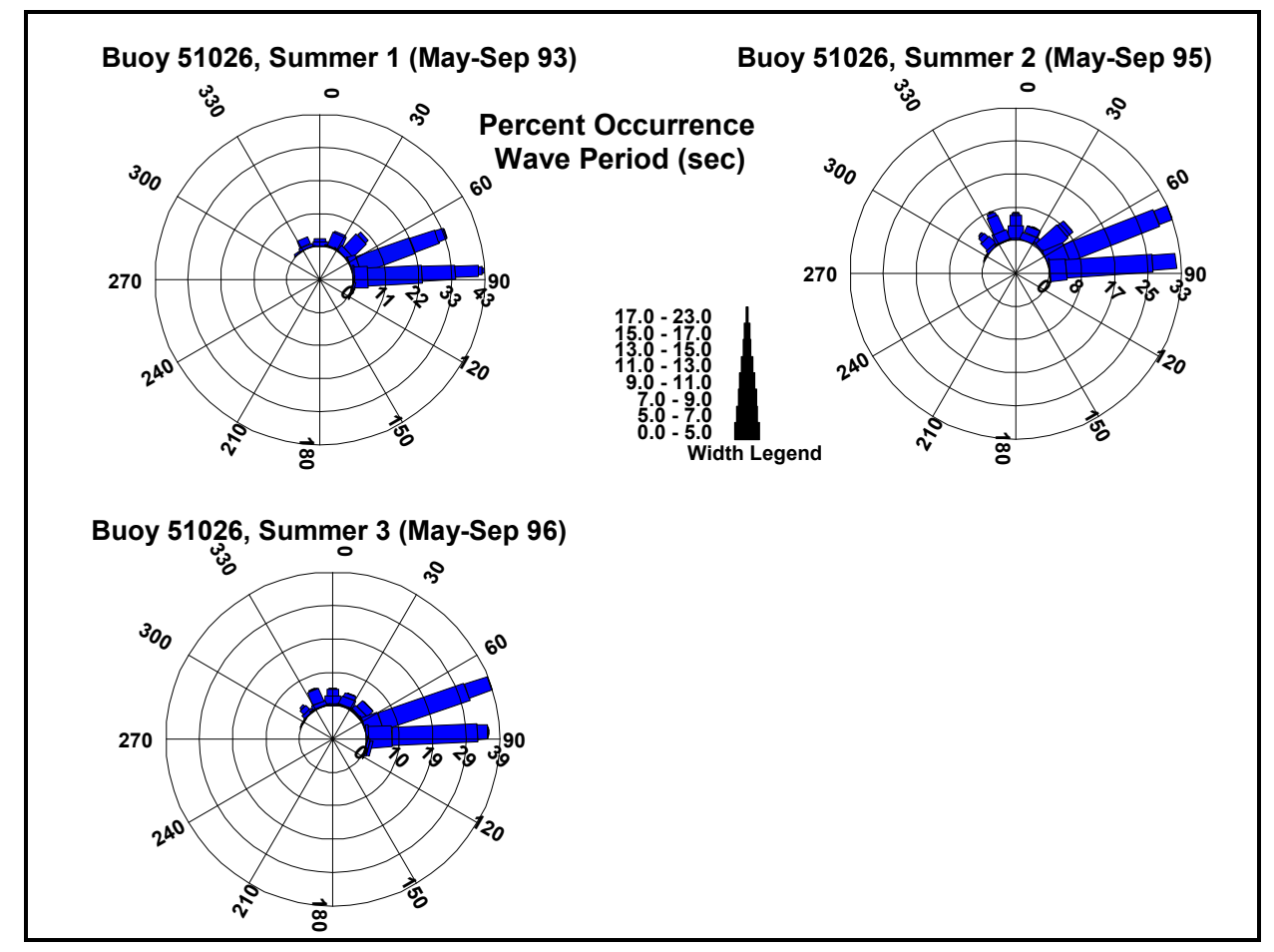

Figure 13. Wave period roses, summer, NDBC buoy 51026 


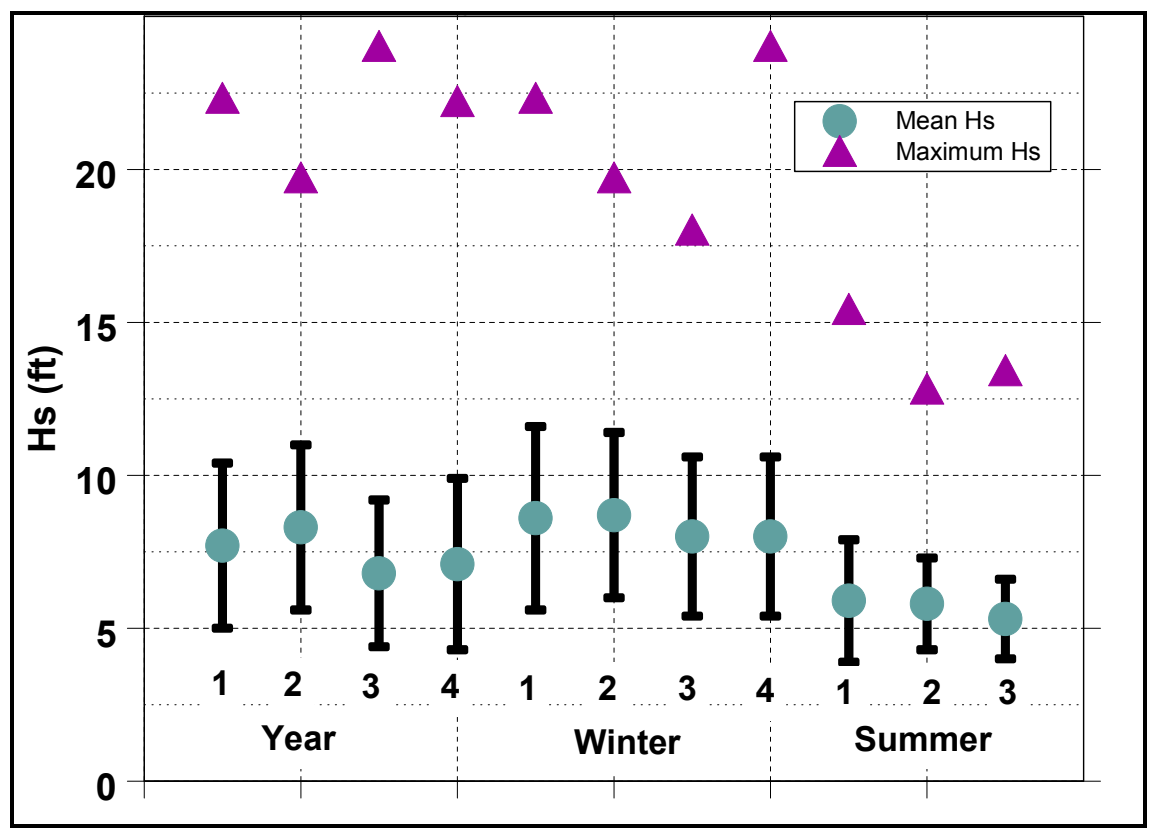

Figure 14. Wave height statistics, NDBC buoy 51026

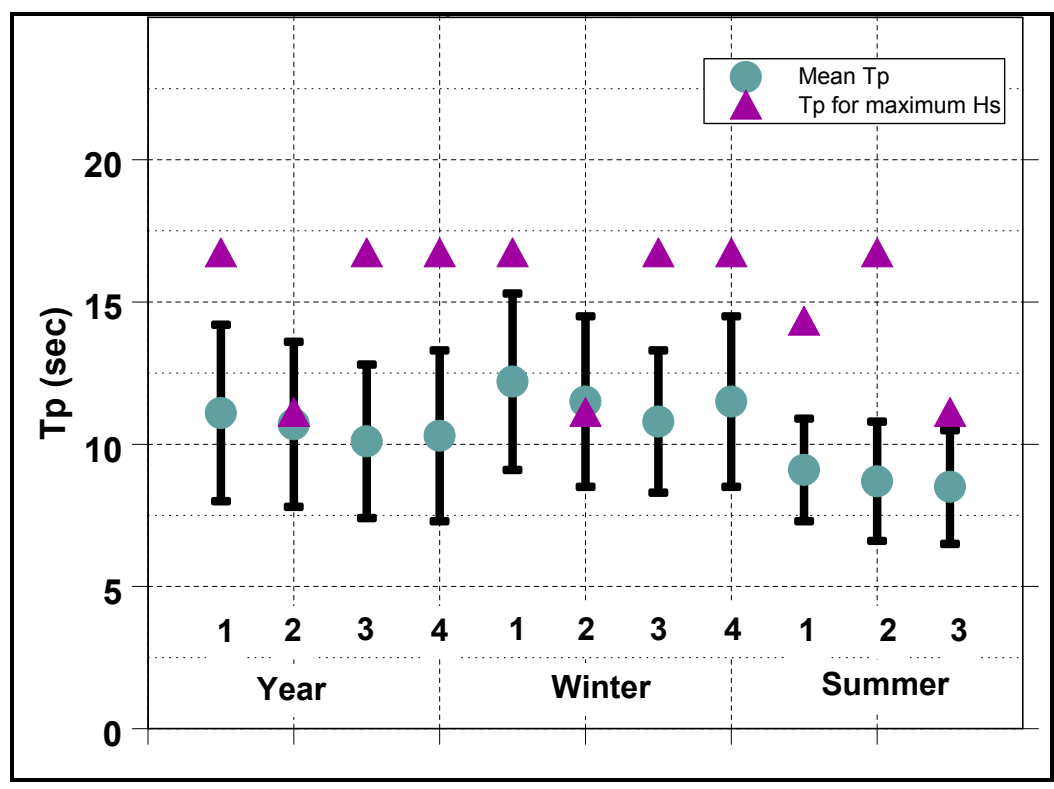

Figure 15. Wave period statistics, NDBC buoy 51026 


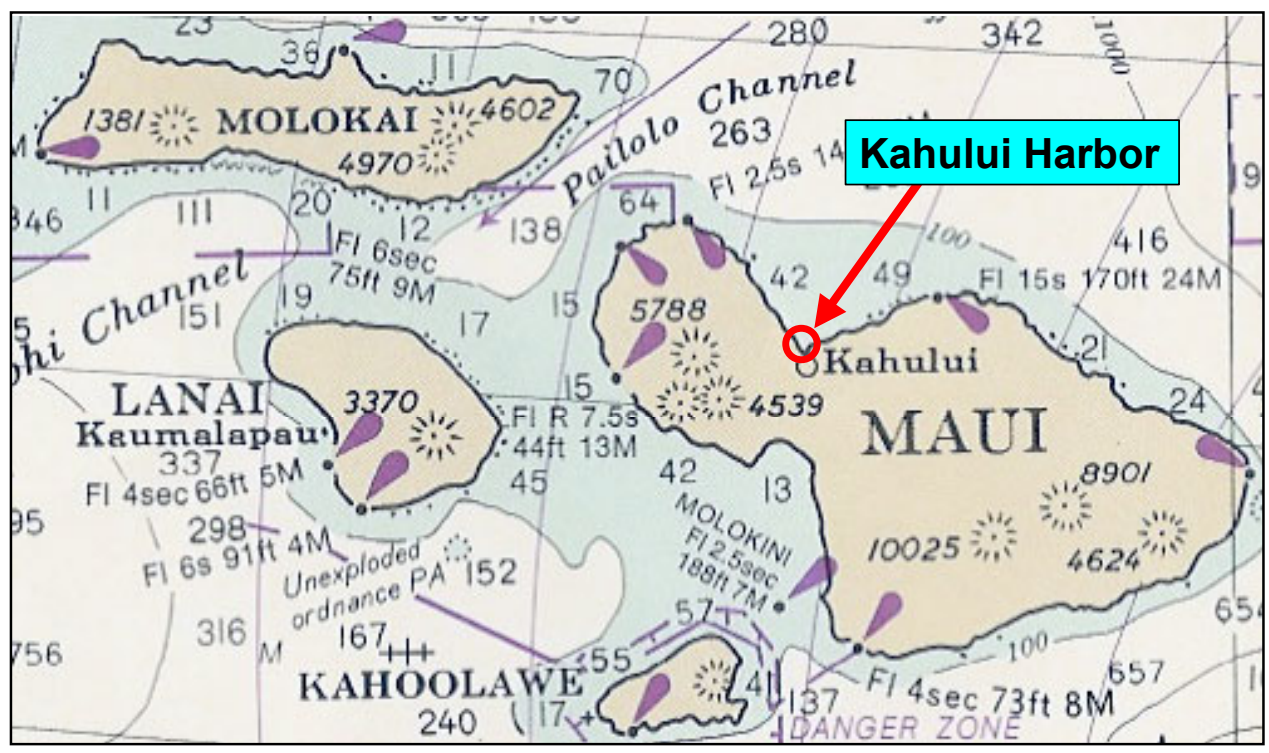

Figure 16. Map showing exposure to deepwater waves (NOS Chart 19007; scale $1: 1,650,000$; depths in fathoms)

height roses are shown in Figure 17. These roses are dramatically different from those for the offshore NDBC buoy. Virtually the entire wave climate is confined to a narrow band of directions between north and northeast. Dominant wave directions in the offshore climate (northwest and east) are no longer a presence near the harbor entrance. The two winter roses are very similar, while the summer rose shows a small shift away from north and into northeast, as would be expected based on the offshore climate.

Peak wave period roses for the Kahului array are shown in Figure 18. Summer wave conditions clearly have shorter periods than winter wave conditions, as was evident in the offshore data.

Significant wave height statistics for the Kahului array (Figure 19) show a mean annual $H_{s}$ of nearly $3 \mathrm{ft}$ and maximum of over $8 \mathrm{ft}$ for the year 1994 . These values are much lower than observed in the offshore wave climate, as would be expected due to the natural protection of Kahului Harbor from dominant offshore wave directions. Peak wave period statistics (Figure 20) are quite similar to those for the offshore buoy.

In conclusion, analysis of wave climate from the array gage helps to confirm that wave conditions during its period of operation were representative of the general wave climate. It is reasonable to use the array data as the source of wave information for driving numerical and physical models of the harbor. Because of seasonal variations, only a 12-month time period, the year 1994, will be used to give a good representation of the overall wind wave and swell climate immediately incident to Kahului Harbor. Percent occurrence values of key wave parameter combinations for year 1994 give a more quantitative indication of the wave climate used for modeling (Figures 21-23). 


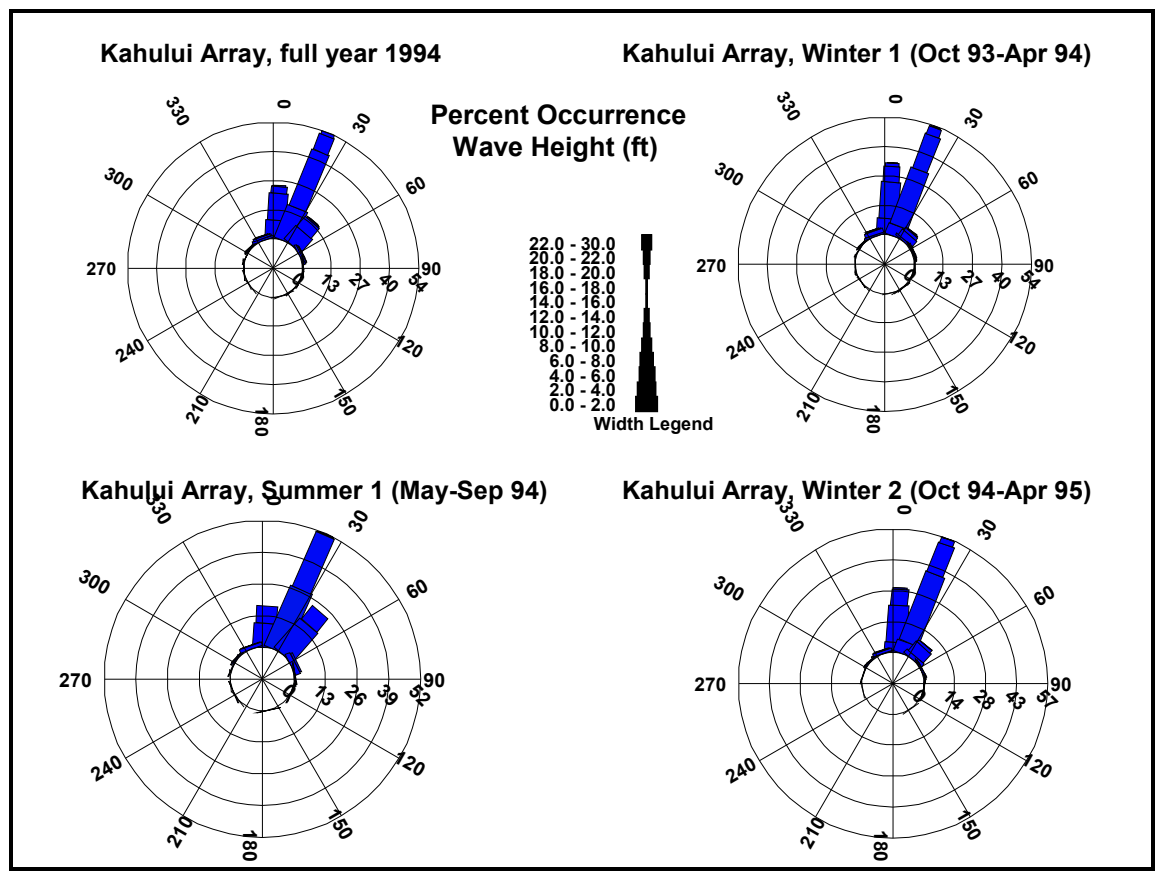

Figure 17. Wave height roses, Kahului array

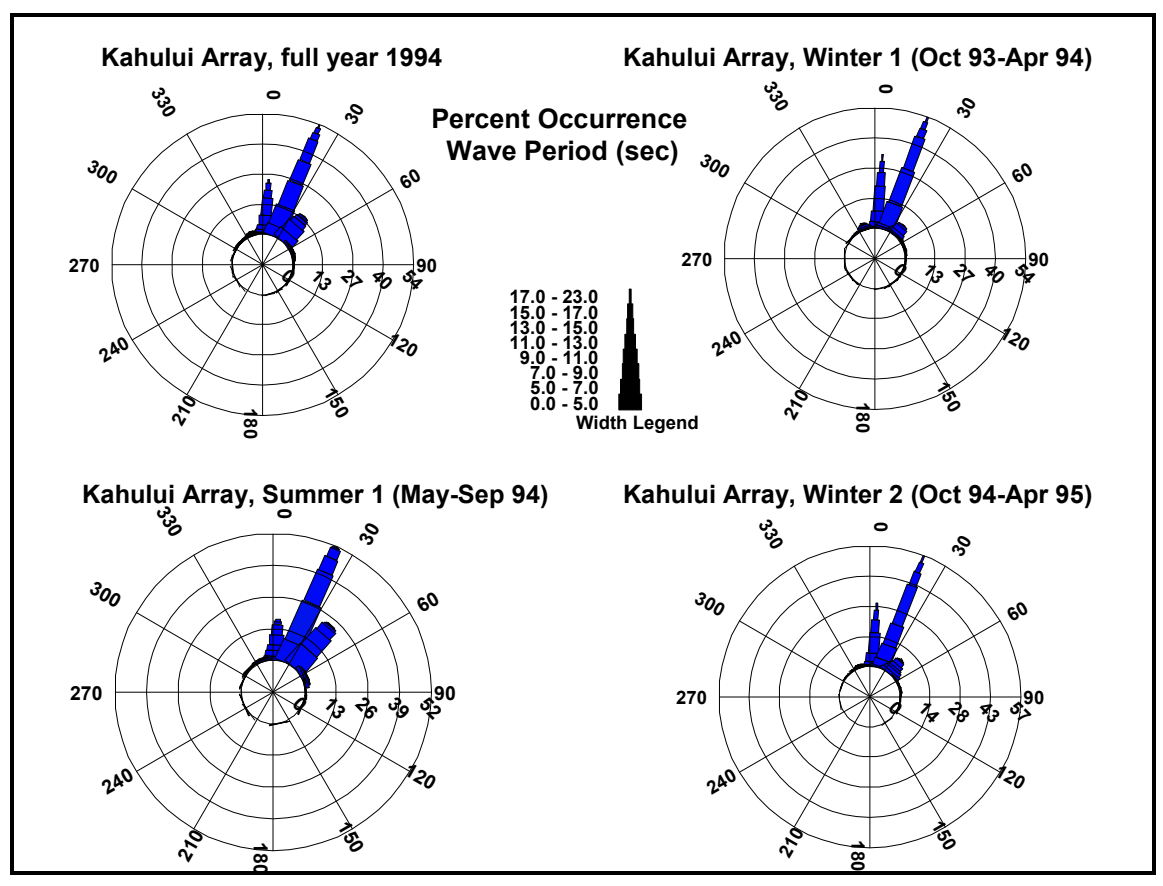

Figure 18. Wave period roses, Kahului array 


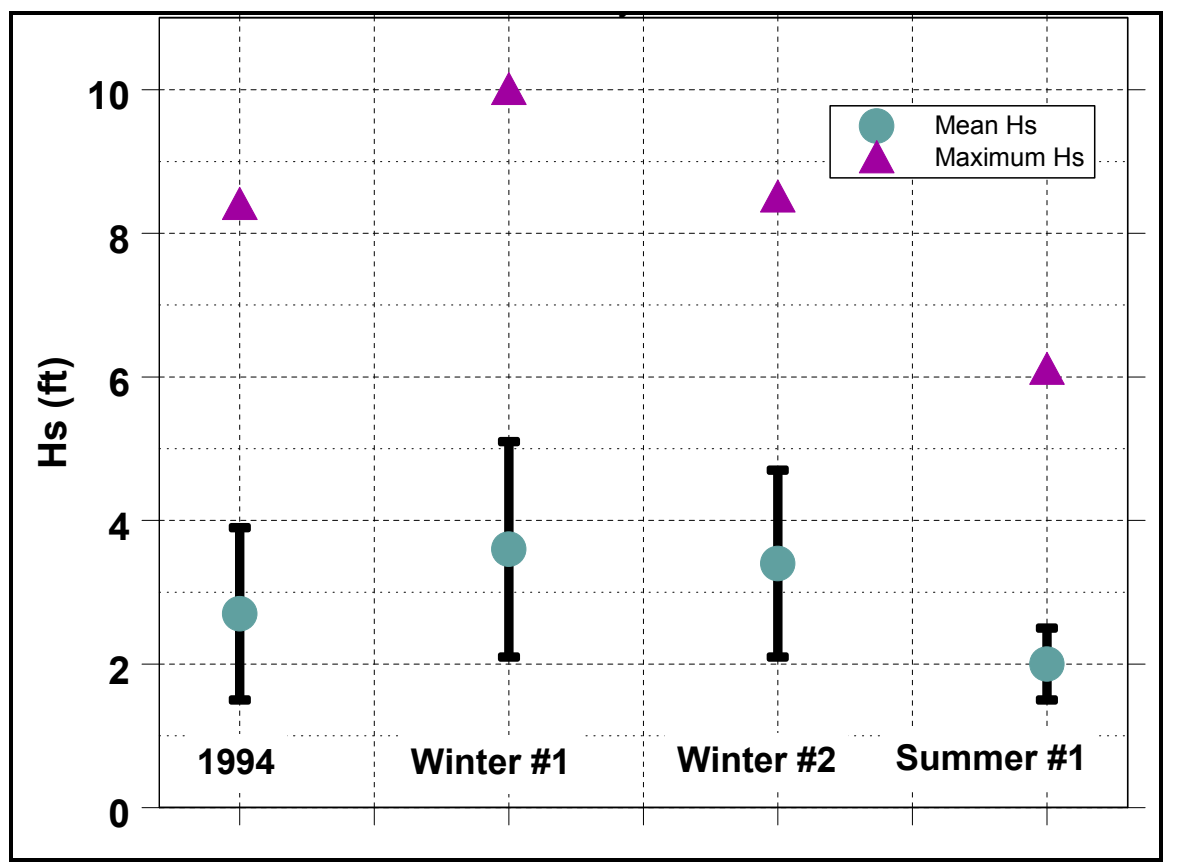

Figure 19. Wave height statistics, Kahului array

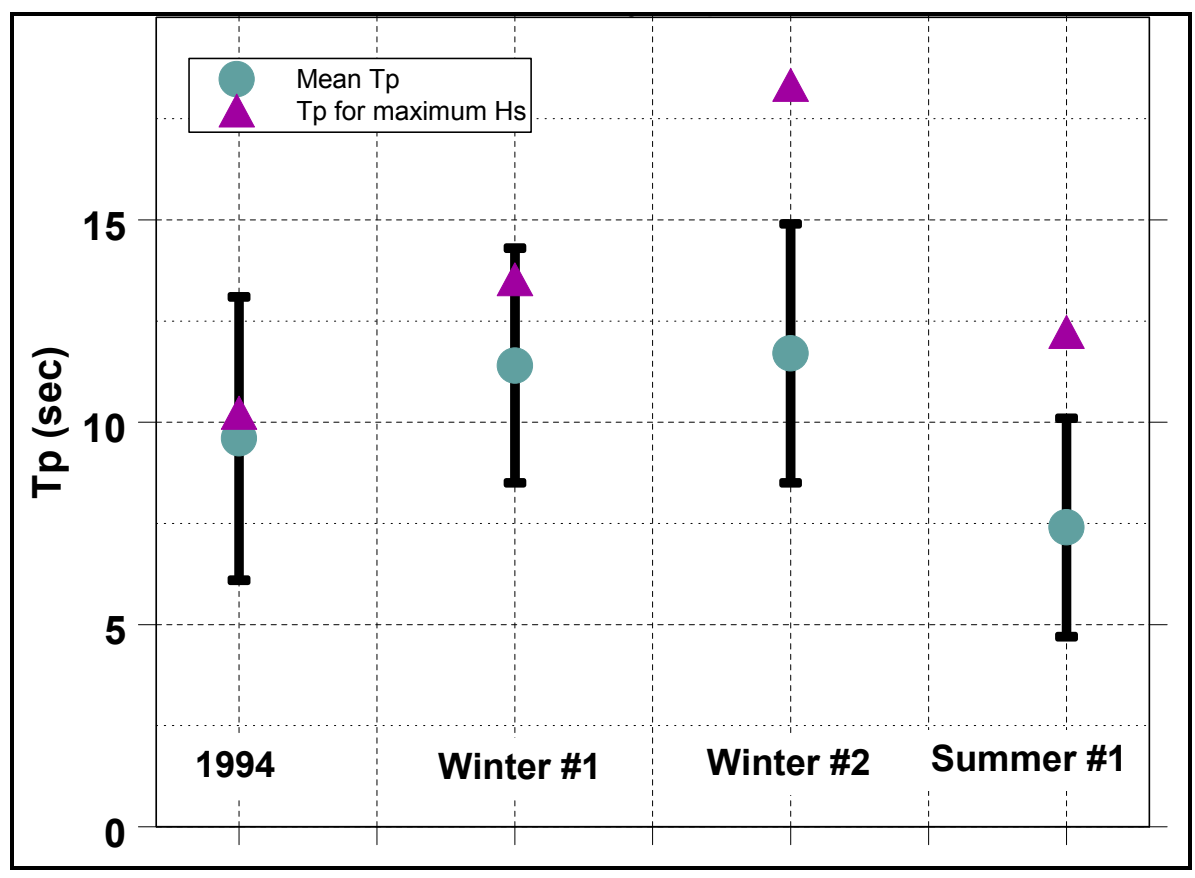

Figure 20. Wave period statistics, Kahului array 


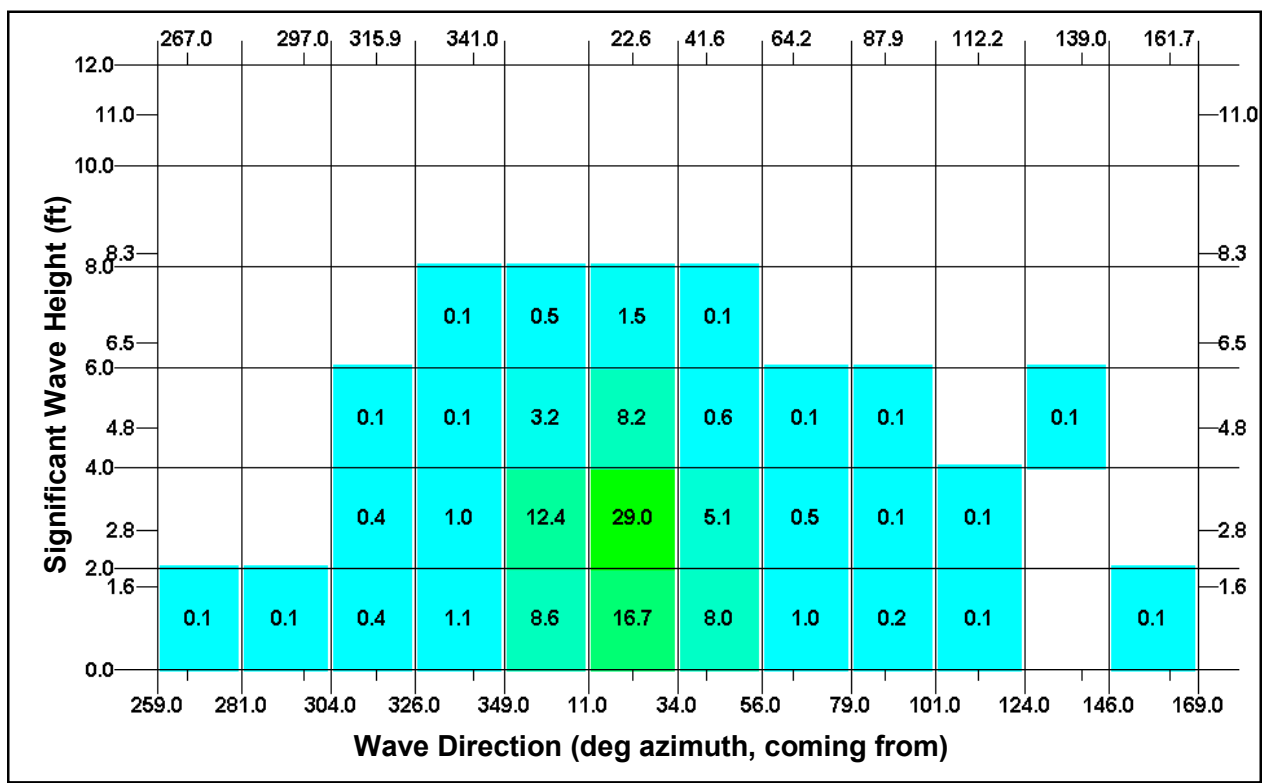

Figure 21. Percent occurrence, significant wave height vs. direction, Kahului array, 1994

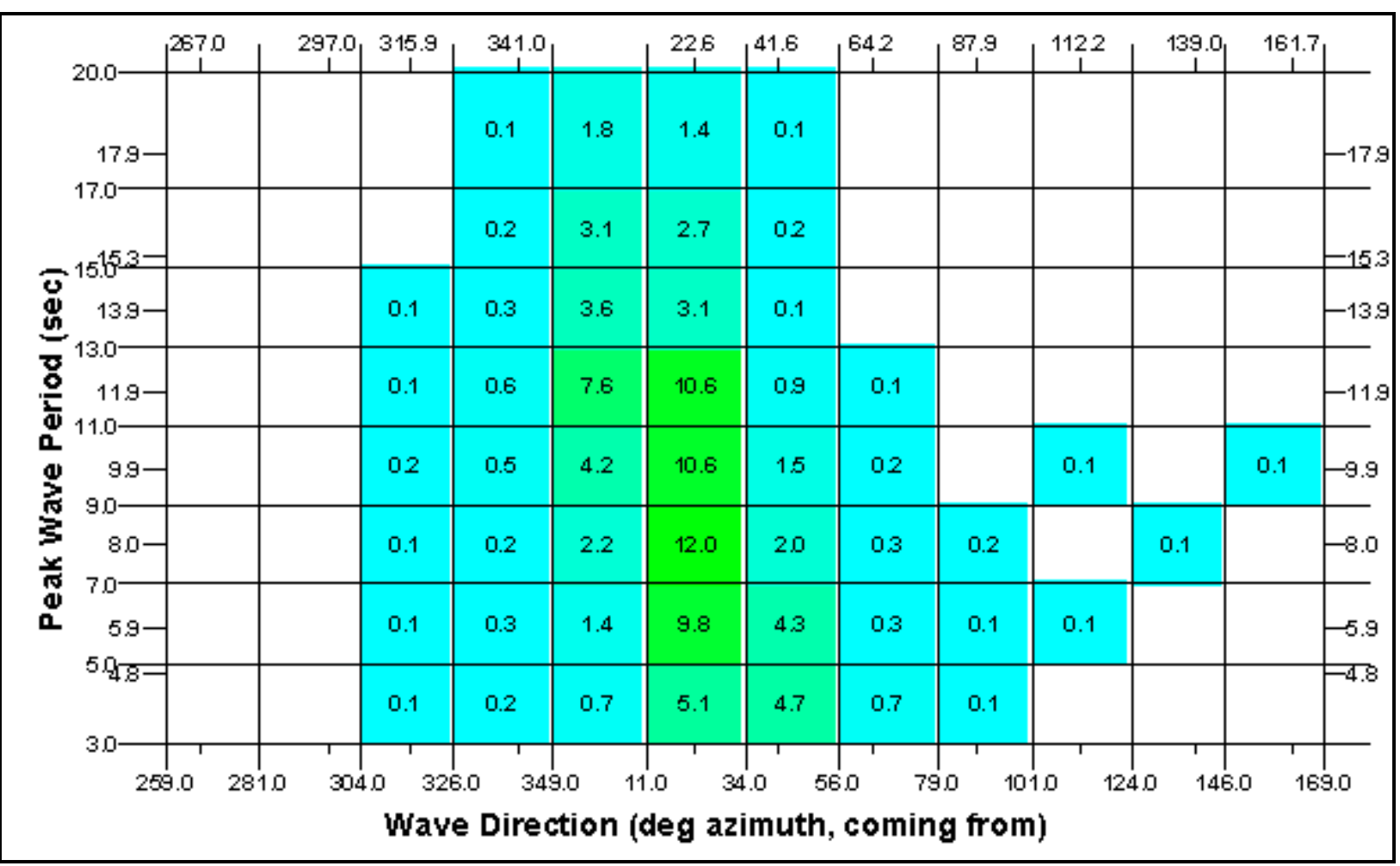

Figure 22. Percent occurrence, peak wave period vs. direction, Kahului array, 1994 


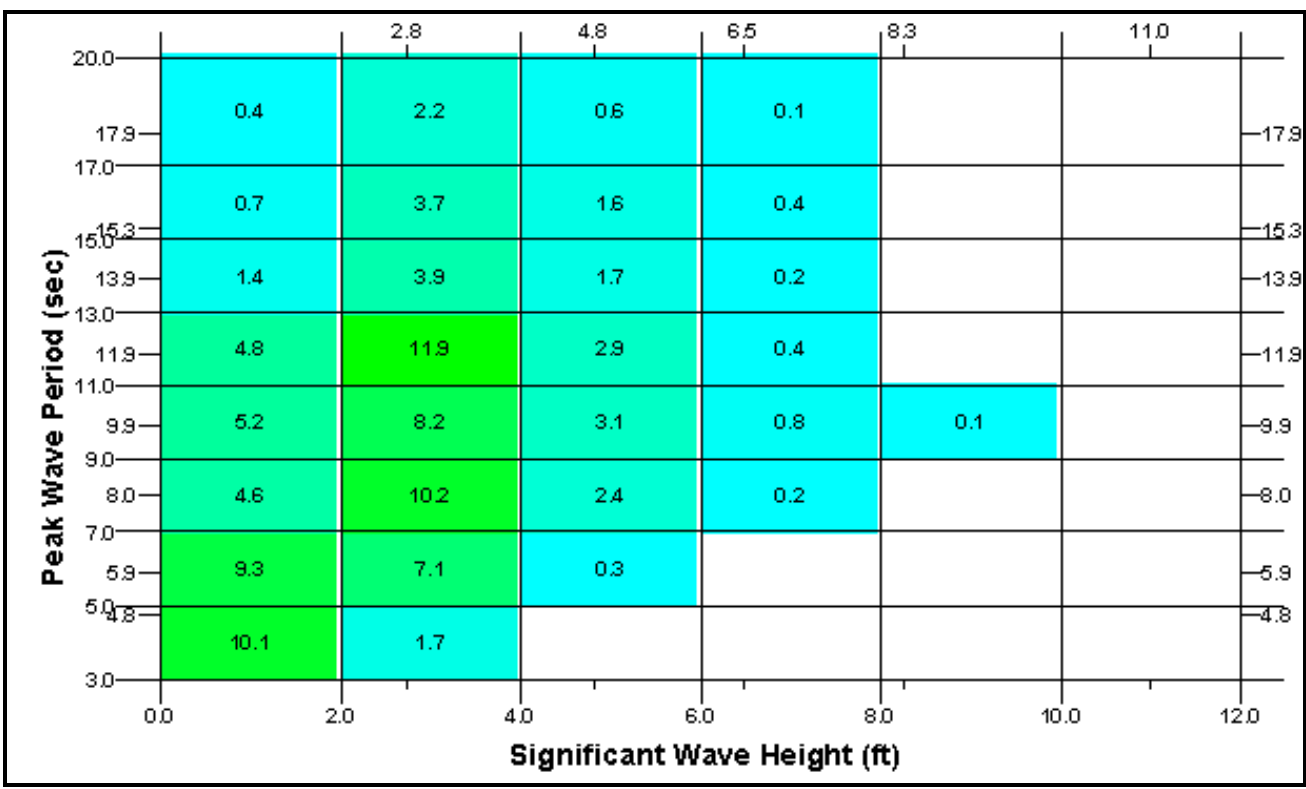

Figure 23. Percent occurrence, peak wave period vs. significant height, Kahului array, 1994 


\section{Numerical Model}

\section{Objectives and Approach}

The numerical model studies had two main objectives:

a. Calibrate and validate the numerical model with field data.

$b$. Use the numerical model to evaluate the effect of proposed harbor modifications on harbor wave response.

The numerical model used for the studies, CGWAVE, is the standard CHL tool for numerical harbor wave investigations. The model includes the following assumptions:

a. No wave transmission through breakwaters.

$b$. No wave overtopping of structures.

c. Structure crest elevations above the water surface cannot be tested or optimized.

d. Currents in the channel cannot be evaluated.

e. Diffraction around structure ends is represented by diffraction around a blunt vertical wall with specified reflection coefficient.

Despite limitations imposed by the aforementioned assumptions, CGWAVE is considered suitable for meeting the numerical modeling objectives of the Kahului Harbor wave response study.

The harbor wave response model is described in the following section, including a general description of the CGWAVE model and implementation of the model at Kahului Harbor. This model is an advancement in technology over the Harbor Deep (HARBD) model used in the previous study. It overcomes some limitations of HARBD, though it has a general similarity to the HARBD model. It is advantageous to present and future Kahului Harbor studies to use CGWAVE, but the switch in model technology required repeating the calibration/validation done in the previous study. Validation was accomplished with a combination of storm wave events selected from available field data. The final section of this chapter describes the test procedures and calculations.

As part of the test procedures, a suite of incident wave conditions must be specified at the seaward boundary of the area covered by CGWAVE. Incident 
short waves are determined by consideration of measurements outside the harbor. Incident long waves are specified over a broad range of frequencies but only a normally-incident direction to identify possible harbor resonant responses.

The existing harbor and three proposed modifications were studied. Results for wind waves and swell are presented in Chapter 4. Harbor oscillation results are presented in Chapter 5 . The presentation focuses on wave conditions in the vicinity of existing or proposed piers, but results over the full harbor area are also given.

\section{Model Description}

\section{Model formulation}

The numerical wave model CGWAVE is a steady state finite element model used in the calculation of wave response in harbors of varying size and depth. It may also be applied along open coastal regions, at coastal inlets, around islands, and around fixed or floating structures. CGWAVE simulates the combined effects of wave refraction and diffraction included in the basic mild-slope equation. It can also include effects of wave dissipation by friction, breaking, nonlinear amplitude dispersion, and harbor entrance losses. The basic model deals with regular waves, but irregular (spectral) wave conditions can be simulated by combining regular wave results.

Several fundamental theoretical and computational advances are included in the model. The open boundary condition (seaward boundary of the model domain) is treated with a new parabolic approximation method along with the classical super-element technique. An efficient iterative procedure (conjugate gradient method) is used to solve the discretized model equations, enabling the model to be used practically for larger domains. This feature overcomes a severe domain size limitation inherent in the HARBD model.

The CGWAVE model is interfaced with commercially available Corps of Engineers-supported software to assist in preparing model grids and other inputs and in displaying model results. This software-assisted pre- and post-processing is needed in any practical application.

More information on CGWAVE is available from Demirbilek and Panchang (1998) and from the model Internet Web site (http://chl.wes.army.mil/research/ wave/wavesprg/numeric/wentrances/cgwave.htp ). The software package for pre- and post-processing is part of the Surface-Water Modeling System (SMS). The SMS software is also described through the model Web site.

\section{Finite element grids}

Bathymetric data for Kahului Harbor and surrounding area are available on National Oceanic and Atmospheric Administration (NOAA), National Ocean Service (NOS) hydrographic chart 19342. In the previous study, these data and U.S. Army Engineer District, Honolulu, conventional bathymetric surveys of the Federal project area provided bathymetry for the numerical model grid. 
The present study took advantage of recent data obtained from the Scanning Hydrographic Operational Airborne Lidar Survey (SHOALS) surveying system. Surveys, funded by the Honolulu District, were available during years 1999 and 2000 (Figure 24). SHOALS coverage areas during the 2 years are somewhat overlapping in the area to be modeled, but each year included some useful coverage that was not repeated. SHOALS bathymetry from both years was compared and reviewed relative to the NOS chart bathymetry. SHOALS appears to give accurate, detailed coverage of areas outside the harbor, including excellent definition of reef areas and the complex shoal about 1 mile seaward of the harbor entrance (Figure 25). Survey points from both years were combined for areas outside the harbor (Figure 26). Inside the harbor, the SHOALS data were not reliable, which was attributed to turbidity in the harbor at the time of survey. Bathymetry from the previous study was used inside the harbor.

Depth contours affecting navigation, as represented in the combined SHOALS data, highlight the open approach path to the harbor entrance for large ships (Figure 27). Depths shown range from the 35-ft depth of the existing Federal project to $45-\mathrm{ft}$ depth, representative of some of the larger ships being accommodated by other U.S. ports.

The numerical model seaward boundary is a semicircle. In the previous study, the semicircle extended to the location of the directional array gage. This choice was advantageous for two reasons: array data could be applied directly as incident wave conditions to the model grid, and a workable size model grid was obtained.

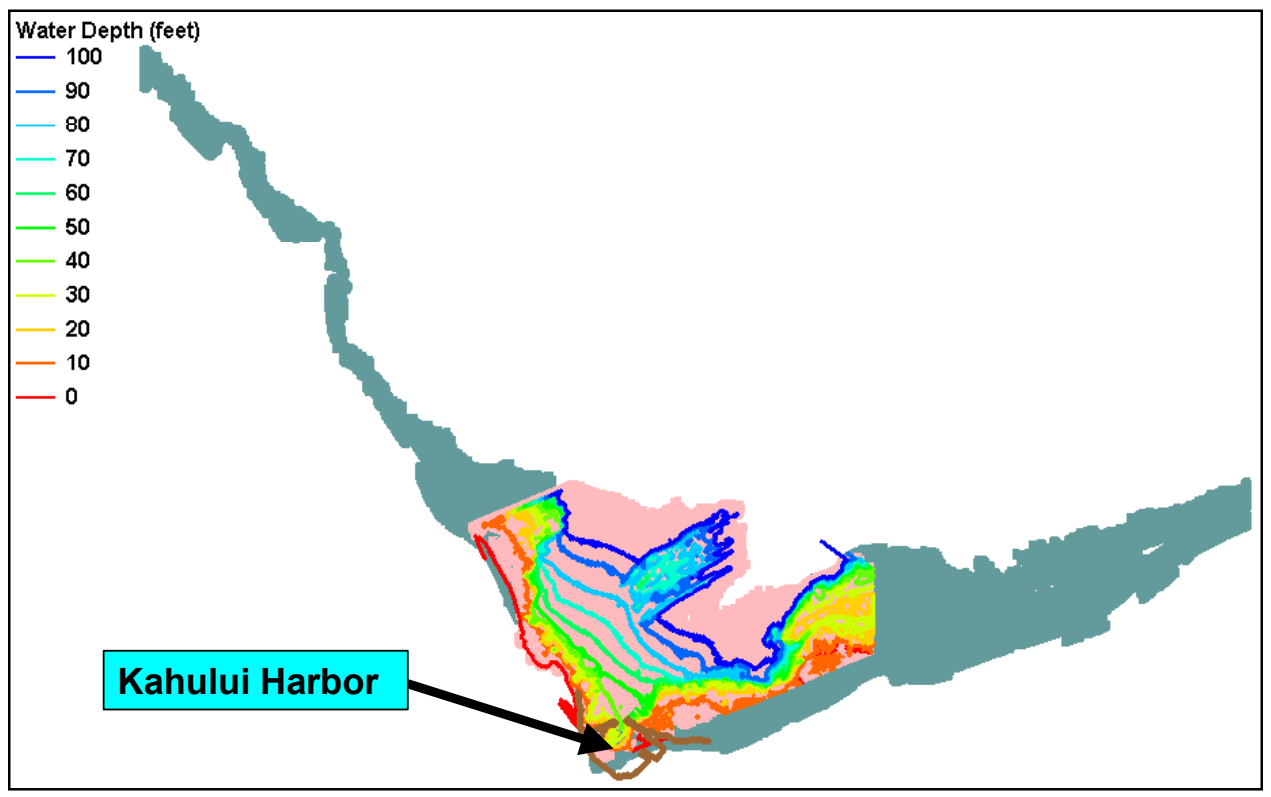

Figure 24. SHOALS coverage: year 2000 points and contours in color; year 1999 points in background 


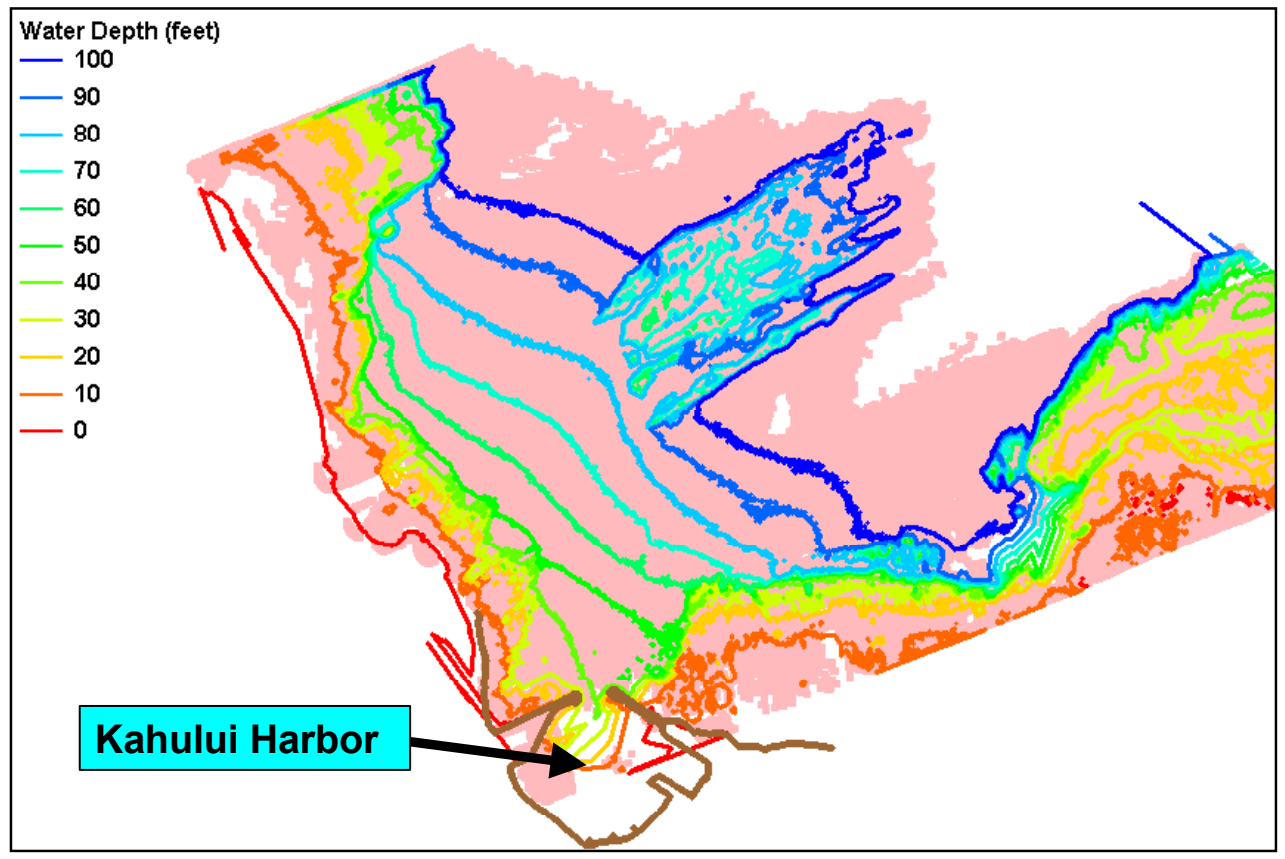

Figure 25. SHOALS 2000 bathymetry

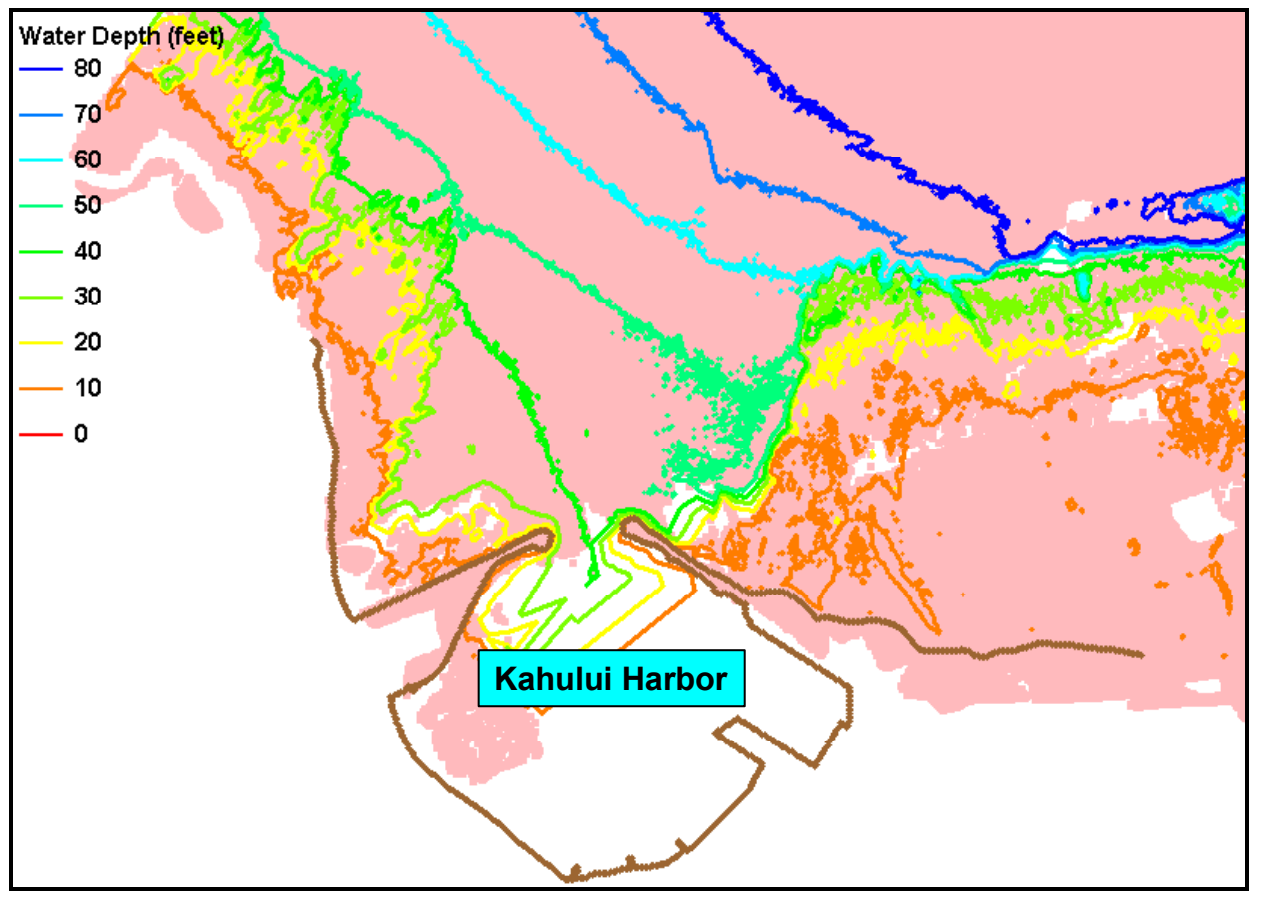

Figure 26. SHOALS bathymetry in vicinity of Kahului Harbor, merged 1999 and 2000 data 


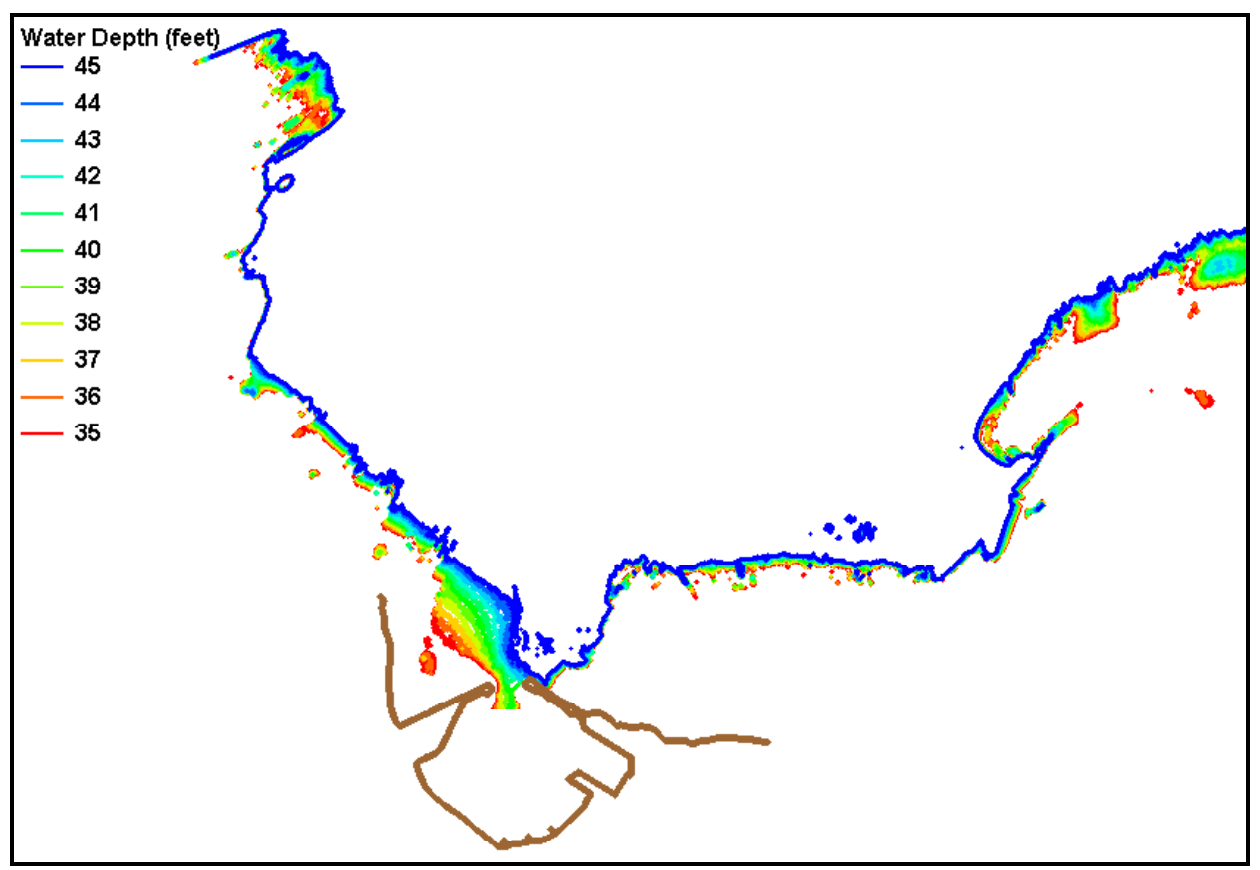

Figure 27. Depth contours affecting navigation

The seaward boundary location needed to be modified in the present study. The proposed breakwater extension in the 2025 master plan for Kahului Harbor approaches too close to the original seaward boundary for reliable modeling. Thus, the seaward boundary needed to be moved significantly further away from the harbor. The new model domain extends well beyond the reef structures constricting wave approach to Kahului Harbor. Fortunately, this expanded domain can be practically modeled with CGWAVE.

A finite element grid of the existing harbor was constructed over the model domain. Grid element size is based on the needed model resolution for the shortest period waves in the shallowest water depth of concern in the study. For the longer period waves, the grid gives a high degree of resolution. Grid characteristics are summarized in Table 2. Bathymetric data from SHOALS and other sources discussed previously were transferred onto the finite element grid. A contour plot of bathymetry is given in Figure 28. The SMS software was used for all bathymetry and grid development.

Reflection coefficients, $K_{r}$, are needed for all solid boundaries. For the short wave tests, $K_{r}$ values were estimated as in the previous study. Values are based on existing U.S. Army Corps of Engineers guidance, photos and field notes from a site visit by CHL personnel, and past experience. The solid boundary was divided into 13 zones and a reflection coefficient was estimated for each zone (Figure 29). Reflection coefficients range from 0.2 for the shallow sandy beach along the southwest shore of the existing harbor to 0.5 for all pier areas and 0.9 for the grouted revetment along the western side of pier 2. Reflection coefficients for shorelines extending beyond the harbor on either side were set to 


\section{Table 2 \\ Grid Sizes}

\begin{tabular}{|l|l|l|l|l||}
\hline \hline $\begin{array}{l}\text { Harbor } \\
\text { Plan }\end{array}$ & Elements & Nodes & $\begin{array}{l}\text { Semicircle Boundary } \\
\text { Nodes }\end{array}$ & $\begin{array}{l}\text { Length of Typical Element } \\
\text { (ft) }\end{array}$ \\
\hline \hline Existing & 216929 & 109320 & 610 & 15 \\
\hline 2025 Plan & 216030 & 108913 & 610 & 18 \\
\hline Plan B & 215523 & 108660 & 610 & 18 \\
\hline Plan C & 215635 & 108720 & 610 & 18 \\
\hline
\end{tabular}

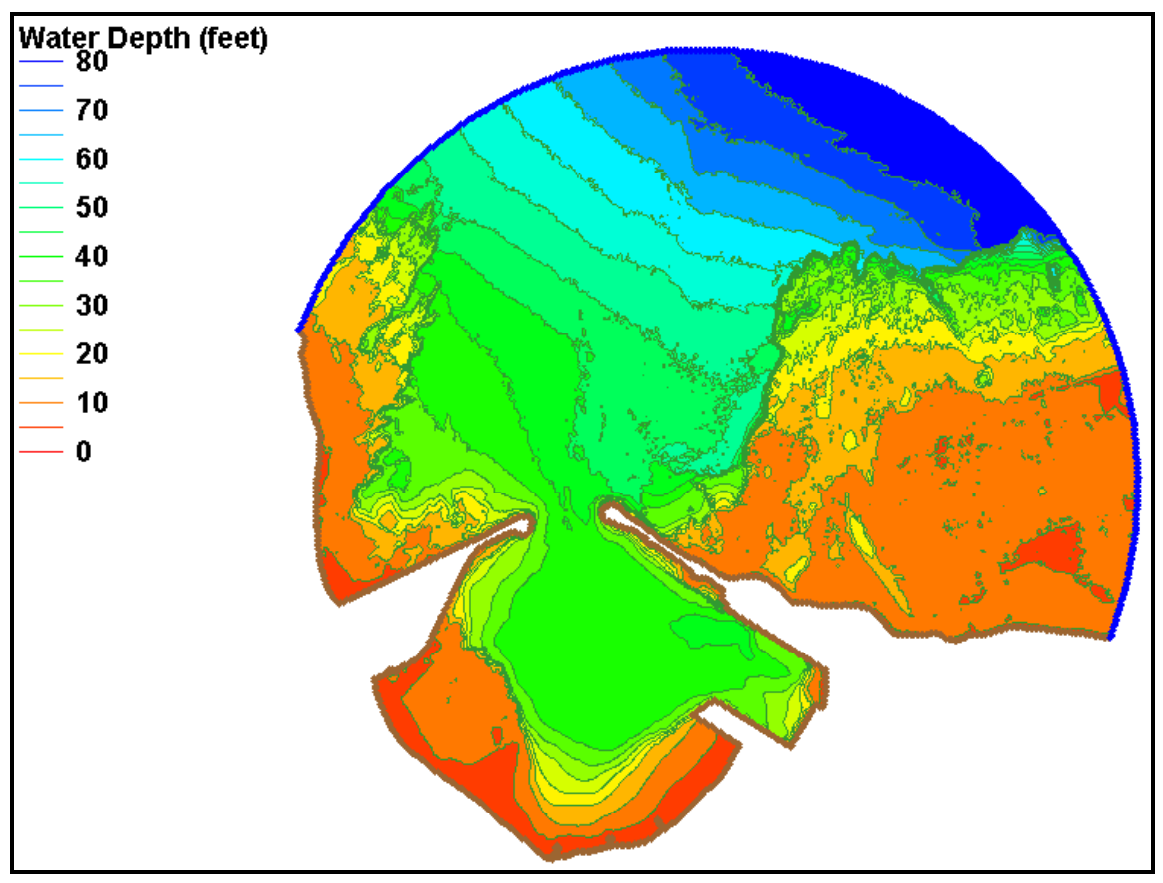

Figure 28. Model bathymetry, existing harbor

0.4 for shoreline encompassed by the grid domain and 0.0 for shoreline beyond the grid domain. Bottom friction was set to zero. Additional parameter values used in the numerical model are summarized in Table 3.

Different parameters are used for the long wave tests. The reflection coefficient was set to 1.0 for all boundaries, since long waves generally reflect very well from a coastal boundary. Long waves are more affected by bottom friction than short waves, so a value greater than zero is appropriate. The value is best determined by calibration with field data, as discussed in the following section. A value of 0.02 was selected. This and other parameters are summarized in Table 3. 


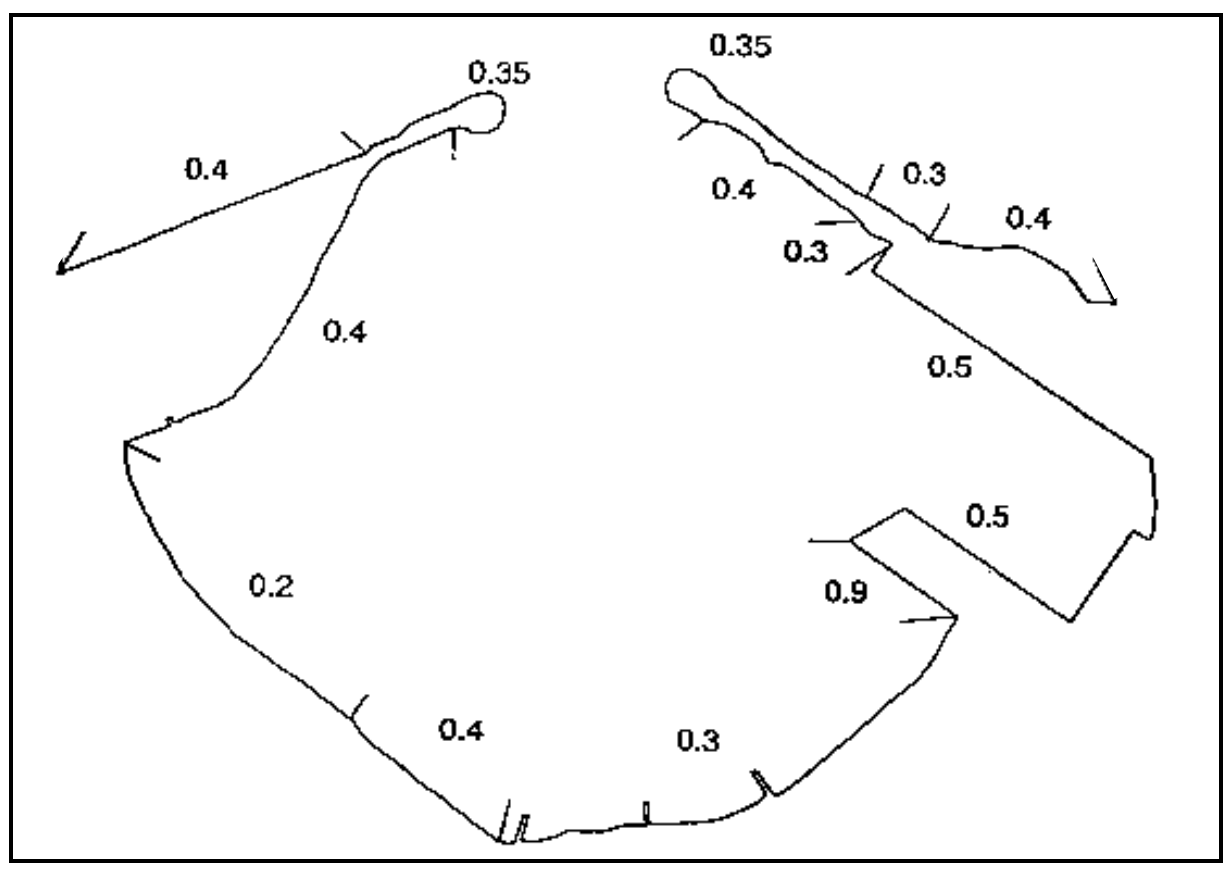

Figure 29. Model wave reflection coefficients, short waves, existing harbor

\section{Table 3}

Parameter Values Used in CGWAVE

\begin{tabular}{||l|l|l||}
\hline \multirow{2}{*}{ Parameter } & \multicolumn{2}{||}{ Value } \\
\cline { 2 - 3 } & $\begin{array}{l}\text { Short } \\
\text { Waves }\end{array}$ & $\begin{array}{l}\text { Long } \\
\text { Waves }\end{array}$ \\
\hline \hline Number of terms in series & 35 & 35 \\
\hline Number of iterations for checking convergence & 1 & 1 \\
\hline Maximum number of iterations & 500,000 & 500,000 \\
\hline Maximum number of iterations for nonlinear mechanisms & $8-25$ & 8 \\
\hline Bottom friction & 0.00 & 0.02 \\
\hline Wave breaking & off & off \\
\hline Nonlinear dispersion & off & off \\
\hline Exterior reflection (shore boundaries outside grid domain) & 0.0 & 1.0 \\
\hline Tolerance for equations & $10-9$ & $10-9$ \\
\hline Tolerance for nonlinear mechanisms & $10-4$ & $10-4$ \\
\hline $\begin{array}{l}\text { Semicircle orthogonal orientation, deg counterclockwise from +x axis } \\
\text { (0=east, 90=north, 180=west) }\end{array}$ & 69.3 & 69.3 \\
\hline \hline
\end{tabular}


In addition to existing conditions, three harbor modification plans were specified for evaluation, as discussed in Chapter 1 and summarized in Table 2. The existing harbor grid boundaries and bathymetry were modified to match the 2025 plan (Figure 30). Additional plan grids were developed by modifying the harbor entrance structures of the 2025 plan grid (Figures 31 and 32). Grid characteristics for each configuration are included in Table 2. Short wave reflection coefficients were modified as appropriate for the plan grids. General guidelines were $K_{r}=0.85$ along proposed pier 5 (due to solid, vertical dock face) and $K_{r}=0.35$ along breakwater extensions. Pier $2 \mathrm{C}$ does not appear in the grid because it is planned as an open, pile-supported structure which does not significantly affect passing waves.

\section{Calibration and validation}

In the previous study, the availability of extensive field data at Kahului Harbor allowed a detailed calibration and validation of the numerical harbor response model. Since the present study used CGWAVE rather than the older HARBD model, calibration and validation was repeated following the same approach as before. Both short and long wave responses were considered.

Short waves. Four high wave events during January and March 1994 were used for short wave calibration and validation (Table 4). These events give a variety of $T_{p}$ and dominant wave direction, $\theta_{m}$, values affecting Kahului Harbor. Incident wave conditions for these events were measured at the directional array offshore from the harbor entrance (Figure 33). Since the model boundary is

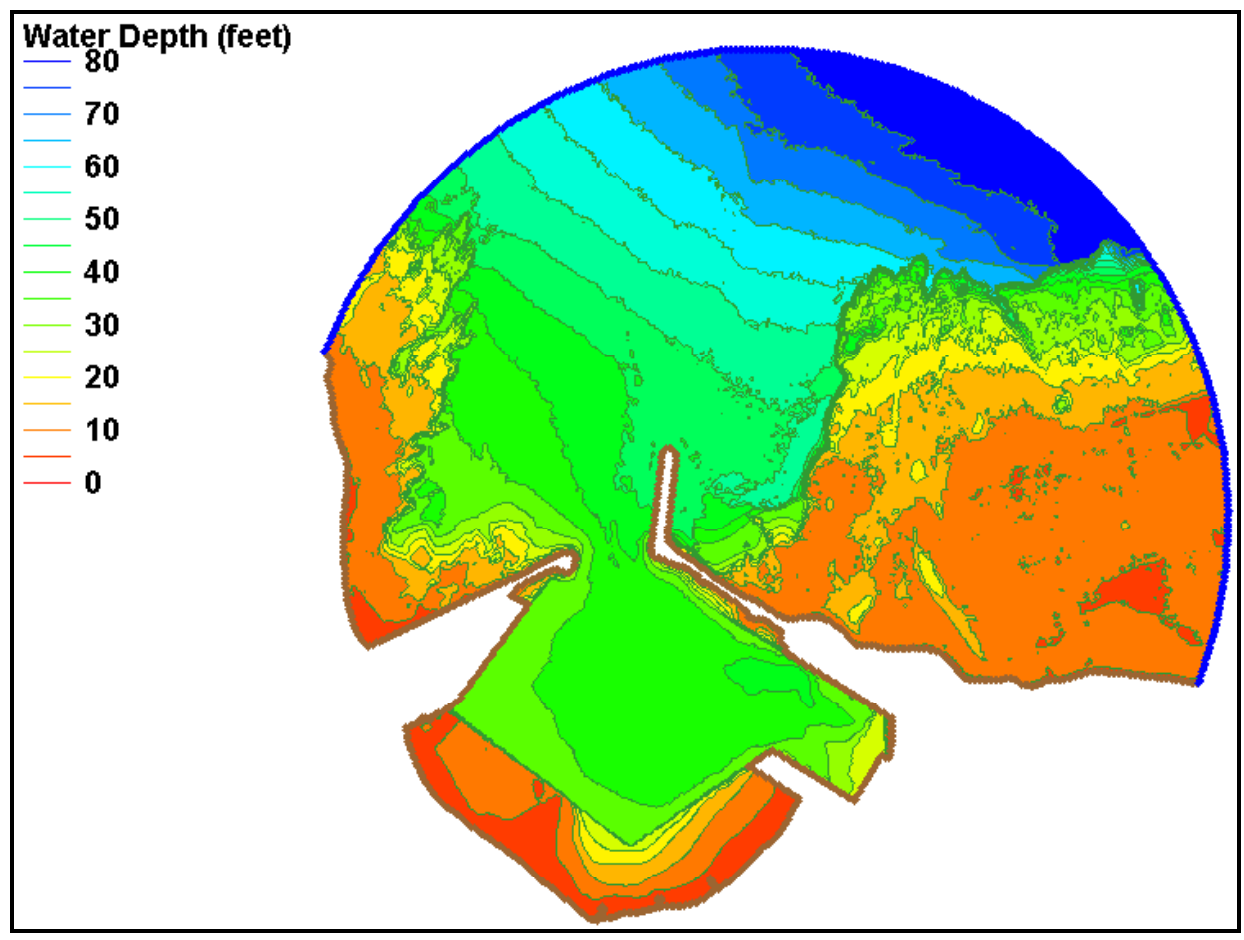

Figure 30. Model bathymetry, 2025 plan 


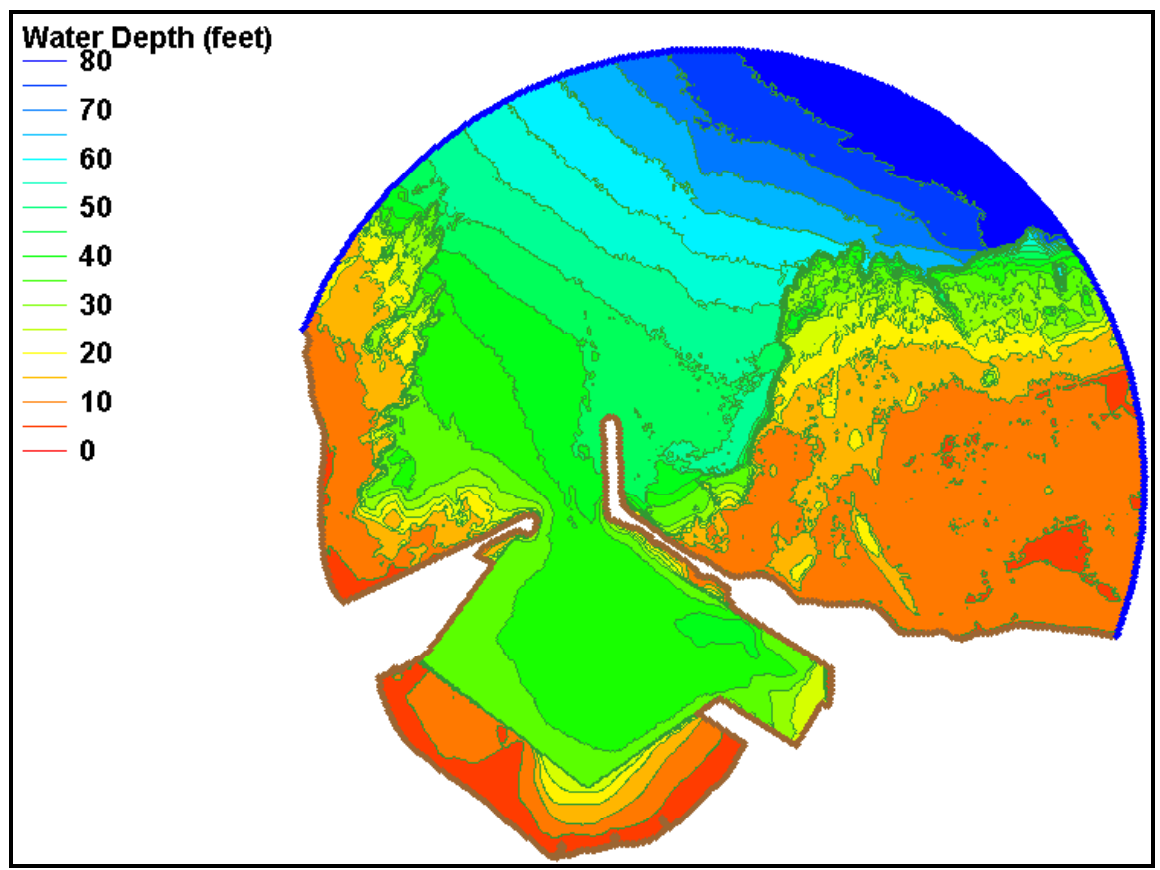

Figure 31. Model bathymetry, Plan B

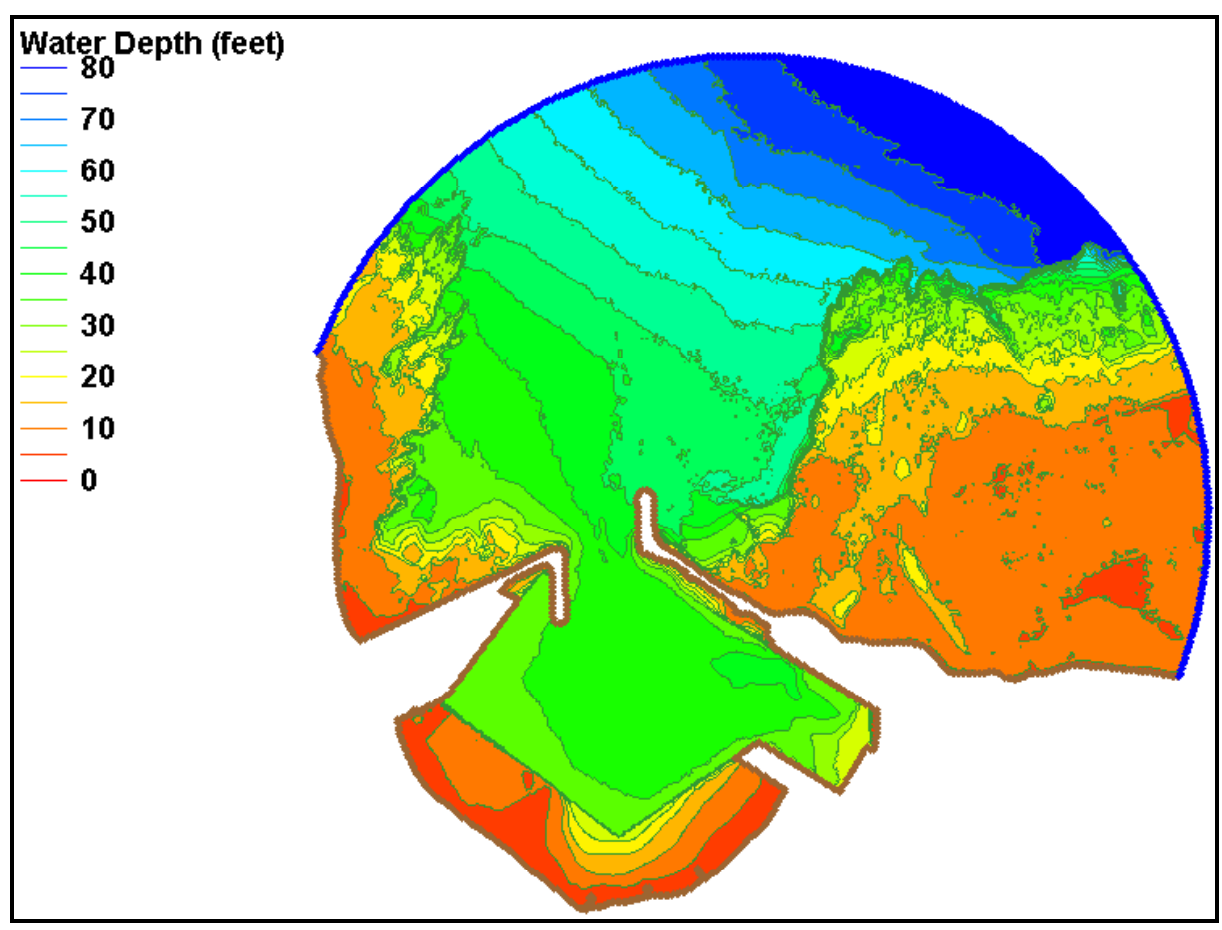

Figure 32. Model bathymetry, Plan C 


\begin{tabular}{|l|l|l|l|l||}
\hline \multicolumn{4}{|l|}{$\begin{array}{l}\text { Table 4 } \\
\text { Field Cases for Short Wave Model Calibration, Array }\end{array}$} \\
\hline \hline Date & Hour & $\begin{array}{l}\boldsymbol{H}_{\boldsymbol{s}} \\
\text { ft }\end{array}$ & $\begin{array}{l}\boldsymbol{T}_{\boldsymbol{p}} \\
\text { sec }\end{array}$ & $\theta_{m}$ deg az., coming from \\
\hline \hline 3 Jan 94 & 1300 & 7.0 & 14.8 & 14 \\
\hline 20 Jan 94 & 1300 & 8.1 & 10.1 & 22 \\
\hline 31 Jan 94 & 0700 & 5.3 & 17.9 & 11 \\
\hline 13 Mar 94 & 1300 & 6.4 & 8.9 & 25 \\
\hline
\end{tabular}

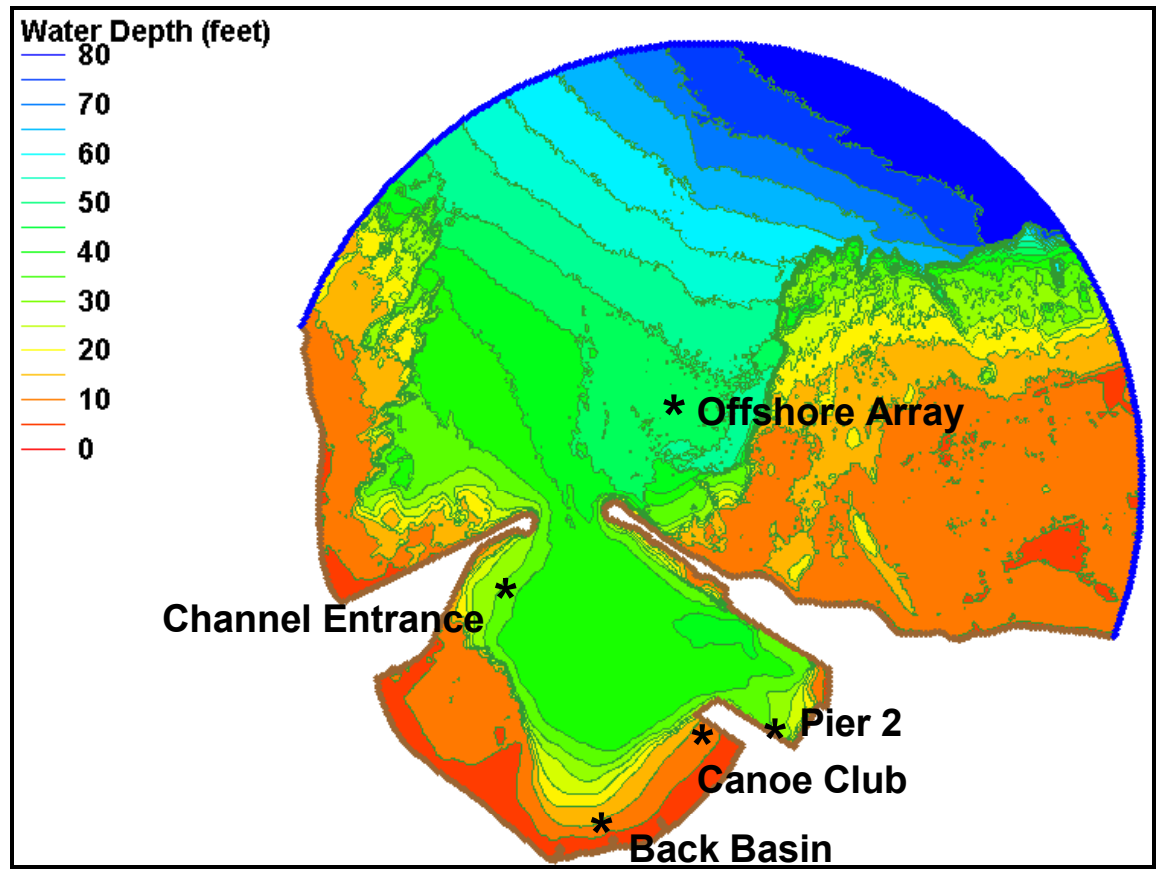

Figure 33. Field gage locations

significantly further seaward than the array, wave directions incident to the model needed to account for small changes in direction that occur between the seaward boundary and the array. These small direction changes were quantified by preliminary model runs. Significant heights and peak periods measured at the array for the four events were sufficiently representative of the model boundary and could be used directly for incident waves.

A suite of wave components was generated for each storm event to approximate the directional spectrum of wave energy. CGWAVE was run for each suite of incident wave components and the output was post-processed to give spectral estimates at each harbor gage location. Amplification factor was calculated from the simulations as $H_{s}$ at a point in the harbor divided by $H_{s}$ at the array location. Model versus gage amplification factors for the four events compare as well or better than in the previous study (Figure 34). This 


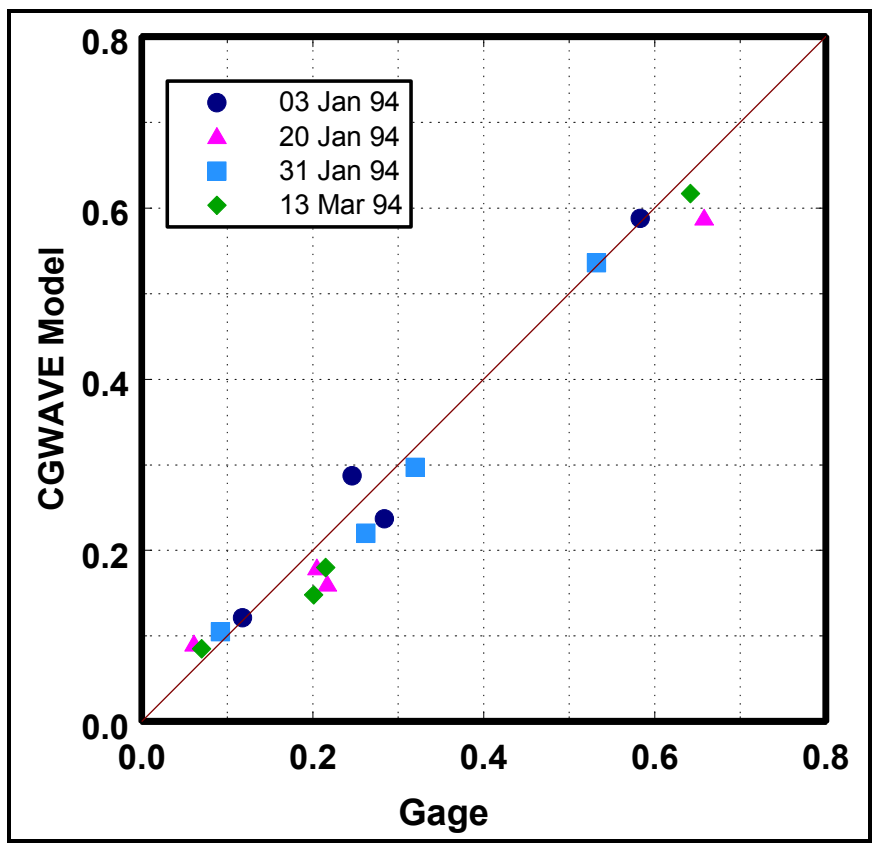

Figure 34. Model short wave calibration to four storm events, amplification factors

comparison was accepted as sufficient calibration and validation of CGWAVE for wind wave and swell applications at Kahului Harbor.

Long waves. Long wave calibration was aimed at adjusting bottom friction to approximately match amplification factors between model and data. Reflection coefficient was set to 1.0. Only the lower frequencies (0.003-0.010 $\mathrm{Hz}$ or 100-333-sec period) were considered because most prominent resonant peaks are in this range and $K_{r}=1.0$ is more strictly correct at low frequencies. Only resonant peaks were considered in calibration because they are the features of greatest interest and are most sensitive to the choice of bottom friction coefficient. A value of bottom friction coefficient equal to 0.02 was found to give a reasonably good match (comparable to that in the previous study) at all peaks in the selected frequency range and at all harbor gages. In CGWAVE, this coefficient is comparable to the roughness coefficient $\mathrm{n}$ commonly used in relation to hydraulic flow in open channels. In that context, the value 0.02 corresponds to "excellent clean canals in firm gravel, of fairly uniform section" (Sabersky and Acosta 1964). Thus, the bottom friction coefficient established by fitting model results to field data also has a reasonable physical basis. 


\section{Test Procedures and Calculations}

\section{Incident wave conditions}

A range of short and long wave conditions incident to Kahului Harbor was considered. A representative range of wave periods and directions which could cause damaging waves inside the harbor was included, based on field measurements.

The short wave periods and approach directions considered are given in Table 5. These conditions provide reasonable coverage of the field

\begin{tabular}{|l|l||}
\hline \hline \multicolumn{2}{|l||}{$\begin{array}{l}\text { Table } 5 \\
\text { Summary of Incident Short } \\
\text { Wave Conditions }\end{array}$} \\
\hline \hline Wave Period (sec) & $\begin{array}{l}\text { Wave Direction } \\
\text { (deg az., coming from) }\end{array}$ \\
\hline \hline 8 & 330 \\
\hline 10 & 340 \\
\hline 12 & 350 \\
\hline 14 & 0 \\
\hline 16 & 10 \\
\hline 18 & 20 \\
\hline 20 & 30 \\
\hline & 40 \\
\hline & 50 \\
\hline
\end{tabular}
measurements. The shortest wave period, representative of strong local storms, is $2 \mathrm{sec}$ shorter than the grid design period. Past experience has shown that the model still provides adequate results for small increments below the grid design period. The longest period represents a very long swell condition. Directions were chosen to cover the full directional exposure of the harbor entrance, in 10-deg increments. These incident wave components can be expected to give a good representation of the directional spectrum in post-processing. Incident wave directions are illustrated in Figure 35.

For the study of existing harbor conditions and comparison of alternatives, CGWAVE was run with the full set of short wave periods and directions in all possible combinations. Model results were then properly weighted and recombined to represent each directional spectrum in the 1-year incident wave time-history from the array.

Incident long wave conditions considered are given in Table 6. A fine resolution in wave frequency was used over the full range of possible resonant conditions to insure that all important peaks were identified. A total of 468 periods was considered, as in the previous study. Only one approach direction is included, since past studies have indicated that harbor response is relatively insensitive to incident long wave direction. This direction, $69.3 \mathrm{deg}$ azimuth, represents a wave coming from the mid point of the semicircle boundary and approaching the harbor entrance from deep water.

One water level was tested. The tide range at Kahului Harbor is relatively small, with a mean range of $1.9 \mathrm{ft}$. Harbor wave response is unlikely to vary much with water level over this tidal range. The water level was selected as mean lower low water, the reference datum for bathymetric data. 


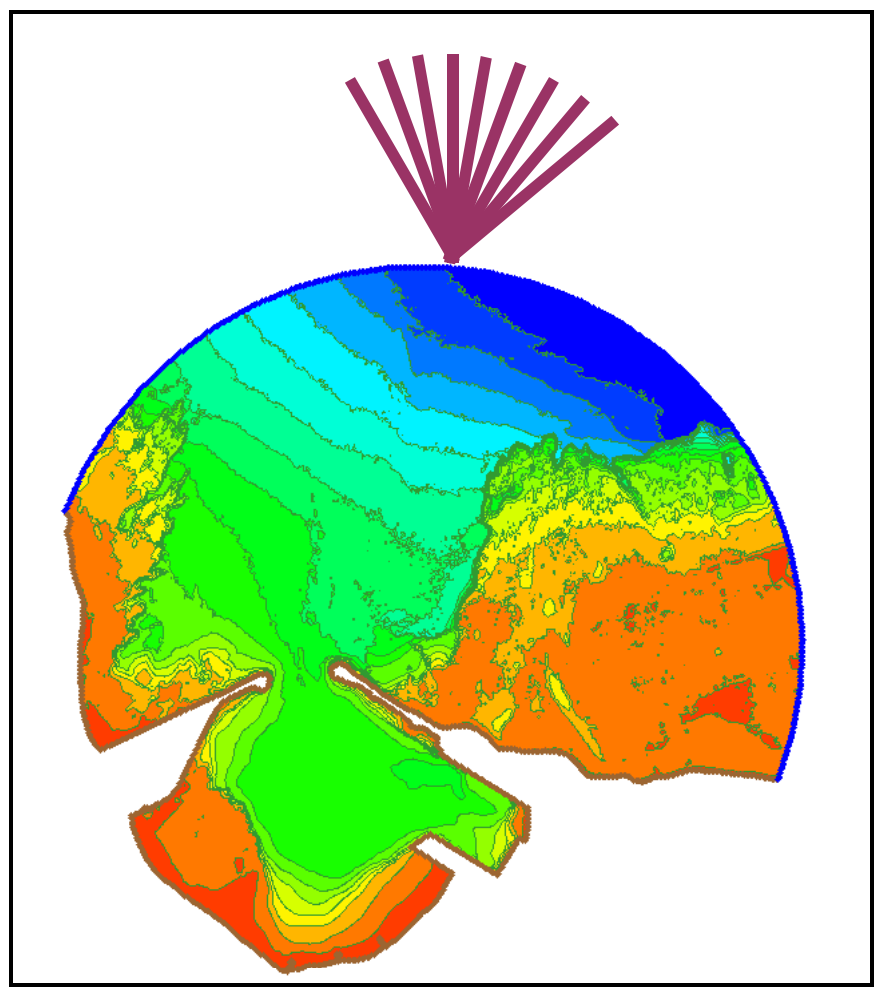

Figure 35. Incident short wave directions modeled

\section{Calculation of spectra}

Numerical model test results for short waves in Kahului Harbor are all based on spectral postprocessing of the initial CGWAVE runs. Hence, short wave amplification factors are all in the form of $\left(A_{\text {amp }}\right)_{\text {eff }}$ as described by Thompson et al. (1996). This approach requires, first, that CGWAVE be run with the range of wave periods and directions to be considered in the spectral calculations. Second, for each value of peak wave period, $T_{p}$, and wave approach direction, $\theta_{m}$; a spectral peak enhancement factor, $\gamma$; and directional spreading factor, $s$, must be specified. The $T_{p}$ and $\theta_{m}$ values were taken directly from the 1-year time-history recorded at the Kahului array gage. Small differences in wave direction between the seaward model boundary and the array were taken into account. Values for $\gamma$ and $s$ were

\begin{tabular}{|c|c|}
\hline \multicolumn{2}{|c|}{$\begin{array}{l}\text { Table } 6 \\
\text { Summary of } \\
\text { Incident Long Wave } \\
\text { Conditions }\end{array}$} \\
\hline $\begin{array}{l}\text { Wave } \\
\text { Period } \\
\text { (sec) }\end{array}$ & $\begin{array}{l}\text { Wave Direction } \\
\text { (deg az., } \\
\text { coming from) }\end{array}$ \\
\hline 25.00 & 20.7 \\
\hline 25.06 & \\
\hline 25.13 & \\
\hline$\ldots{ }^{1}$ & \\
\hline 1000.0 & \\
\hline \multicolumn{2}{|c|}{$\begin{array}{l}{ }^{1} \text { Frequency increments are } \\
0.0001 \mathrm{~Hz} \text { for periods of } 25- \\
80 \mathrm{sec} \text { and } 0.00006 \mathrm{~Hz} \text { for } \\
\text { periods of } 80-1,000 \mathrm{sec} \text {. }\end{array}$} \\
\hline
\end{tabular}
approximated by the same procedure developed in the previous study. This procedure has been further tested and has become a standard approach in CHL spectral wave model studies. Thus, a 1-year time-history of wind waves and swell can be reconstructed at any point in the model domain. 


\section{Output locations}

In order to get special coverage of areas where harbor operations would most likely be affected by wave conditions, output lines were selected to cover mooring areas along all piers in each harbor layout (Figure 36). The saving sequence began with the northwest end of pier 1 and proceeded clockwise around the harbor, as indicated in the figure. Further, an output line was designated along the center of the entrance channel, beginning seaward and ending landward of all proposed breakwater extensions. Model results were saved at about $100-\mathrm{ft}$ intervals along each line.

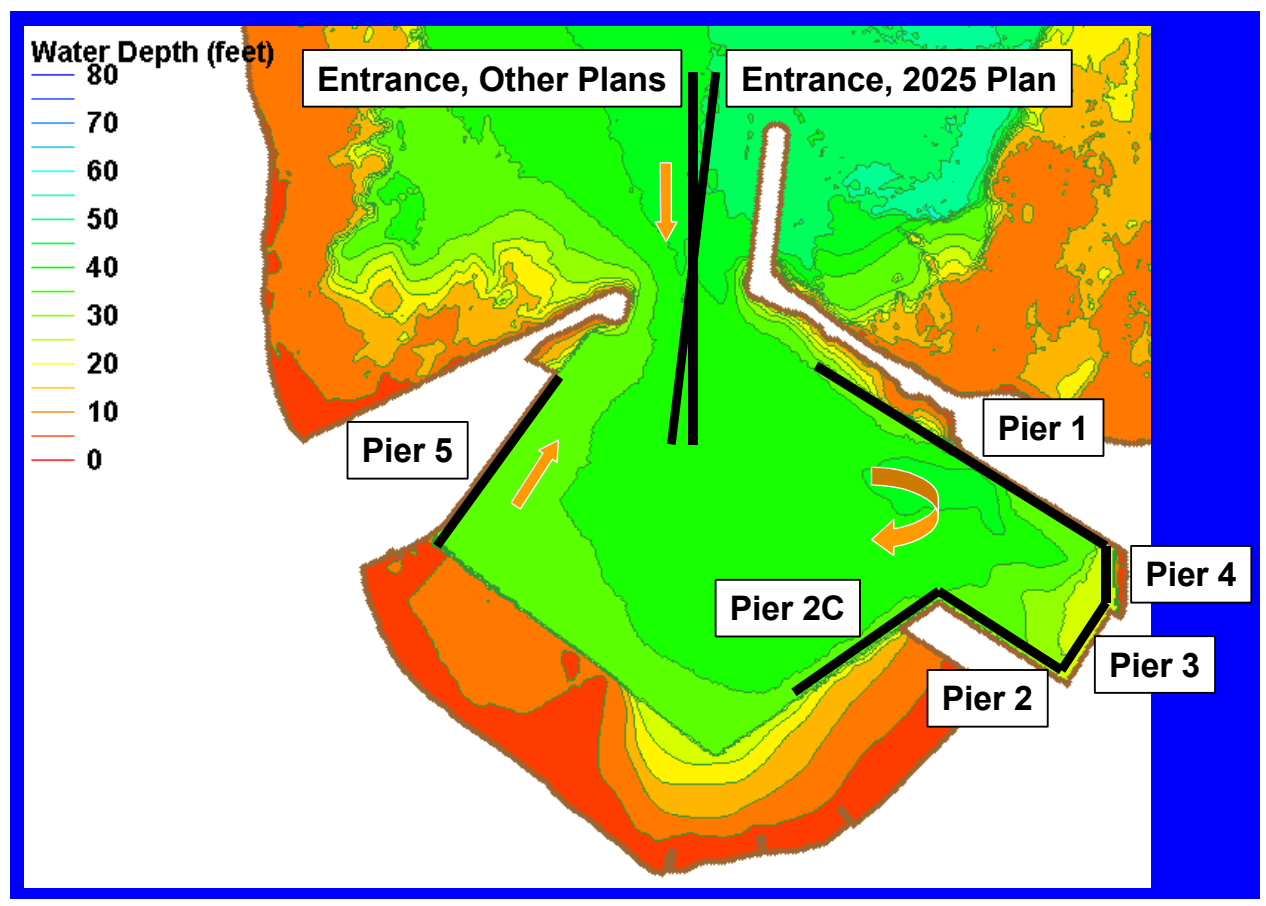

Figure 36. Model output lines 


\section{Harbor Response to Wind Waves and Swell}

Numerical model studies of the harbor response to wind waves and swell were directed primarily toward assessing the operational performance of alternative harbor modifications. Results, especially at existing and proposed new pier areas, are summarized in this chapter. Amplification factors are discussed in the following section. The final section gives $H_{s}$ values exceeded 10 percent and 1 percent of the time, a result more directly applicable to operational performance. The $H_{s}$ values are derived from a combination of amplification factors from the numerical model and wave measurements at the directional array outside the harbor. They are compared to operational criteria for wind waves and swell.

\section{Amplification Factors}

Amplification factors, representing directionally-spread short wave spectra in the form of $\left(A_{\text {amp }}\right)_{\text {eff }}$, were calculated for the variety of wind wave and swell conditions measured at the Kahului array gage during 1994. Figures 37-40 illustrate amplification factor patterns over the harbor for each of the four calibration storms. Amplification factors are the ratio of local $H_{s}$ to that at the array.

For each storm, wave responses of the existing harbor and the three-plan harbors are shown. Amplification factor at any place in the harbor changes between plans only if there are significant changes in sheltering by breakwater extensions. For example, the pier 5 location gains a small measure of protection from the seaward extension to the east breakwater, but it gains substantial protection from the landward extension to the west breakwater (Plan C). Wind wave and swell response in the harbor is basically a result of diffraction through the breakwater gap. Boundary reflection characteristics have a localized effect on the waves, but changes in the western half of the harbor have virtually no effect on the existing pier areas. 


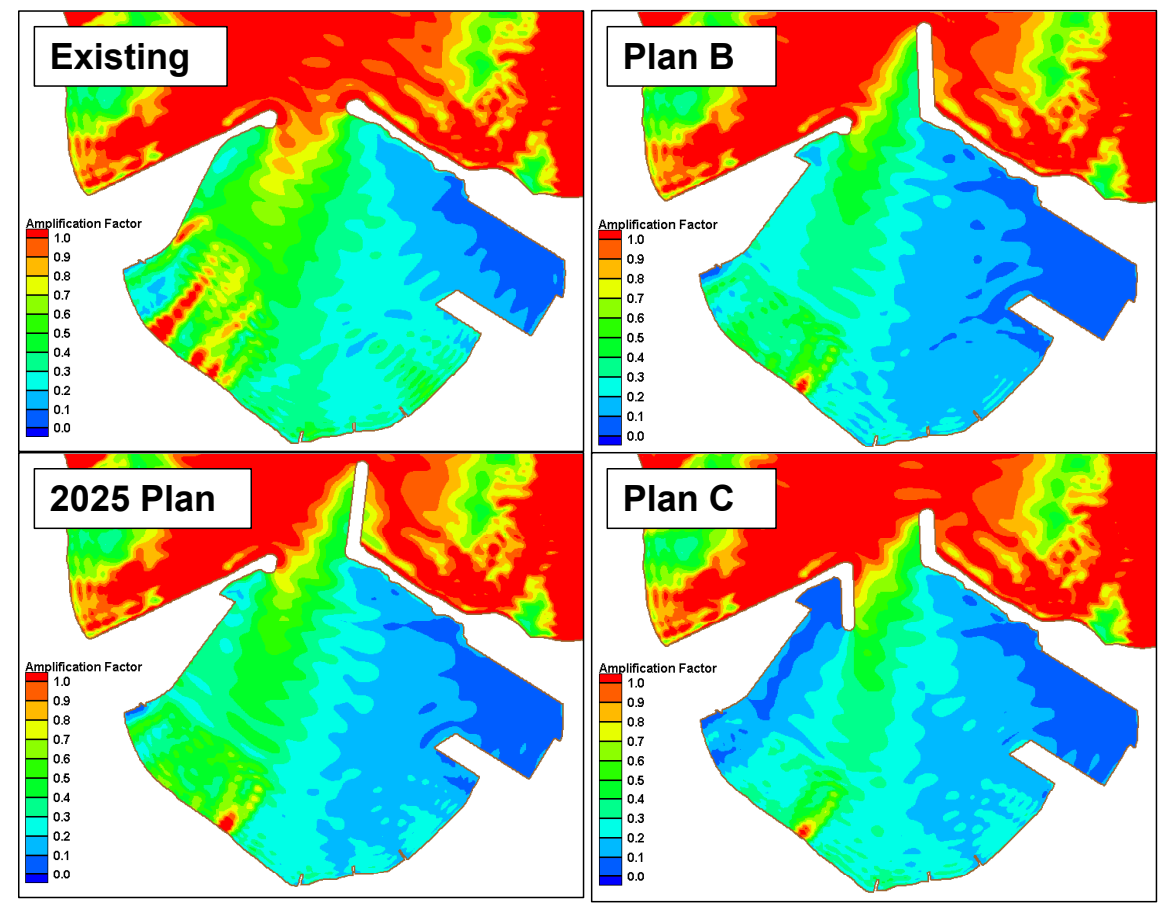

Figure 37. Wave height amplification factor, storm event of 3 Jan. 1994

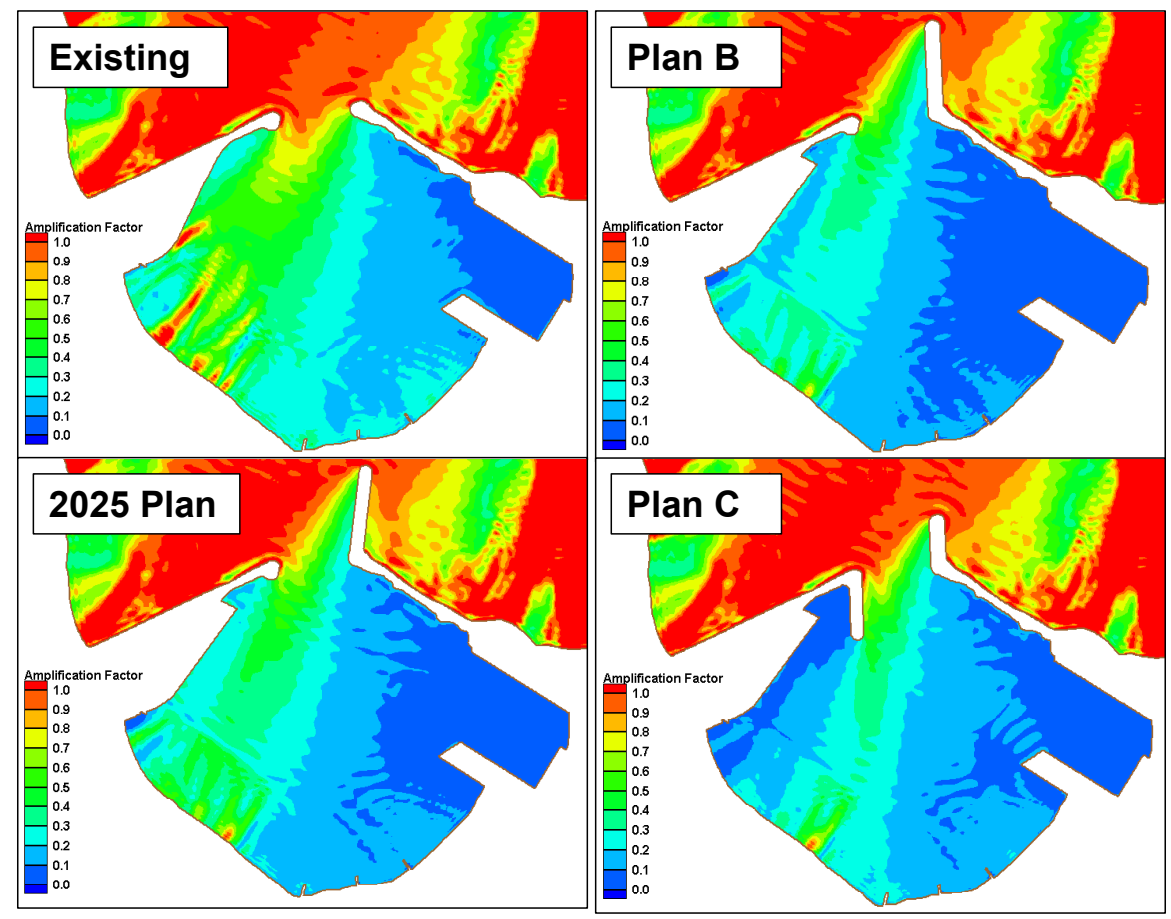

Figure 38. Wave height amplification factor, storm event of 20 Jan. 1994 


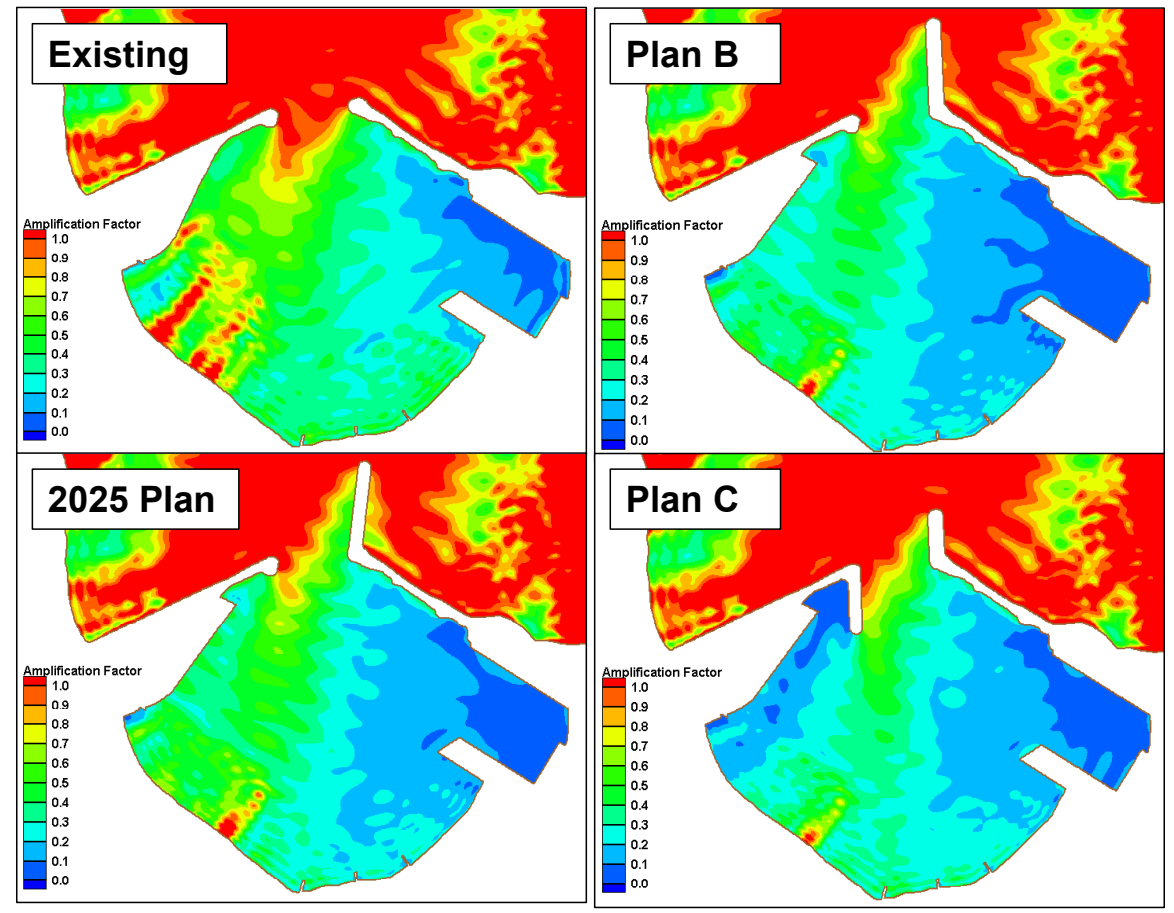

Figure 39. Wave height amplification factor, storm event of 31 Jan. 1994

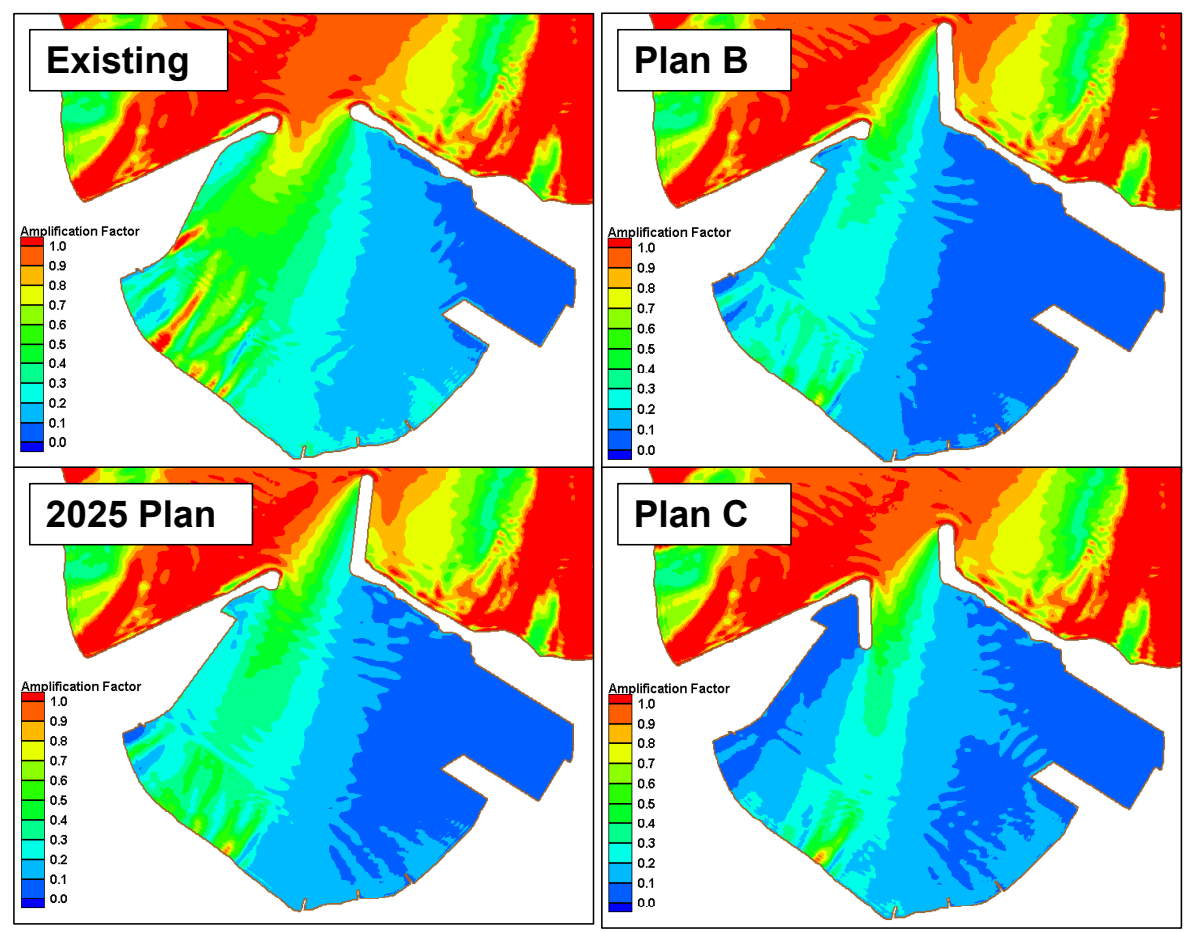

Figure 40. Wave height amplification factor, storm event of 13 Mar. 1994 


\section{Evaluation Against Operational Criteria for Wind Waves and Swell}

Standard operational criteria used by USACE for wind waves and swell in shallow draft harbors are as follows:

a. wave height in berthing areas will not exceed $1 \mathrm{ft}$ more than 10 percent of the time

$b$. wave height in entrance and access channels and turning basins will not exceed $2 \mathrm{ft}$ more than 10 percent of the time

Standard criteria for wind waves and swell in deep draft harbors, such as Kahului Harbor, are not so well established. However, the criteria for shallow draft harbors can provide a useful basis for comparing alternative plans at Kahului Harbor. Experience with the Alaska ferry system (vessel lengths up to $300 \mathrm{ft}$ ) suggests that the USACE 1-ft criterion in berthing areas is a meaningful threshold for that application (Personal Communication, 2002, Harvey Smith, Department of Transportation and Public Facilities, State of Alaska).

Another, perhaps more valuable criterion for evaluating proposed new pier areas is to compare with the existing piers. Many years of practical experience at piers 1 and 2 can then be approximately transferred to new plans.

Wave heights for assessing the USACE criteria were computed by combining the time-history of array gage parameters over the time period January through December 1994 with numerical model results to create a timehistory of wave heights along each output line. For each array record, the corresponding wave height at a harbor point is

$$
\left(H_{s}\right)_{\text {harbor }}=\left(A_{\text {amp }}\right)_{\text {eff }} x\left(H_{S}\right)_{\text {array }}
$$

where

$$
\begin{aligned}
& \left(H_{s}\right)_{\text {harbor }}=\text { significant wave height at a point in the harbor } \\
& \left(A_{\text {amp }}\right)_{\text {eff }}= \\
& \text { spectral amplification factor calculated from model results for the } \\
& \text { periods and directions in Table } 5 \text { to represent } T_{p} \text { and } \theta_{m} \text { at the array } \\
& \left(H_{s}\right)_{\text {array }}=\text { significant wave height at the array }
\end{aligned}
$$

The 1-year time-history of $\left(H_{s}\right)_{\text {harbor }}$ at each point along the output lines was sorted into descending order and the value of $H_{s}$, which was exceeded 10 percent of the time, was identified. The $H_{s}$ value exceeded 1 percent of the time was also identified. The $H_{s}$ with 1 percent exceedance relates to a more demanding operational condition, which may be more applicable to large commercial vessels.

Significant wave height exceeded 10 percent of the time is about $4.5 \mathrm{ft}$ at the exposed end of the entrance channel, dropping to $2 \mathrm{ft}$ or less at the protected end 
of the entrance channel transect (Figure 41). As would be expected, the dropoff in $H_{s}$ occurs only gradually until the channel begins to experience sheltering from the breakwater(s). The Plan B breakwater extension provides the most effective protection to the entrance channel, because it is relatively long and is best oriented to block the incident wave climate. Significant wave height exceeded 1 percent of the time shows a similar pattern (Figure 42). Heights drop from nearly $7 \mathrm{ft}$ at the exposed end of the entrance channel transect to about 2-3 $\mathrm{ft}$ at the protected end.

Along the existing and proposed piers, $H_{s}$ values exceeded 10 percent of the time are less than $1 \mathrm{ft}$ in most cases (Figure 43). Exceptions are the most exposed (west) end of the pier 2C location in the existing harbor and along pier 5. The southwest end of the proposed pier 5 location in the existing harbor configuration shows elevated wave heights due to the shallow water depths. A similar, though less pronounced, shallow water effect is evident at piers 3 and 4 in the existing harbor. This effect is absent in the plan harbors because water depths along piers 3-5 are deepened. The $H_{s}$ exceeded 10 percent of the time computed directly from pier 2 wave gage results is $0.39 \mathrm{ft}$, which compares well with corresponding numerical model results in the existing harbor and helps to validate the model wave heights.

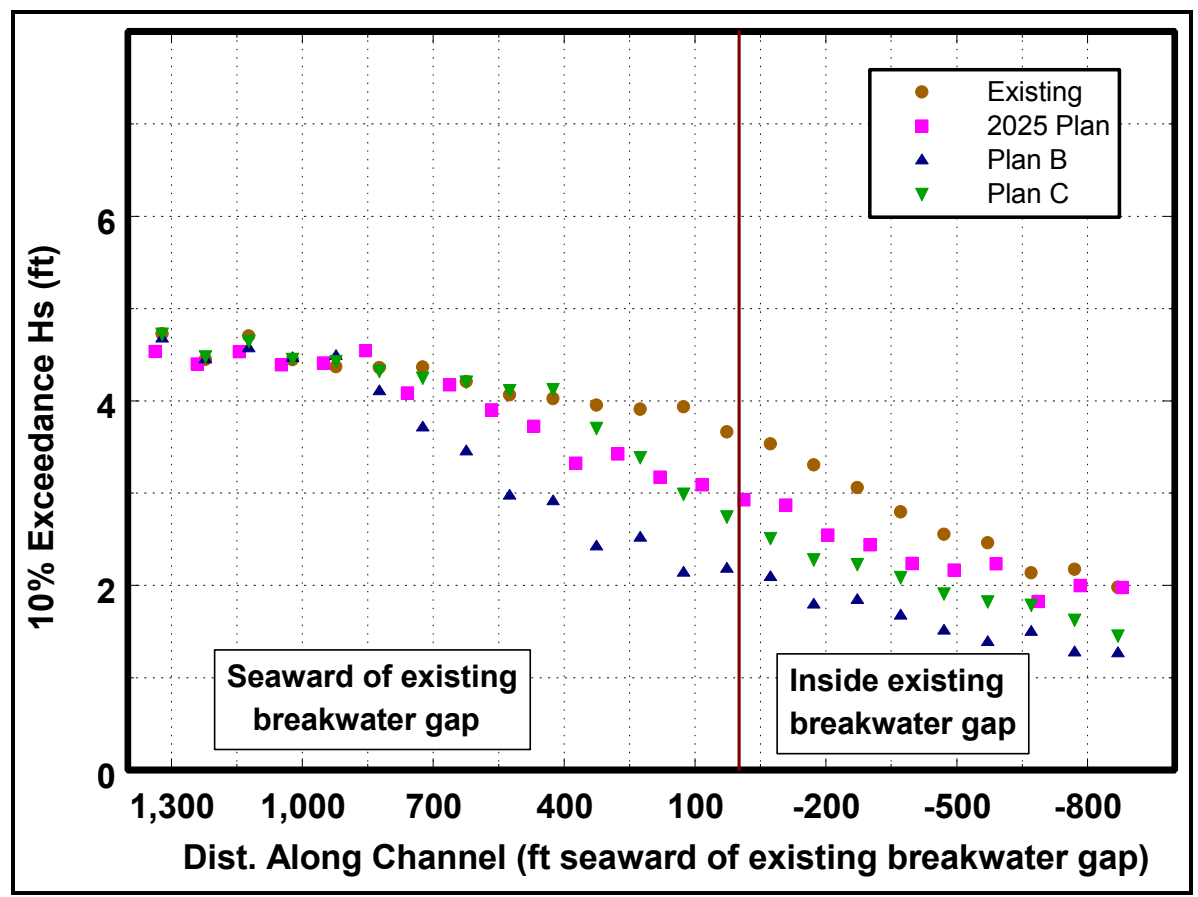

Figure 41. Comparison of $H_{s}$ exceeded 10 percent of time in entrance channel 


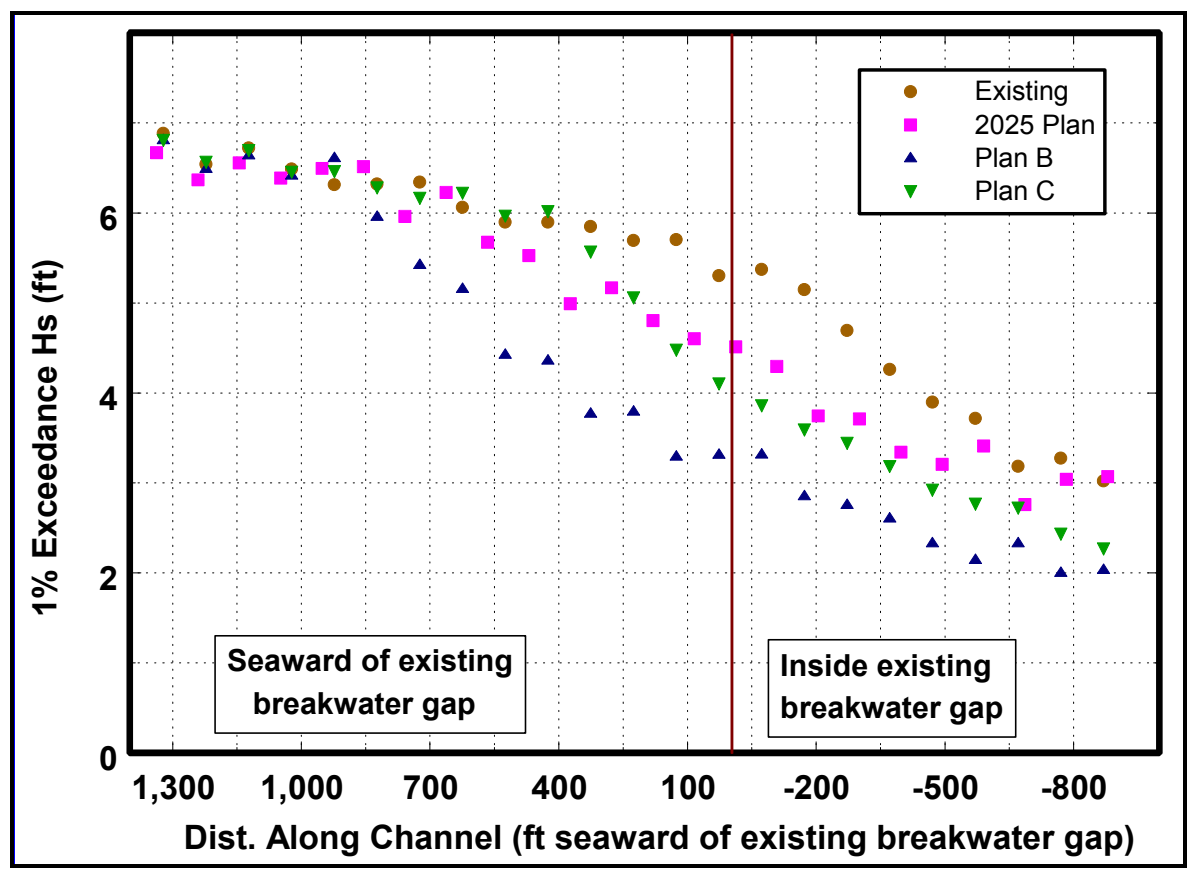

Figure 42. Comparison of $H_{s}$ exceeded 1 percent of time in entrance channel

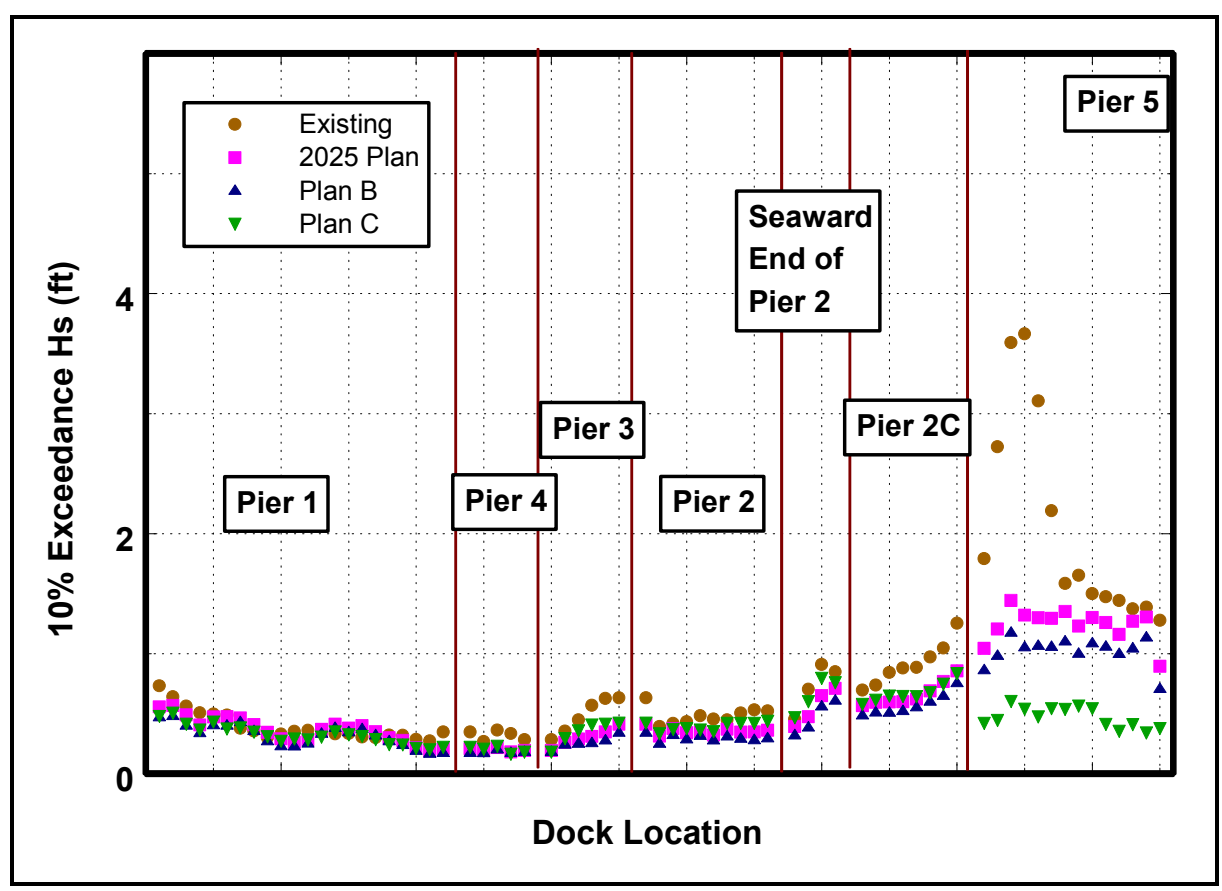

Figure 43. Comparison of $H_{s}$ exceeded 10 percent of time at piers

Significant height with 10 percent exceedance along pier $2 \mathrm{C}$ is higher than the presently-used pier 1 and protected, main dock area of pier 2 but still less than $1 \mathrm{ft}$ along most of the pier length in the plan conditions. Wave activitiy at 
pier $2 \mathrm{C}$ is comparable to the center of the exposed seaward end of the existing pier 2. Thus, wind wave and swell conditions to be expected at pier $2 \mathrm{C}$ can be related to past experience in the existing harbor. Wave heights along the southwest half of the exposed seaward end of pier 2 decrease noticeably along the adjacent (northeast) end of pier $2 \mathrm{C}$ due to differences in wave reflection from the solid end of pier 2 versus the open, pile-supported pier $2 \mathrm{C}$ structure. Plan changes to the entrance provide a small, but significant increase in protection to pier 2C. Plan B provides the best protection to this area.

Significant height with 10 percent exceedance along pier 5 with the protection of Plan $\mathrm{C}$ is comparable, but a little higher, than along pier 1. For other plans and the existing harbor, $H_{s}$ is higher than along pier 1 , well over the 1 -ft threshold in the existing harbor and 2025 plan.

The $H_{s}$ values exceeded 1 percent of the time are considerably higher than those exceeded 10 percent of the time, but show similar relative trends (Figure 44). Existing pier areas still fall below the 1-ft wave height threshold for the improvement plans, with the exception of the exposed, seaward end of pier 2 and, possibly, the northwest end of pier 1. Values of $H_{s}$ at the proposed new pier $2 \mathrm{C}$ lie very near the threshold. At pier $5, H_{s}$ values are well above the threshold in all plans except Plan C.

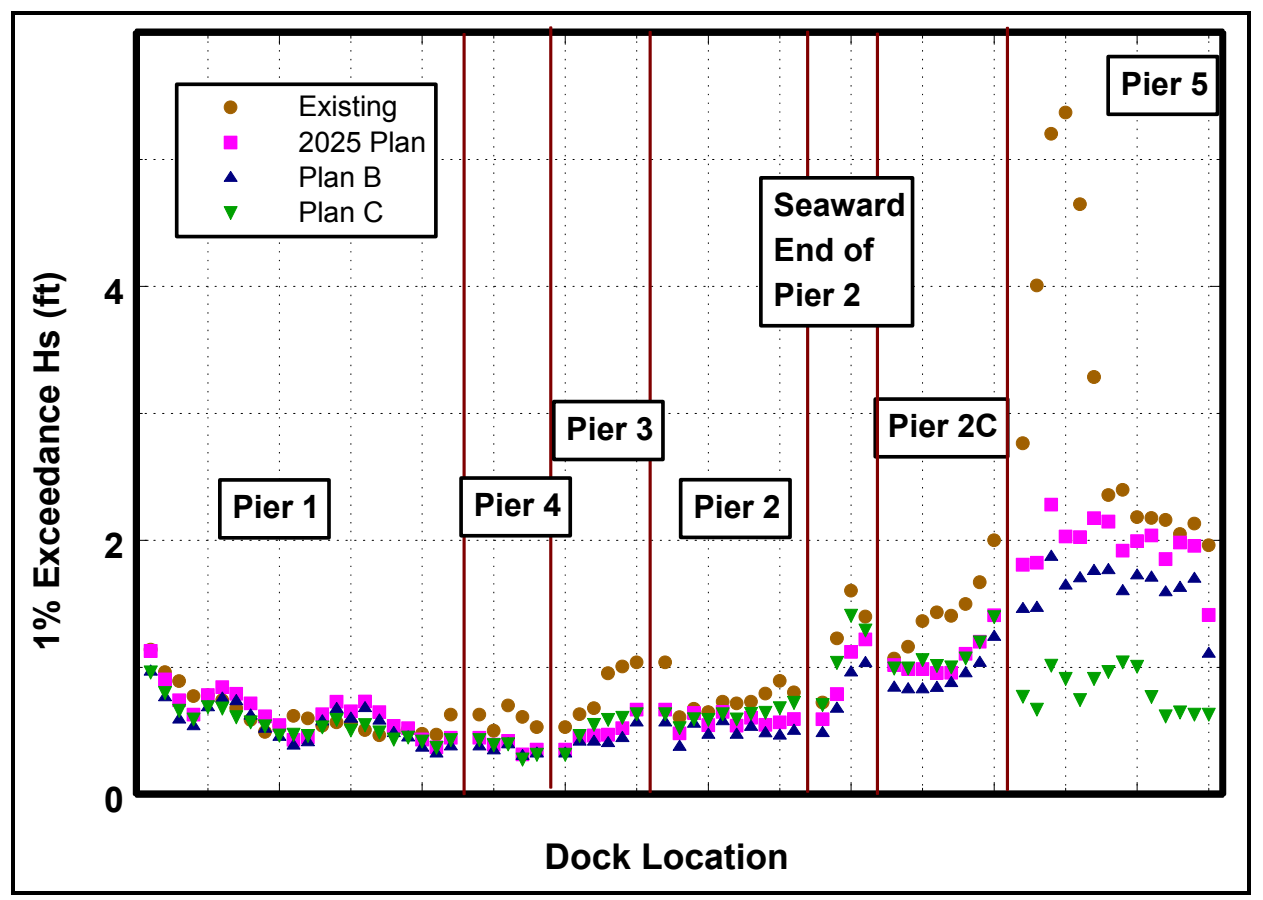

Figure 44. Comparison of $H_{s}$ exceeded 1 percent of time at piers 


\section{Harbor Oscillations}

To evaluate harbor resonance characteristics, the CGWAVE numerical model was run for the existing harbor and all alternative plans. Incident long wave periods ranged from $25 \mathrm{sec}$ to $1,000 \mathrm{sec}$ in very fine increments, as discussed in Chapter 3. These evaluations were included because oscillations are an important part of interpreting the existing harbor wave response (as evidenced by gage data in the harbor), and modifications to the harbor can potentially lead to increased operational problems due to harbor oscillations. Amplification factor results are presented in the following section. Discussion of the results relative to operational performance criteria is given in the final section of this chapter. An interesting analysis of long wave data from gages outside and inside Kahului Harbor was done by Okihiro and Guza (1996).

\section{Amplification Factors}

\section{Background}

Amplification factors for the long waves involved in harbor oscillation behave differently than those for wind waves and swell. Long waves, because of their length relative to harbor dimensions and their reflectivity from harbor boundaries, form standing wave patterns in the harbor. Standing wave behavior in a simple closed basin of uniform depth is illustrated in Figure 45. In the fundamental mode of oscillation, antinodes occur at both basin walls and a node midway between walls. The distance between walls is equal to one-half of the oscillation wavelength. Second and third modes of oscillation are also illustrated. Antinodes always occur at the walls. Additional antinodes and nodes occur at regular intervals between walls, with the number of antinodes and nodes dependent on the mode of oscillation.

The water surface in a standing wave has its greatest vertical motion at antinodes. There is no vertical movement at an ideal node, but horizontal velocities reach a maximum there. In terms of amplification factors, $A_{a m p, l}$, this behavior gives large values of $A_{a m p, l}$ at antinodes and small values around nodes. Contrary to wind waves and swell, small values of $A_{a m p, l}$ are not necessarily indicative of a tranquil harbor area. 


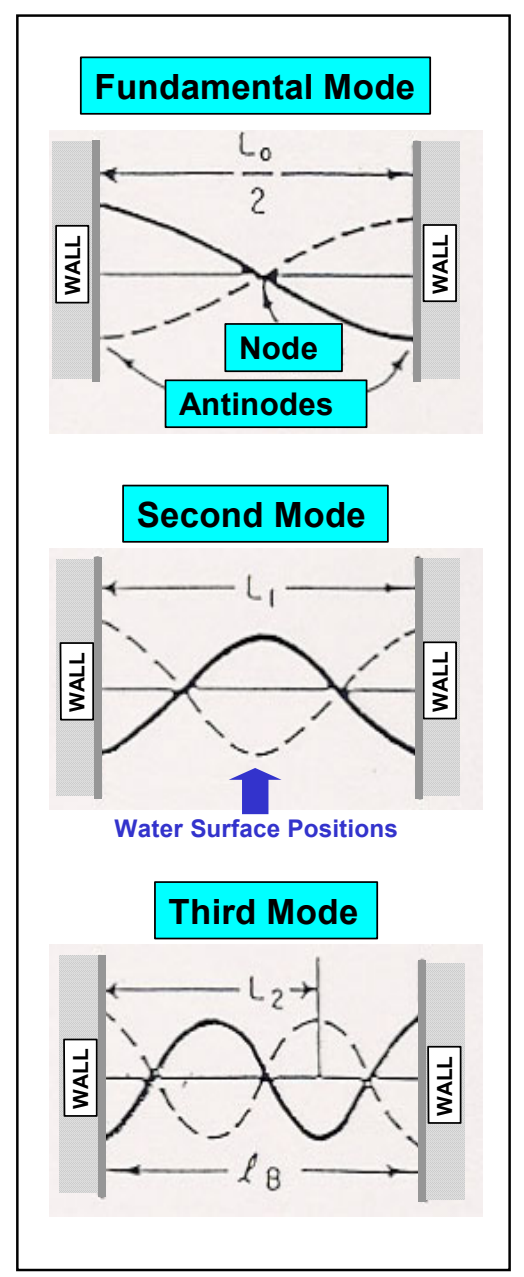

Figure 45. Harbor oscillation definitions
Phases in a standing wave also behave differently than for typical wind waves and swell. For example, the water surface in the fundamental mode of oscillation in Figure 45 simultaneously reaches a maximum at every point to the left of the node. These points are all in phase. At the same time, every point to the right of the node reaches a minimum value. These points are also in phase with each other but exactly out of phase with the points to the left of the node. Thus phases in a simple standing wave are constant between an antinode and node. They quickly change by $180 \mathrm{deg}$ (or $\pi$ radians) across the node and remain constant up to the next node or boundary.

\section{Existing harbor}

Amplification factors for pier areas in the existing harbor are shown as a function of wave frequency in Figure 46. Amplification factor shown at each frequency and pier location is the maximum value for all output points along the length of the pier. Similar results were presented in the previous study. They are repeated here for convenience in comparing with plan results. Also, these results were obtained with the CGWAVE model. They generally resemble the earlier results obtained with the HARBD model. Peak values of $A_{\text {amp }, l}$ at special output locations tend to be higher in the present study, as compared to the previous study, due to differences in location along the piers. In the previous study, results were saved at a few selected locations along the piers. In the present study, results were saved on lines stretching along the entire length of the piers. Also, $A_{\text {amp }, l}$ at pier 3, which was not saved in the previous study, is affected by the shallow water depths in this area of the existing harbor. Values of $A_{a m p, l}$ along the proposed pier 5 location were even more exaggerated by shallow depths in this area of the existing harbor, and they are not included in figure.

Some frequencies produce a strong resonant amplification, with peak $A_{\text {amp, }}$ values between about 2 and 10. Many of the same resonant frequencies appear at all pier areas, though the strength of amplification can vary considerably. A large peak at very low frequency $(0.0007 \mathrm{~Hz}$ or 1,500 -sec period) shows at every location and plan. This peak represents the Helmholtz (or grave) mode of oscillation, in which the entire harbor rises and falls in unison. Phase is constant over the whole harbor. This peak also dominates long wave spectra at the array (Thompson et al. 1996).

Amplification factor and phase contour plots for the three highest resonant peaks at frequencies lower than $0.02 \mathrm{~Hz}$ (50-sec period), excluding Helmholtz resonance, show oscillation patterns in the existing harbor. These peaks are numbered in Figure 46 for easy reference. In amplification factor plots, areas of 


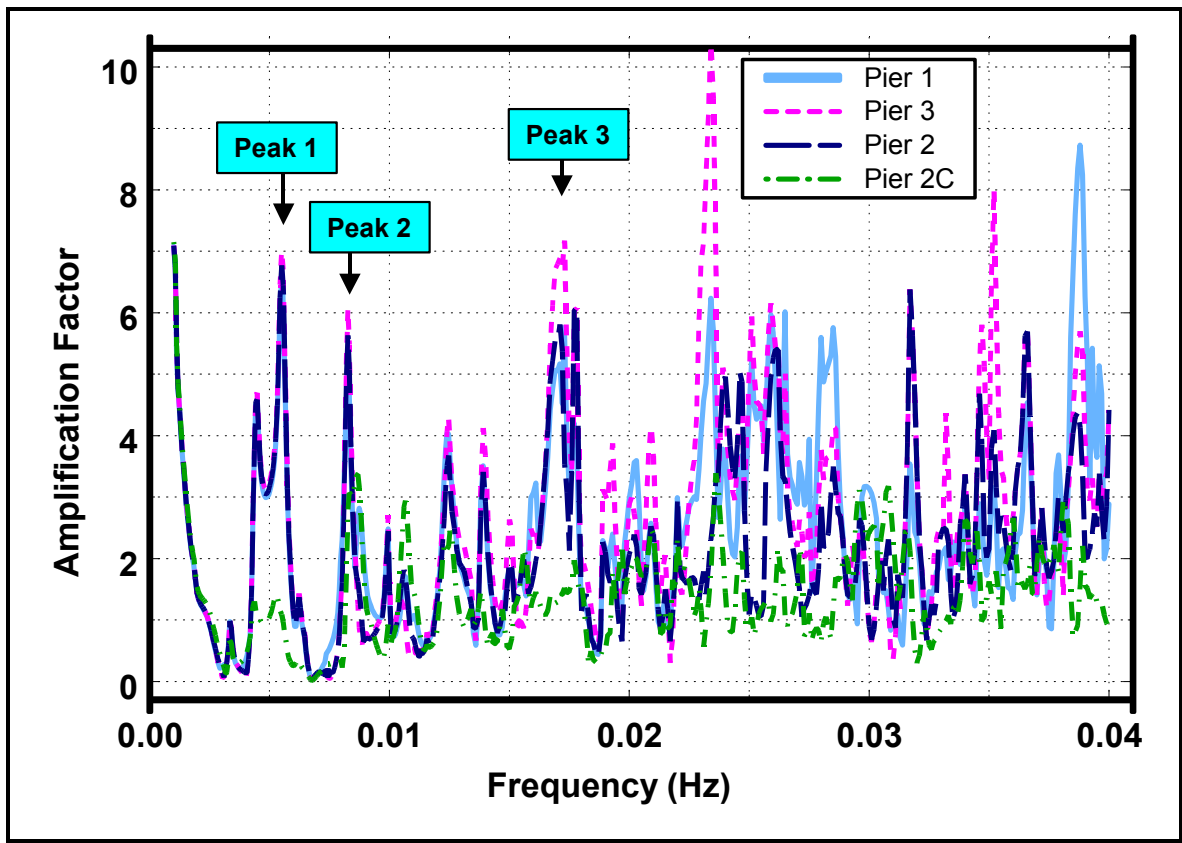

Figure 46. Long wave response, existing harbor

high amplification are evident as orange and red colors (Figure 47).

Corresponding phase contours are shown in Figure 48. Areas in which $A_{a m p, l}$ is near zero and phase contours are tightly bunched indicate nodal zones.

Relatively strong currents would occur across nodal lines during resonance events. The phase plots also indicate areas of the harbor which rise and fall together during the resonant condition (areas with the same color). Thus the oscillation patterns can be interpreted. Nodes which may impact present harbor operations intersect the outer part of pier 1 for 181.8 -sec resonance and the middle of pier 1 and end of pier 2 for $121.1-\mathrm{sec}$ resonance. The 58.5 -sec resonance shows two nodes impacting piers 1 and 2 .

The 181.8-sec resonance (peak 1) is primarily a rocking between piers 1-3 and the coral stockpile along the west breakwater. The shorter period oscillations are more complex patterns. They represent higher order modes of oscillation between the existing commercial piers and the west side of the harbor, similar to those in Figure 45 but adapted to the shape of Kahului Harbor. They generally indicate a strong nodal area at or near pier 1 and the seaward end of pier 2.

Long wave amplification factors shown here may be overestimated for resonant peaks at periods less than about $100 \mathrm{sec}(0.01-\mathrm{Hz}$ frequency). Wave reflection coefficient at all solid boundaries was set to 1.0 for all long wave runs, but comparison of model results to field data in the previous study showed that peaks at the shorter long wave periods tend to be overestimated. Some reduction in reflection coefficient as wave period decreases could be expected physically. In the previous study, it was demonstrated that even a small decrease in reflection coefficient to $K_{r}=0.95$ can reduce resonant peaks dramatically. Additional tests with $K_{r}=0.95$ helped confirm that this choice would improve the long wave calibration at periods between $25 \mathrm{sec}$ and $100 \mathrm{sec}$. It was not practical to refine 


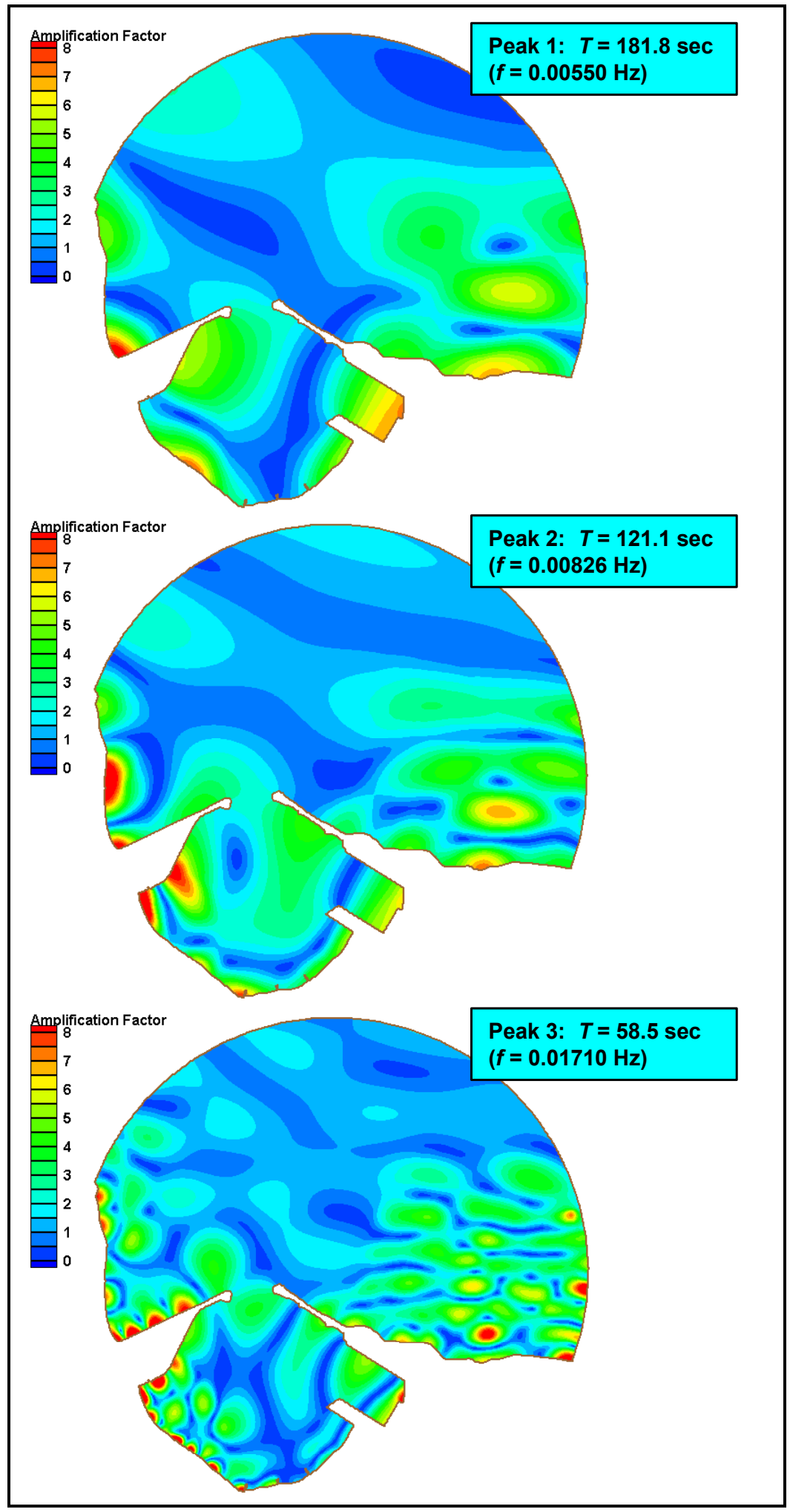

Figure 47. Resonant long wave amplification factor contours, existing harbor 


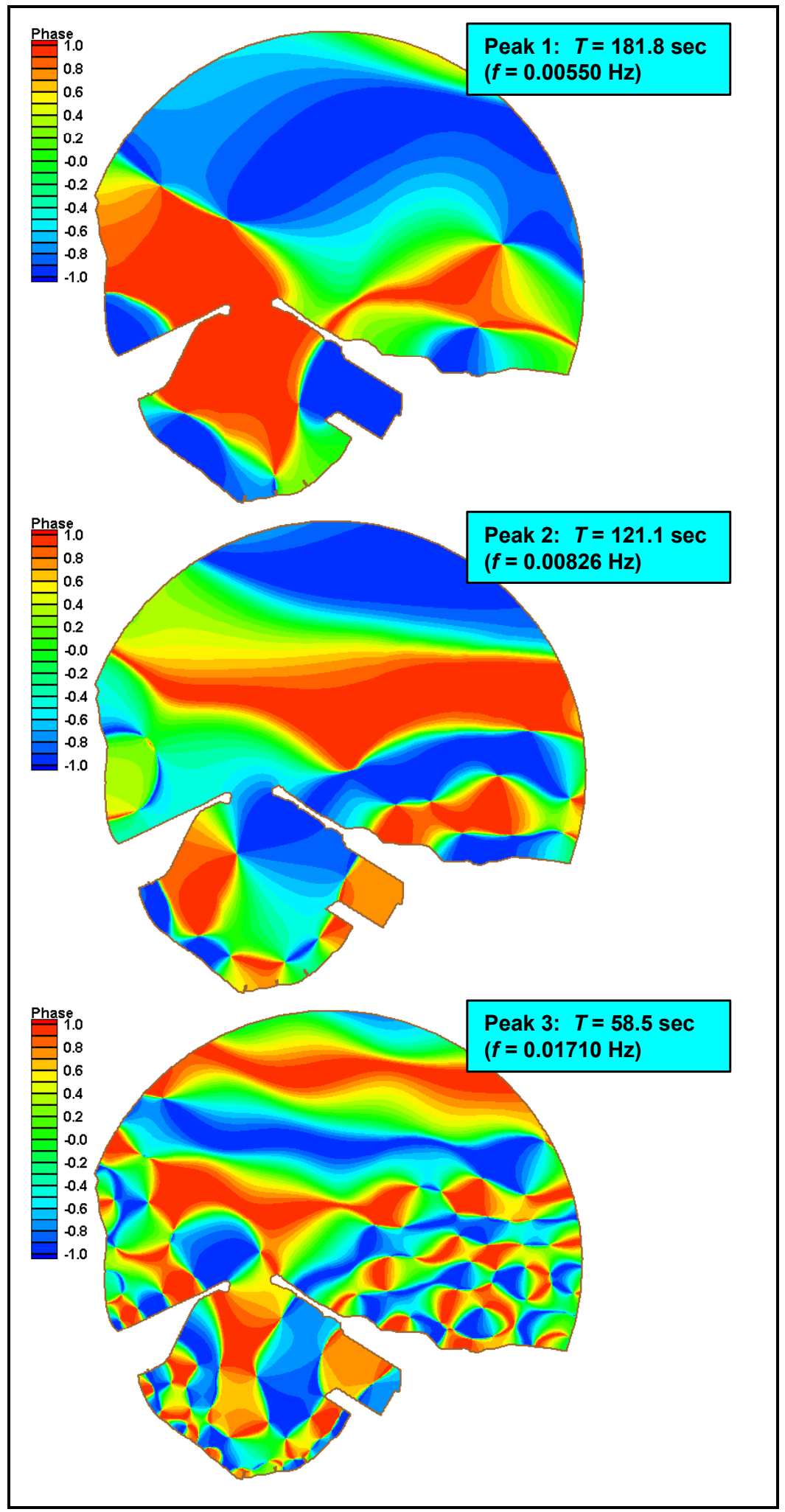

Figure 48. Resonant long wave phase contours, existing harbor 
$K_{r}$ values in the previous study, and runs with $K_{r}=1.0$ were considered adequate for evaluating alternative plans. The same approach was taken in the present study.

\section{5 plan}

Amplification factors for main pier areas in the 2025 plan show a presence of resonant peaks that resembles those for the existing harbor, though the strength of resonance varies (Figure 49). As with the existing harbor, amplification factors shown are maximum values along the length of each pier. Amplification factor and phase over the harbor for three prominent resonant conditions show patterns similar to the existing harbor (Figures 50 and 51). Resonant periods are a few seconds shorter than for the existing harbor because of additional deepening in the 2025 plan. Nodes which may impact harbor operations include a node at the seaward end of pier 5 in addition to the nodes near piers 1 and 2 mentioned earlier for the existing harbor. The 49.5-sec resonance also shows a node intersecting the middle of pier 5 .

The 2025 plan bears a strong resemblance to Plan $4 \mathrm{a}$ in the previous study. The seaward extension of the east breakwater in the 2025 plan has little impact on harbor resonance. Differences inside the harbor between the 2025 plan and Plan $4 \mathrm{a}$ are relatively small. Long wave results for the 2025 plan are quite similar to those for Plan 4a in the previous study.

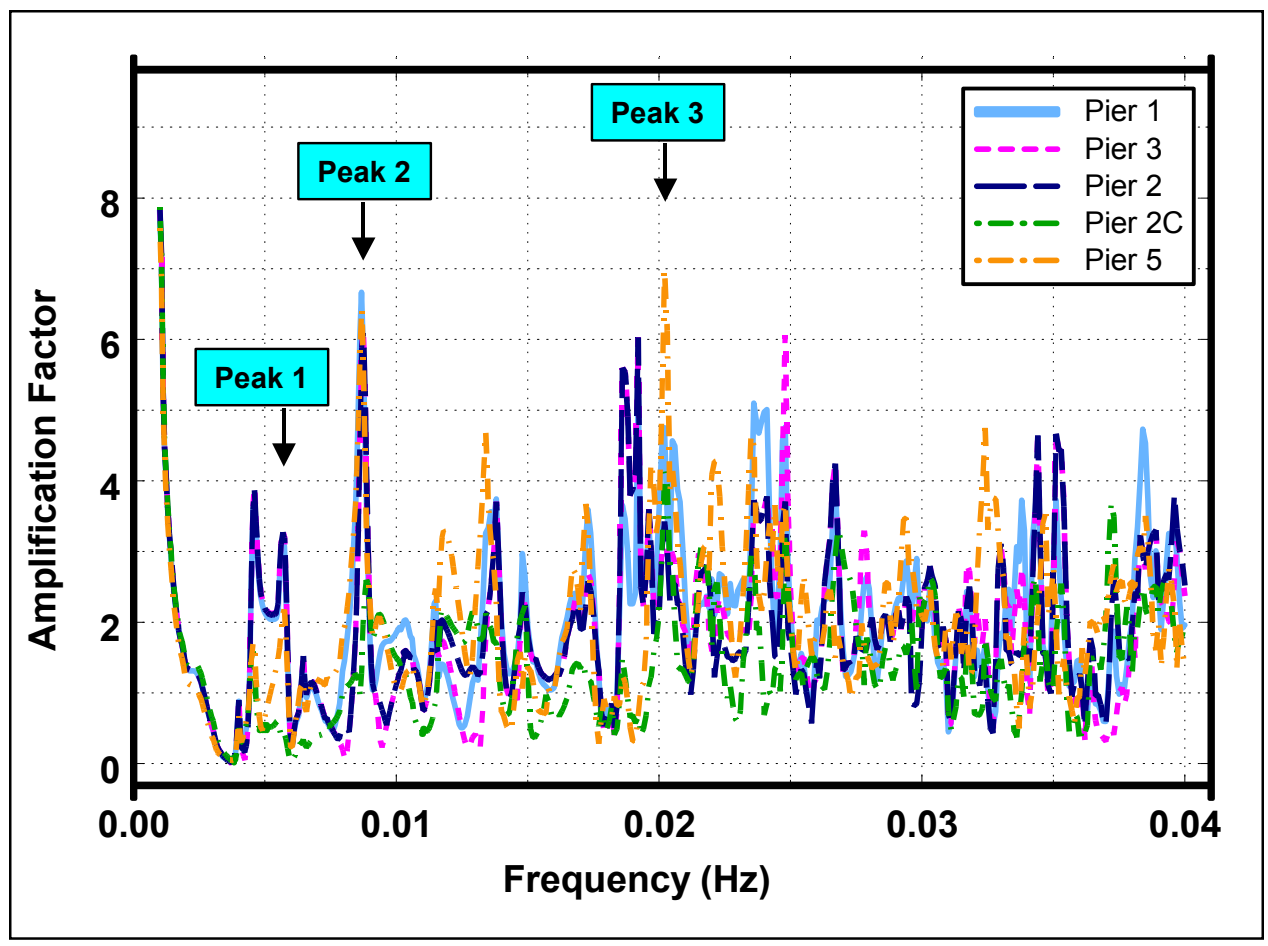

Figure 49. Long wave response, 2025 plan 


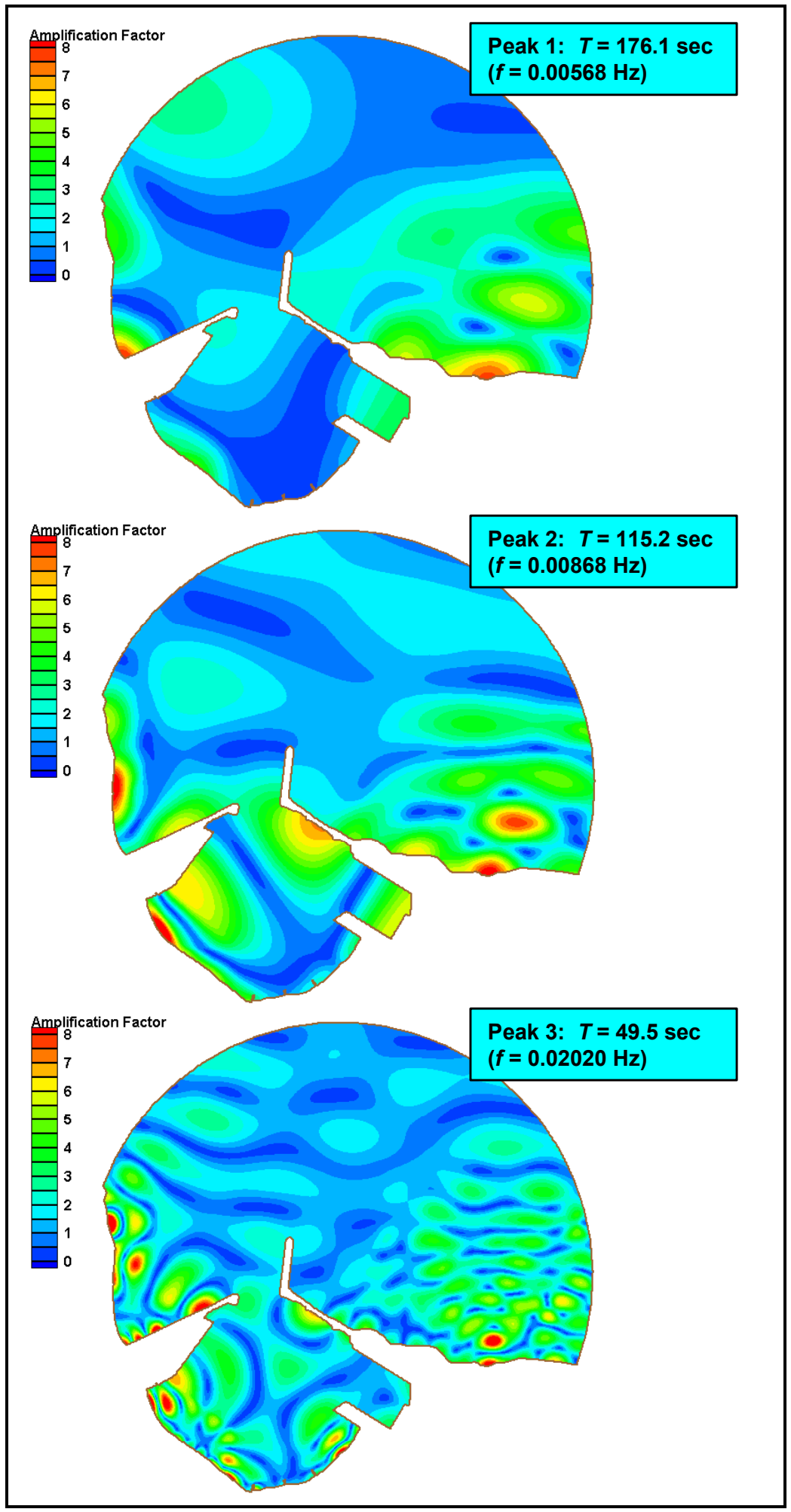

Figure 50. Resonant long wave amplification factor contours, 2025 plan 


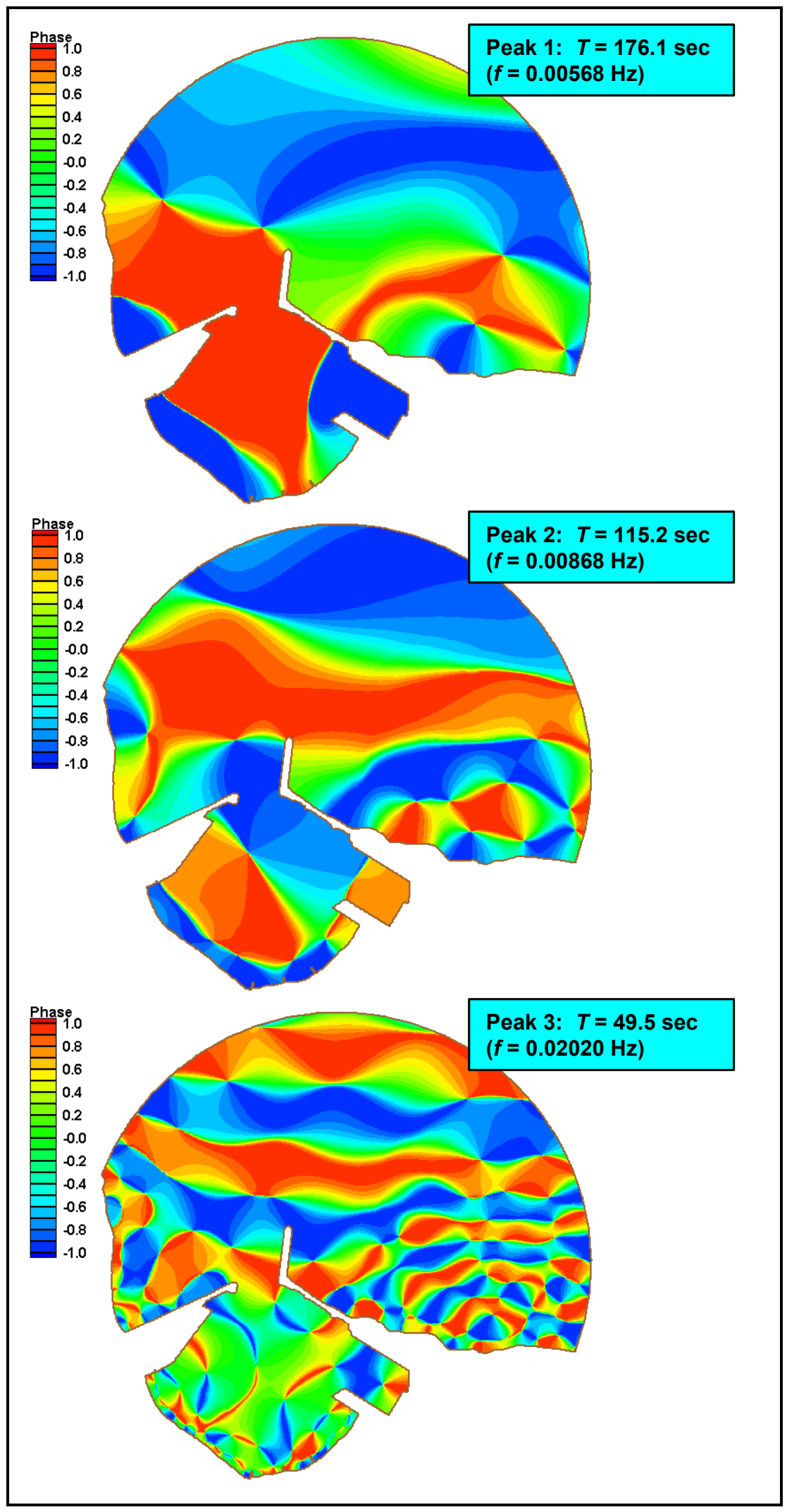

Figure 51. Resonant long wave phase contours, 2025 plan 


\section{Plans B and C}

Amplification factor plots for Plans B and C are given in Figures 52 and 53. Plan B results are nearly identical to those for the 2025 plan, since the harbor interior is exactly the same in both plans. Plan $\mathrm{C}$ results show resonant peaks at about the same frequencies, but $A_{a m p, l}$ at the peak 2 resonance is significantly increased, to a value of over 10. Increased $A_{a m p, l}$ at some higher-frequency peaks are also evident.

Amplification factor and phase contour plots for the main resonant frequencies show that the stub extending landward from the west breakwater (Plan C) acts to enhance resonant response at the 121.1-sec period (Figures 54 and 55). Amplification factor is increased in several harbor areas due to the stub, including the area between piers 1 and 2, pier 5, and the area south of the outer part of the east breakwater. The node intersecting the middle of pier 1 for the 121.1-sec resonance, though in about the same location as in other plans considered, would be expected to have stronger flows due to the increased amplification factors. Plan $\mathrm{C}$ changes inside the harbor are very similar to those for Plan $4 \mathrm{~b}$ in the previous study and the long wave results are similar, as well.

\section{Evaluation Against Operational Criteria for Long Waves}

Procedures for evaluating the operational acceptability of different harbor plans subjected to long waves were reviewed in the previous study and by Thompson, Boc, and Nunes (1998). Three guidelines are applied in this study, as discussed in the following paragraphs. Each guideline provides a different and useful perspective on the long wave response of the various harbor plans.

One operational guideline is based on the value of $A_{\text {amp, }}$ for the higher resonant peaks. Experience with Los Angeles and Long Beach Harbors has indicated that if $A_{a m p, l}$ is greater than about 5, some operational difficulties may be encountered. If $A_{a m p, l}$ is greater than 10, major operational problems can be expected (Personal Communication, 1996, William Seabergh, research hydraulic engineer, CHL, ERDC).

This guideline may be applied to the plots of $A_{\text {amp }, l}$ versus frequency. If the very low frequency Helmholtz peak and frequencies greater than $0.01 \mathrm{~Hz}$ (wave periods shorter than $100 \mathrm{sec}$, for which $K_{r}$ would be less than 1.0) are excluded, the existing harbor, 2025 plan, and Plan B have maximum $A_{a m p, l}$ values of about 7 and Plan $\mathrm{C}$ has a maximum of about 10 . Based on this metric, the existing harbor, 2025 plan, and Plan B appear to be free of major operational difficulties. Some operational difficulties may be encountered. By this criterion, both the 2025 plan and Plan B can be expected to perform as well or better than the existing harbor. On the other hand, Plan $\mathrm{C}$ may have more severe operational difficulties. Harbor oscillations are potentially a greater operational concern in Plan $\mathrm{C}$ than in the existing harbor.

A second operational guideline takes into account the actual long wave climate at Kahului Harbor, as represented by the array gage, as well as 


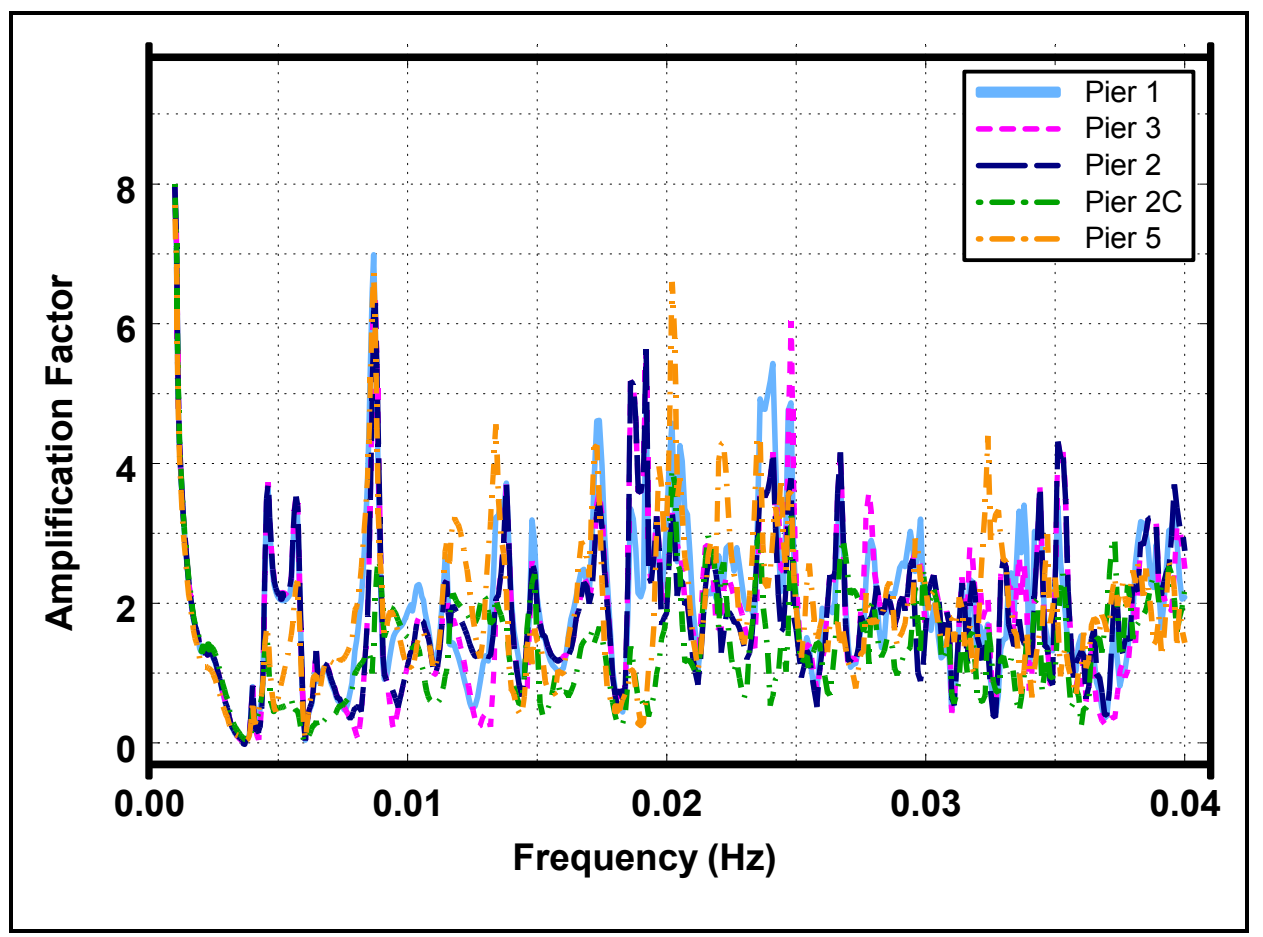

Figure 52. Long wave response, Plan B

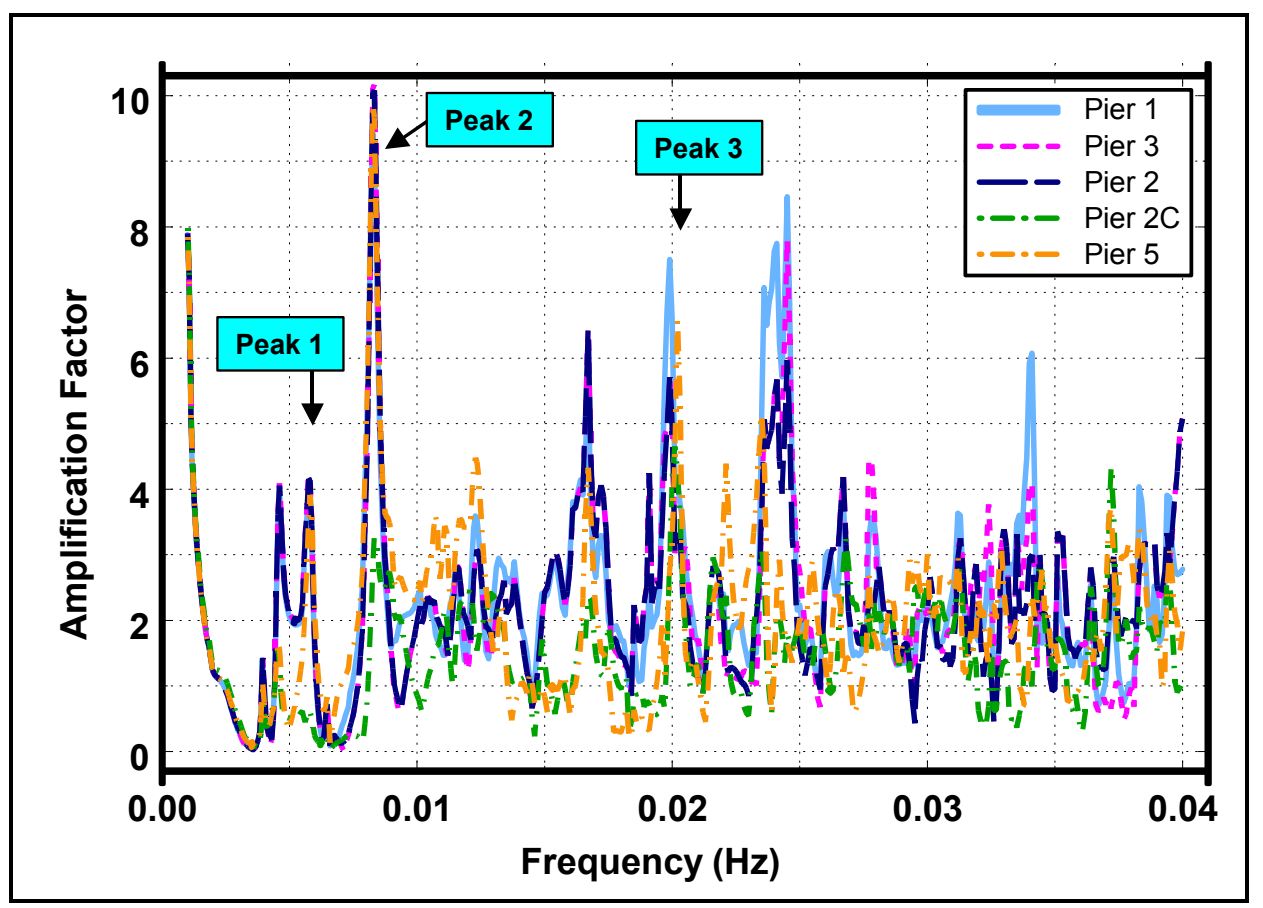

Figure 53. Long wave response, Plan C 


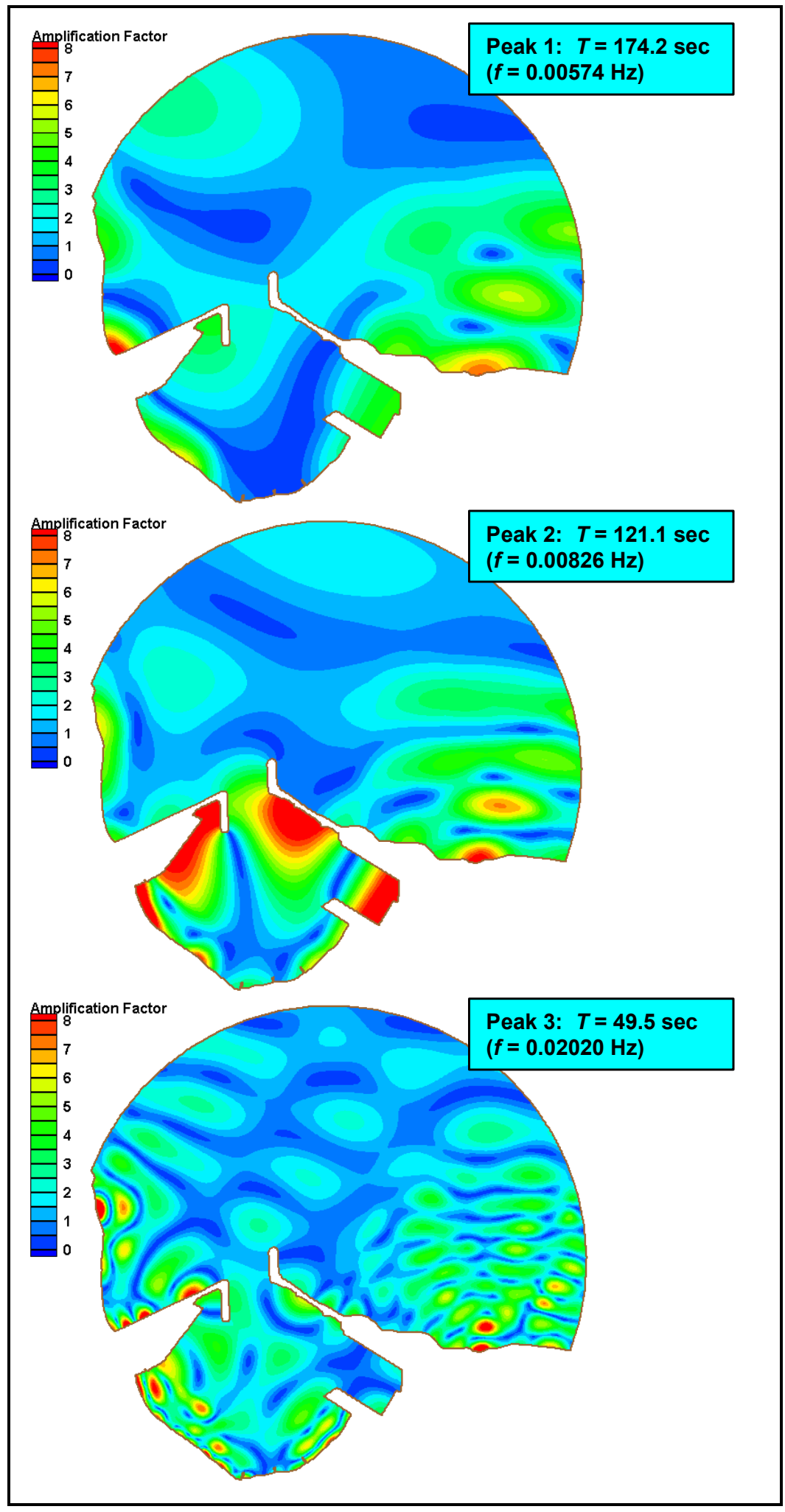

Figure 54. Resonant long wave amplification factor contours, Plan C 


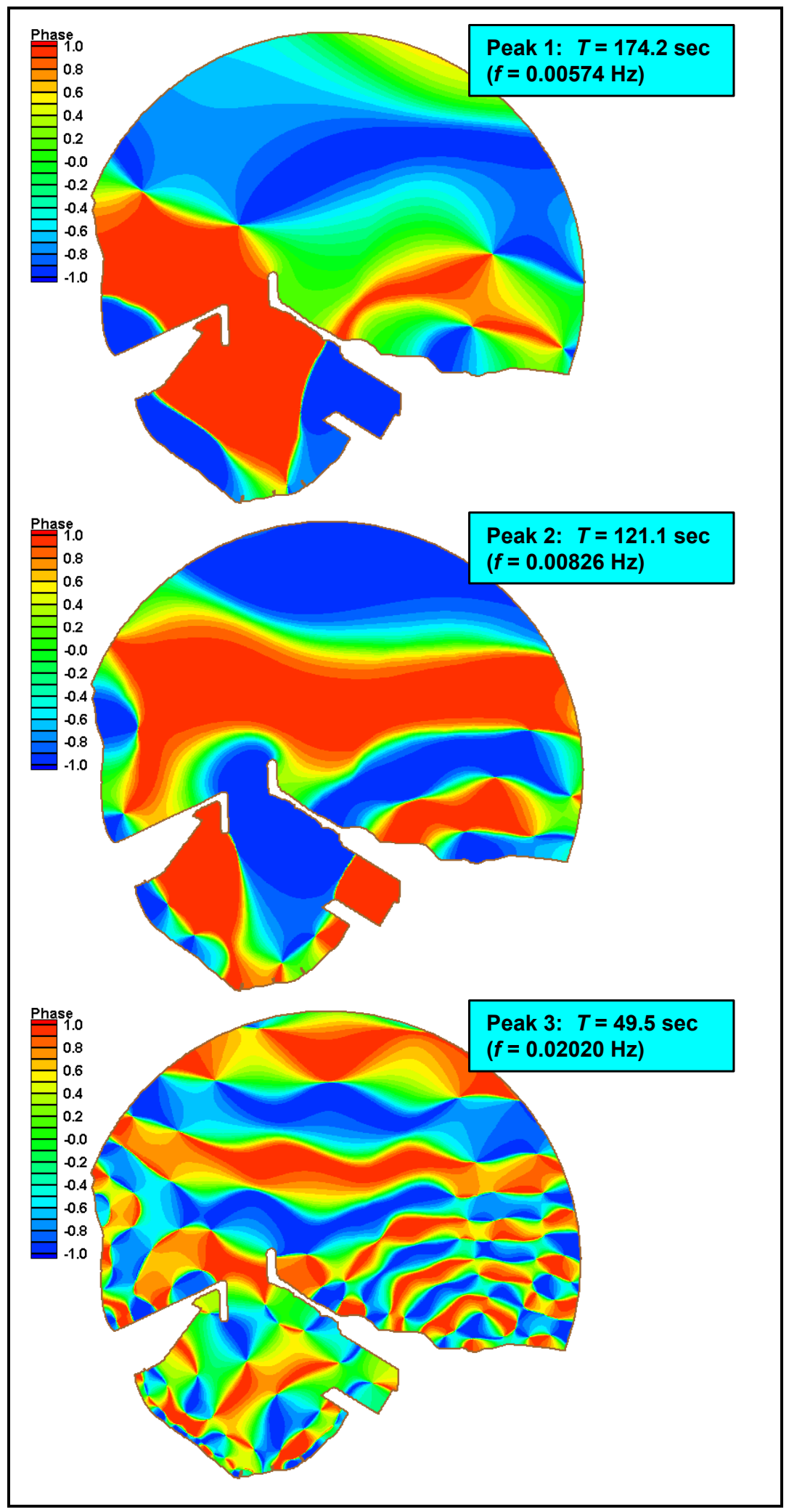

Figure 55. Resonant long wave phase contours, Plan C 
amplification factors inside the harbor. The percent of observations with $H_{\text {s,long }}$ greater than $10 \mathrm{~cm}$ was computed along existing and proposed piers. A $10-\mathrm{cm}-$ long wave height is an approximate threshold for operational use, as discussed by Thompson, Boc, and Nunes (1998) and Thompson, et al. (1996). The calculation procedure was similar to that used in the previous study. For each frequency in the long wave spectrum, amplification factor at each point along the piers was divided by amplification factor at the array gage. These factors were then applied to incident long wave spectra from the gage for data at 3-hr intervals over a 12-month time period. For each gage record, long wave significant height was computed from two segments of the long wave spectrum: one representing wave periods between 100 and $400 \mathrm{sec}$ and the other for wave periods of 30-100 sec. The choice of $100 \mathrm{sec}$ as the dividing point was based on an expected sensitivity of barges to periods in the shorter period range and a lower confidence in that range because of the concern that $K_{r}$ may be slightly high.

The percent of observations with $H_{s, \text { long }}$ greater than or equal to $10 \mathrm{~cm}$ was computed over the 12-month time period November 1993 through October 1994 (Figures 56 and 57). A full year is needed to adequately represent all seasons in the statistics. The year was begun in November 1993 because that month had an exceptionally high level of long wave energy and it should be included in the analysis. These results give insight on the percent of time that operations may be affected. They are best interpreted relative to the existing harbor and past experience. They differ somewhat from the earlier study results because a 12month gage record was used (as compared to the 11-month record available for the previous study), the procedure for interpolating model amplification factors to gage spectral frequencies was upgraded, and the output point locations are more refined.

For the 100-400-sec period range, the 2025 plan and Plan B show consistently reduced long wave activity relative to existing conditions. Plan C shows generally comparable long wave activity relative to existing conditions, but the distribution of long wave activity along the piers is changed. In Plan C, occurrences of $H_{s, \text { long }}$ exceeding $10 \mathrm{~cm}$ are more common along the seaward ends of piers 1 and 5 . This difference is consistent with changes to the harbor and oscillation patterns illustrated earlier.

Results for the 30-100-sec period range are more scattered, but some trends are evident. The 2025 plan and Plan B show reduced long wave activity along piers 1 and 3-5 relative to existing conditions. At pier 2, the 2025 plan, Plan B, and existing harbor are all comparable. In Plan $\mathrm{C}$ (compared to the existing harbor), occurrences of $H_{s, \text { long }}$ exceeding $10 \mathrm{~cm}$ are more common along much of piers 1, 2, and 3. At pier 4, Plan $\mathrm{C}$ is comparable to the existing harbor. At pier 5, Plan $\mathrm{C}$ is comparable to the other plans and considerably less active than the existing harbor. Some of these trends are suggested by the case in the 30100 -sec period range shown in oscillation patterns illustrated earlier.

The third operational guideline relates to long wave velocity along the piers. PIANC (1995) gives criteria for maximum horizontal translational motions of moored vessels in terms of distance and velocity. Since horizontal motions are highly constrained by mooring lines, the velocity criteria seem more useful for 


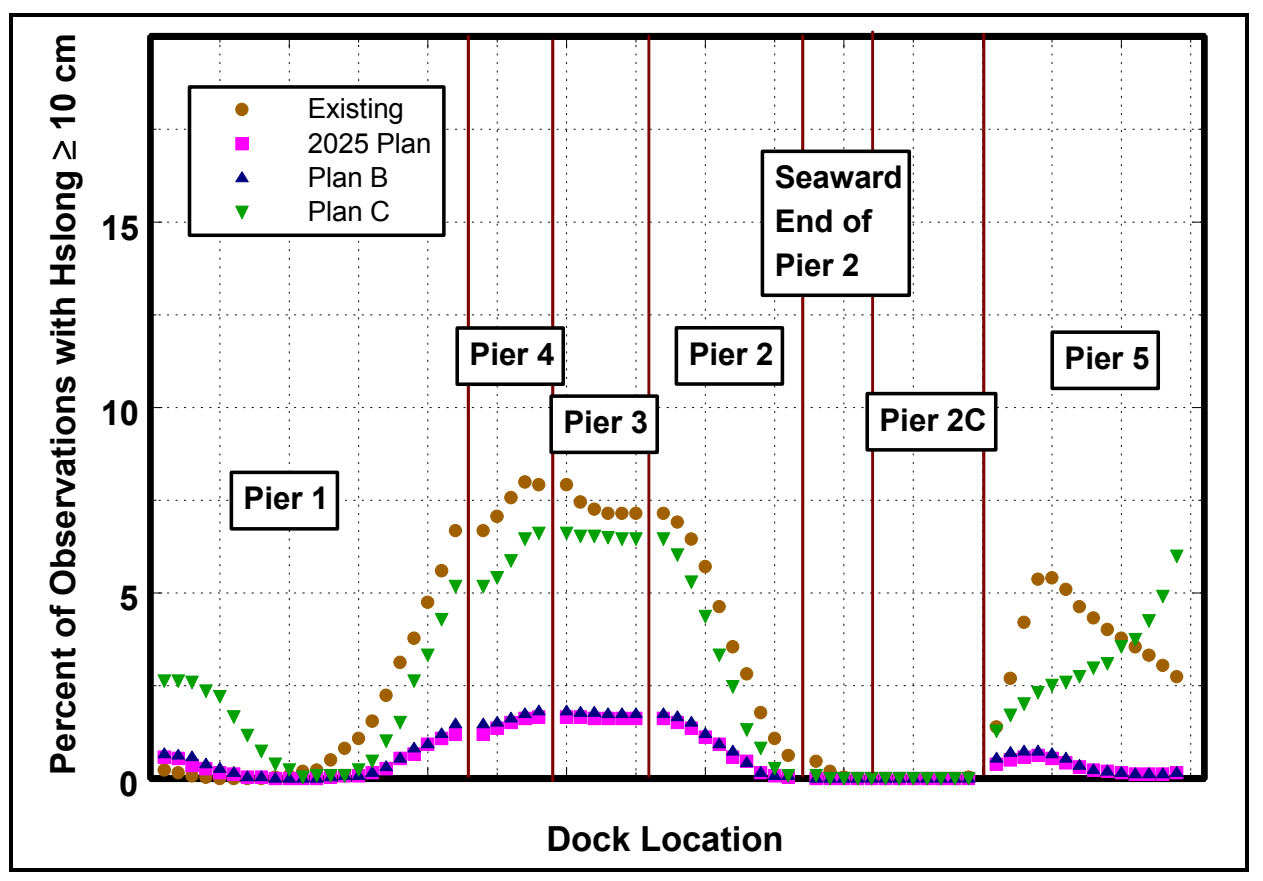

Figure 56. Percent occurrence of $H_{s, \text { long }} \geq 10 \mathrm{~cm}$ at piers, $T=100-400 \mathrm{sec}$

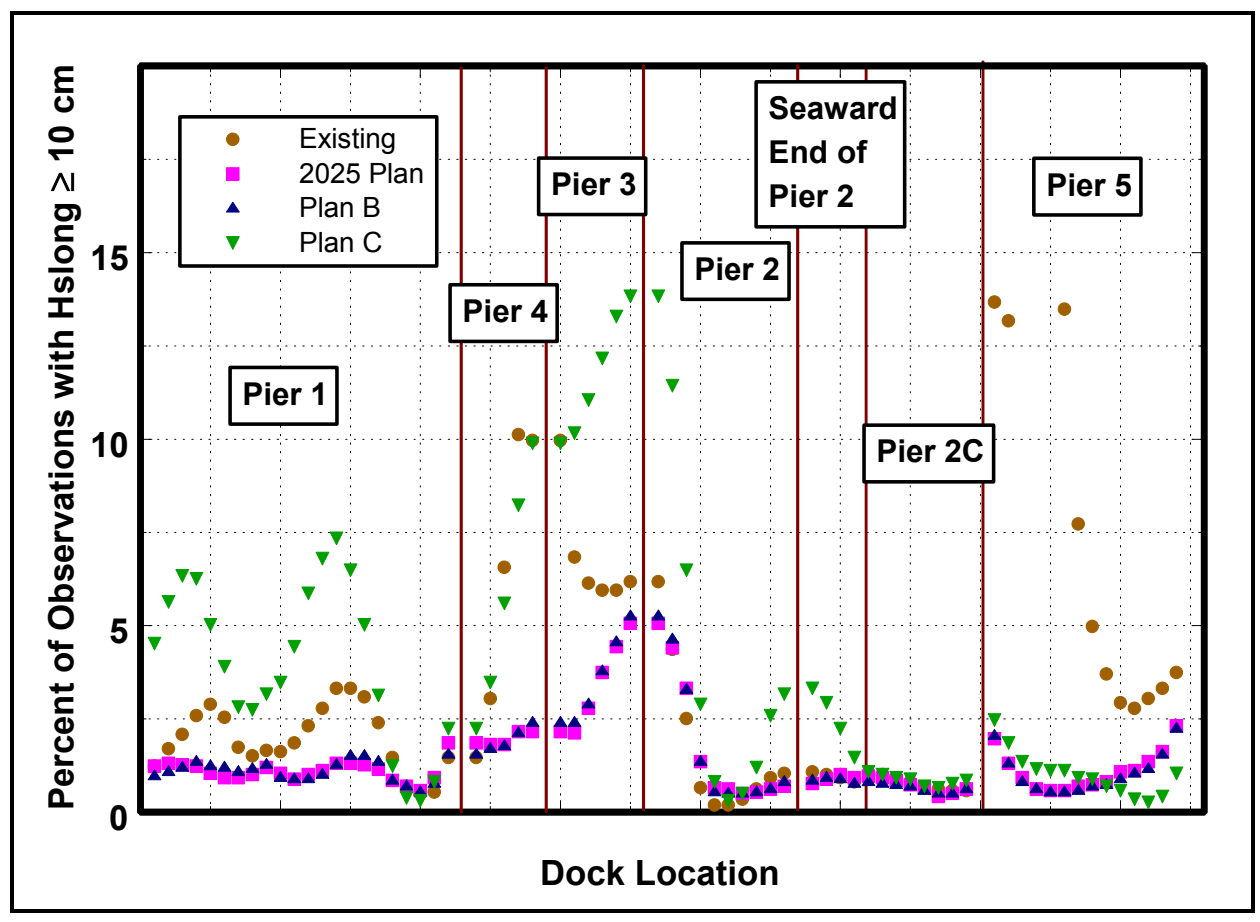

Figure 57. Percent occurrence of $H_{\mathrm{s}, \text { long }} \geq 10 \mathrm{~cm}$ at piers, $T=30-100 \mathrm{sec}$ 
present purposes (though they are stated to be applicable only for fishing vessels, coasters, freighters, ferries, and Ro-Ro vessels). The operational criteria for maximum velocity vary with size of ship, but they can be summarized as: maximum horizontal velocity less than $0.3-0.6 \mathrm{~m} / \mathrm{sec}(1-2 \mathrm{ft} / \mathrm{sec})$. Maximum velocity decreases as ship size increases, with $0.3 \mathrm{~m} / \mathrm{sec}(1 \mathrm{ft} / \mathrm{sec})$ representing an 8,000 DWT ship and $0.6 \mathrm{~m} / \mathrm{sec}(2 \mathrm{ft} / \mathrm{sec})$ representing a 1,000 DWT ship.

Horizontal velocity was computed over the existing harbor for the three selected resonant conditions (Figure 58). Velocity magnitude is directly related to long wave height. Long wave height was $0.1 \mathrm{~m}(0.3 \mathrm{ft})$ in the simulations. Field data in the previous study indicated that incident long wave significant height exceeded $0.15 \mathrm{~m}(0.5 \mathrm{ft})$ for about one event per month during the winter months, with a maximum of about $0.30 \mathrm{~m}(1.0 \mathrm{ft})$. However, long wave energy in the ocean is typically spread over a range of long wave frequencies rather than concentrated at a single resonant frequency. Thus, velocity results in this study are probably representative of a severe long wave event. Although these are velocities of the water due to long wave motion rather than moored ship velocities (as in the PIANC criteria), they still provide a relevant metric for comparing harbor plans. Velocity in mooring areas along existing piers is less than $1 \mathrm{ft} / \mathrm{sec}$ in all three cases. Localized velocities exceeding $1 \mathrm{ft} / \mathrm{sec}$ appear at the north corners of pier 2 and pier 3.

Horizontal velocity results for the 2025 plan and Plan C are given in Figures 59 and 60. Velocity magnitudes are less than $1 \mathrm{ft} / \mathrm{sec}$ along the piers, including pier $2 \mathrm{C}$ and pier 5 . In comparison to the existing harbor, the 2025 plan shows no adverse velocity impact along existing piers. For the peak 3 case, velocity along the middle of pier 5 is higher and covers a longer distance along the pier for the 2025 plan than any of the existing harbor resonances. Again, the significance of model results for periods less than about $100 \mathrm{sec}$ may be exaggerated because the boundary reflection coefficients used. For Plan C, a similar region of higher velocity occurs in the peak 3 case.

Plan $\mathrm{C}$ results in strong velocities in much of the harbor for the peak 2 resonance. The velocity magnitude is greater than in the existing harbor along nearly the entire length of piers 1 and 2 (excluding the exposed end of pier 2). Peak 2 results also indicate a region of strong velocities extending south from the tip of the west breakwater stub. Though not at a pier location, this high velocity region is not present in the other configurations tested, and it might be a navigation concern. 


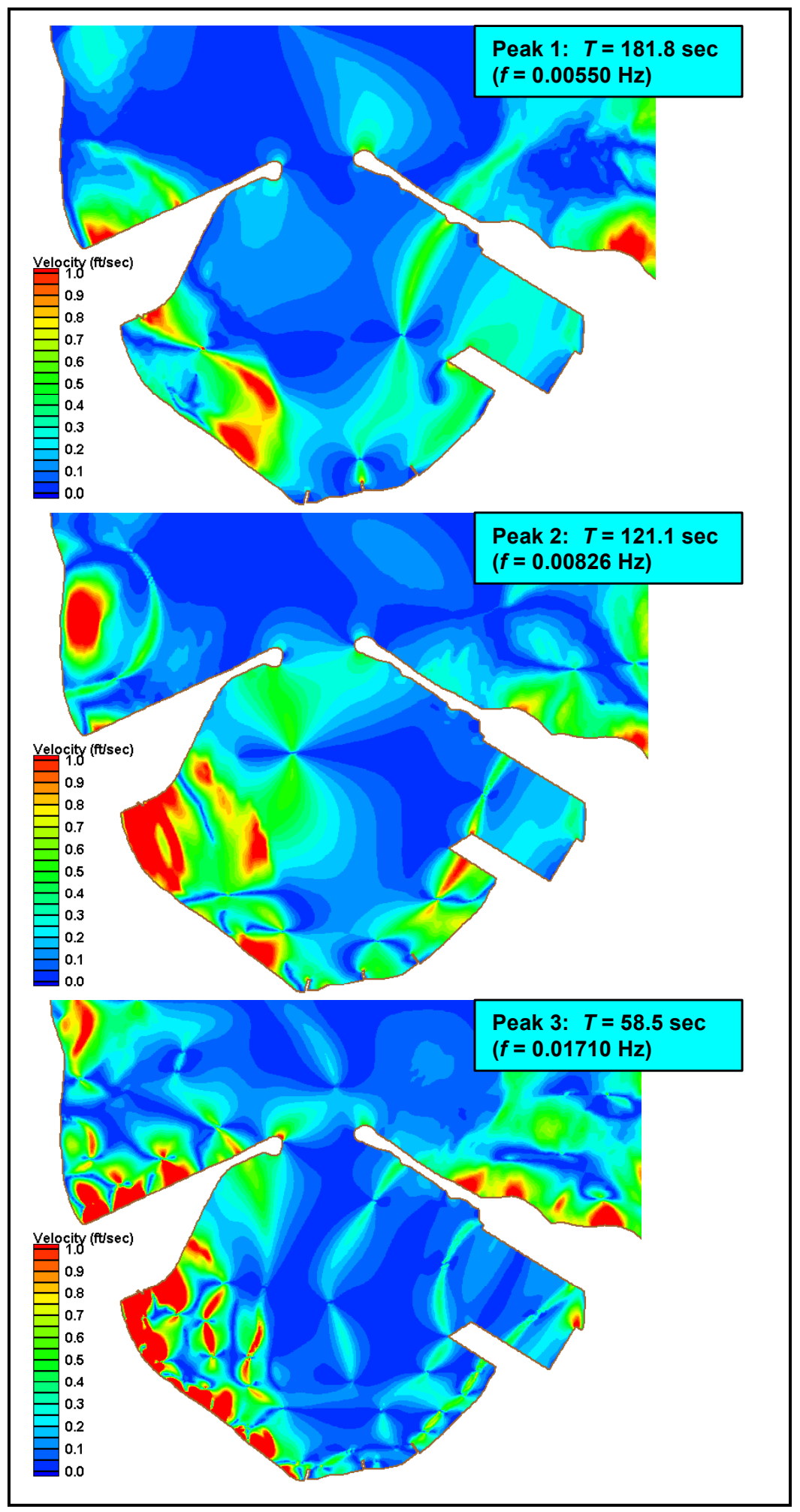

Figure 58. Resonant long wave velocity contours, existing harbor 


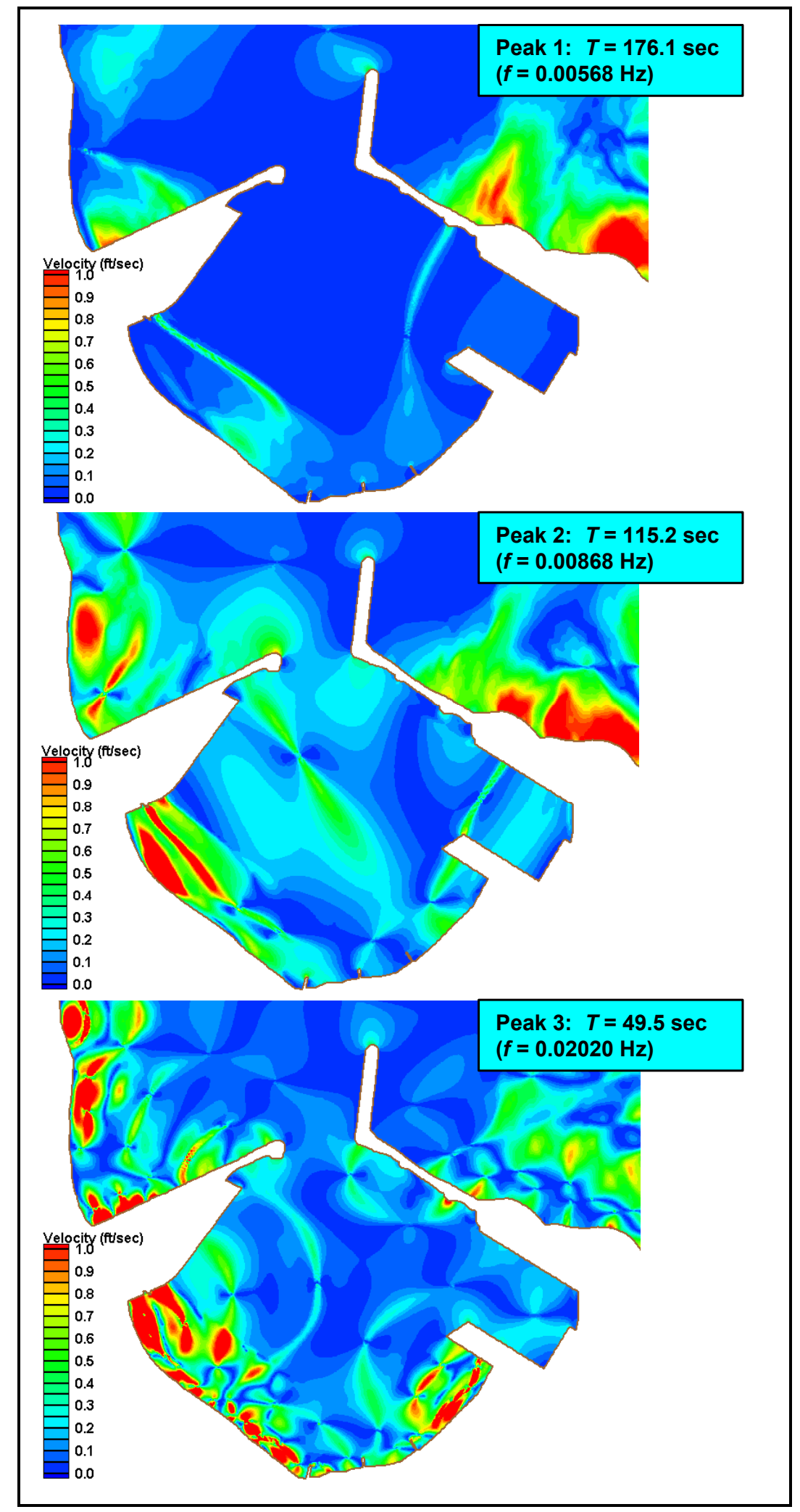

Figure 59. Resonant long wave velocity contours, 2025 plan 


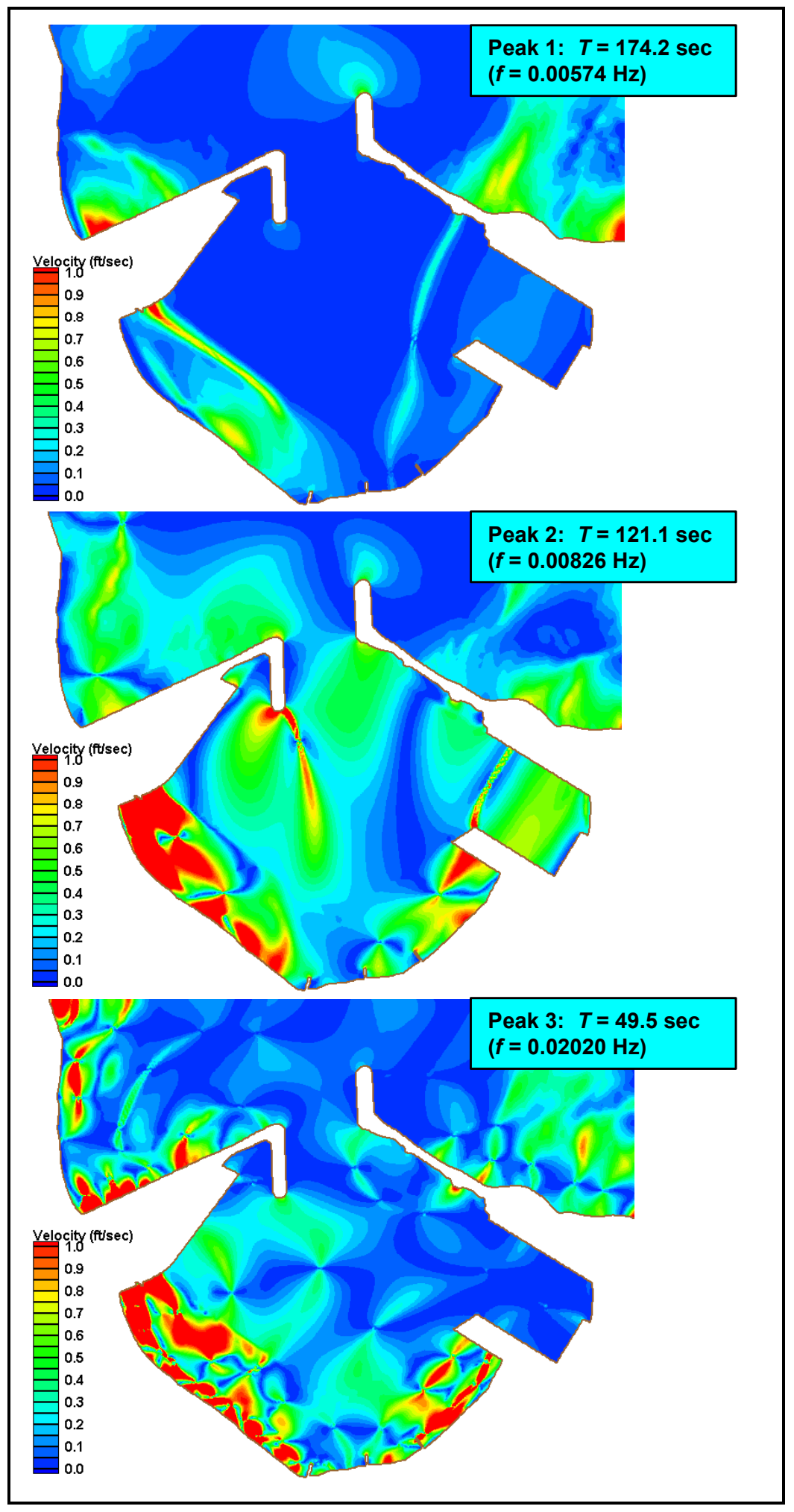

Figure 60. Resonant long wave velocity contours, Plan C 


\section{Conclusions and Recommendations}

Studies of the wave response of Kahului Harbor have produced valuable information about the 2025 master plan and other possible modifications to the harbor. This information updates an earlier study (Thompson et al. 1996) to take into account additional planning, summarized in the 2025 master plan for Kahului Harbor (State of Hawaii 2000).

The numerical model CGWAVE was used to simulate the behavior of three alternative modifications to the harbor. Model results are compared with criteria for operational acceptability and with experience in the existing harbor to the extent possible. The effectiveness of proposed new harbor areas for wind wave and swell protection often has little relationship to protection from oscillations. These two aspects of pier operability must both be considered in judging success of the alternative plans.

An overview of performance of the alternative plans is given by their success relative to a simple, meaningful criterion. For wind waves and swell, success was defined as having $H_{s}>1 \mathrm{ft}$ less than 1 percent of the time along all commercial piers (Table 7). The 1 percent level was chosen because the existing piers 1 and 2 (which are considered successful) meet this criterion but the seaward ends of piers 1 and 2 (which are believed to be approaching the limit of operational conditions) slightly exceed the criterion. Thus, successful piers in Table 7 should be comparable or better than the existing facilities for wind waves and swell.

A similar overview of plan performance for harbor oscillations is given in Tables 8-11. The criteria are expressed in comparative terms relative to the existing harbor facilities.

Specific conclusions and recommendations are as follows:

a. 2025 plan. Generally acceptable for both short and long waves. Wind wave and swell energy may be a concern at pier 5 .

b. Plan B. Generally acceptable for both short and long waves. Wind wave and swell energy may be a concern at pier 5 (but less of a concern than in the 2025 plan). 


\begin{tabular}{|c|c|c|c|c|c|}
\hline \multicolumn{6}{|c|}{$\begin{array}{l}\text { Table } 7 \\
\text { Plans With } H_{s}>1 \mathrm{ft} \text { Less than } 1 \text { Percent of Time }\end{array}$} \\
\hline \multirow[b]{2}{*}{ Plan } & \multicolumn{5}{|c|}{ Area } \\
\hline & Pier 1 & Piers 3 and 4 & Pier 2 & Pier 2C & Pier 5 \\
\hline Existing & $x$ & $x$ & $x$ & & \\
\hline 2025 Plan & $x$ & $x$ & $\mathrm{x}$ & $x$ & \\
\hline Plan B & $\mathrm{x}$ & $x$ & $\mathrm{x}$ & $x$ & \\
\hline Plan C & $x$ & $x$ & $x$ & $x$ & $x$ \\
\hline
\end{tabular}

\section{Table 8}

Plans With $A_{a m p, l}$ Along Piers Comparable to or Less than Existing Harbor Piers

\begin{tabular}{|l|l|l||l||l||l||}
\hline \multirow{2}{*}{ Plan } & \multicolumn{5}{|c|}{ Area } \\
\cline { 2 - 6 } & Pier 1 & Piers 3 and 4 & Pier 2 & Pier 2C & Pier 5 \\
\hline \hline 2025 Plan & X & X & X & X & X \\
\hline Plan B & X & X & X & X & X \\
\hline Plan C & X & X & X & X & \\
\hline
\end{tabular}

Table 9

Plans With Percent $\boldsymbol{H}_{s, \text { long }}$ Greater than or Equal to $10 \mathrm{~cm}$ Along Piers Comparable to or Less than Existing Harbor Piers, 100- to 400-sec Periods

\begin{tabular}{||l|l|l|l|l|l||}
\hline \multirow{2}{*}{ Plan } & \multicolumn{5}{|c||}{ Area } \\
\cline { 2 - 6 } & Pier 1 & Piers 3 and 4 & Pier 2 & Pier 2C & Pier 5 \\
\hline \hline 2025 Plan & X & X & X & X & X \\
\hline Plan B & X & $X$ & $X$ & $X$ & $X$ \\
\hline Plan C & $X$ & $X$ & $X$ & $X$ & $X$ \\
\hline
\end{tabular}




\begin{tabular}{|c|c|c|c|c|c|}
\hline \multicolumn{6}{|c|}{$\begin{array}{l}\text { Table } 10 \\
\text { Plans With Percent } H_{s, \text { long }} \text { Greater than or Equal to } 10 \mathrm{~cm} \text { Along Piers } \\
\text { Comparable to or Less than Existing Harbor Piers, } 30-\text { to } 100-\mathrm{sec} \\
\text { Periods }\end{array}$} \\
\hline \multirow[b]{2}{*}{ Plan } & \multicolumn{5}{|c|}{ Area } \\
\hline & Pier 1 & Piers 3 and 4 & Pier 2 & Pier 2C & Pier 5 \\
\hline 2025 Plan & $x$ & $x$ & $x$ & $x$ & $x$ \\
\hline Plan B & $x$ & $x$ & $x$ & $x$ & $x$ \\
\hline Plan C & & & & $x$ & $x$ \\
\hline
\end{tabular}

\section{Table 11}

Plans With Maximum Long Wave Velocity Along Piers Comparable to or Less than Existing Harbor Piers

\begin{tabular}{|l|l|l|l|l|l||}
\hline \multirow{2}{*}{ Plan } & \multicolumn{5}{|c|}{ Area } \\
\cline { 2 - 6 } & Pier 1 & Piers 3 and 4 & Pier 2 & Pier 2C & Pier 5 \\
\hline \hline 2025 Plan & $\mathrm{X}$ & $\mathrm{X}$ & $\mathrm{X}$ & $\mathrm{X}$ & $\mathrm{X}$ \\
\hline Plan B & $\mathrm{X}$ & $\mathrm{X}$ & $\mathrm{X}$ & $\mathrm{X}$ & $\mathrm{X}$ \\
\hline Plan C & & $\mathrm{X}$ & & $\mathrm{X}$ & $\mathrm{X}$ \\
\hline
\end{tabular}

c. Plan C. Generally acceptable for short waves; possible operational problems for long waves. The long wave amplification factors at one resonance (121.1-sec period) are quite high at piers 1-4 and pier 5, indicating a potential for greater operational difficulties than in the existing harbor. For this resonance, strong velocities could be experienced along most of the length of piers 1 and 2. Long wave significant heights exceeding the 10 -cm threshold in the $30-100-\mathrm{sec}$ period range indicate that piers 1-3 will be somewhat more active than in the existing harbor.

Wind wave and swell significant height along piers 1-4 is generally reduced in the plans in comparison to the existing harbor. The increased entrance protection has only a slight impact at these piers, but deepening the harbor adjacent to piers 3 and 4 has a noticeable effect. At the exposed end of pier 2 and along pier $2 \mathrm{C}$, plan changes to the entrance significantly reduce wave heights relative to the existing harbor. Differences between plan impacts along pier $2 \mathrm{C}$ are relatively small.

In all of the plans, wind wave and swell energy along pier 5 is greater than along pier 1 in the existing harbor. This is a natural consequence of creating a new pier area on the west side of the harbor, which is more exposed to incoming waves through the breakwater gap. Pier 5 is planned as a passenger ship facility. Operational tolerance of wave activity for passenger ships expected to be calling at pier 5 is not well established. Thus, the importance of the increasing level of 
protection afforded by the 2025 plan, Plan B, and Plan C is difficult to judge. The criterion used in this study conclusions, 1-ft significant wave height exceeded 1 percent of the time, is expected to be a useful (possibly conservative) guideline.

Plans tested in this study bore a similarity to some plans considered in the previous study. Other than the seaward extension of the east breakwater, the 2025 plan and Plan B resemble Plan 4a in the previous study. The breakwater stub acts to decrease wind wave and swell energy entering the harbor, but has no appreciable impact on harbor oscillations. Plan $C$ resembles Plan $4 \mathrm{~b}$ in the previous study. Comparing these plans, Plan $\mathrm{C}$ has lower short wave heights in the harbor (due to the seaward-extending east breakwater stub) but long wave response is nearly the same.

Although Plans B and C provided better wind wave and swell protection to pier areas than the 2025 plan, it should be re-emphasized that the reoriented entrance channel in the 2025 plan takes better advantage of a naturally deep approach to the harbor entrance. The approach in Plans B and C, which is the same as the existing approach, is adequate for vessels considered in the 2025 master plan. However, longer range considerations of anticipated vessel sizes and navigation needs might also be appropriate if plans progress toward building a relatively costly seaward extension of the east breakwater.

A physical model study to refine and validate the preferred plan for design is strongly recommended as a final phase of the studies. The physical model could include a capability to evaluate the impact of crosscurrents outside the harbor entrance on navigation. The physical modeling component was part of the originally proposed CHL study. 


\section{References}

Demirbilek, Z., and Panchang, V. (1998). "CGWAVE: a coastal surface water wave model of the mild slope equation," Technical Report CHL-98-26, U.S. Army Engineer Waterways Experiment Station, Vicksburg, MS.

Markle, D. G., and Boc, S. J., Jr. (1994). "Periodic inspections of Kahului and Laupahoehoe breakwaters, Hawaii; Report 1, base conditions," Technical Report CERC-94-12, U.S. Army Engineer Waterways Experiment Station, Vicksburg, MS.

Okihiro, M. S., and Guza, R. T. (1996). "Observations of seiche forcing and amplification in three small harbors," Journal of Waterway, Port, Coastal and Ocean Engineering, American Society of Civil Engineers, 122(5), 232238.

PIANC. (1995). "Criteria for movements of moored ships in harbours, a practical guide," Report of Working Group No. 24, Supplement To Bulletin No. 88, Brussels, Belgium.

Sabersky, R. H., and Acosta, A. J. (1964). Fluid flow, a first course in fluid mechanics. Fred Landis, ed., The Macmillan Co., New York.

Sargent, F. E., Markle, D. G., and Grace, P. J. (1988). "Case histories of Corps breakwater and jetty structures; Report 4, Pacific Ocean Division," Technical Report REMR-CO-3, U.S. Army Engineer Waterways Experiment Station, Vicksburg, MS.

State of Hawaii. (1994). "Master plan update for Kahului Harbor," Harbors Division, Department of Transportation, State of Hawaii, and Kahului Harbor Task Force, Honolulu, Hawaii.

State of Hawaii. (2000). "Kahului Commercial Harbor, 2025 master plan," Harbors Division, Department of Transportation, State of Hawaii, Honolulu, Hawaii.

Thompson, E. F., Boc, S. J., Jr., and Nunes, F. S. (1998). "Evaluating operational impact of waves along proposed harbor piers," Proceedings, Ports '98, ASCE and PIANC, Long Beach, CA, 8-11 March 1992.

Thompson, E. F., Hadley, L. L., Brandon, W. A., McGehee, D. D., and Hubertz, J. M. (1996). "Wave response of Kahului Harbor, Maui, Hawaii," Technical Report CERC-96-11, U.S. Army Engineer Waterways Experiment Station, Vicksburg, MS. 


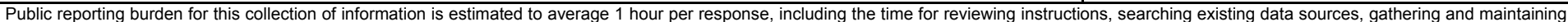

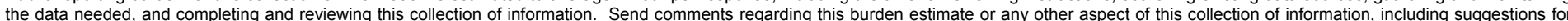

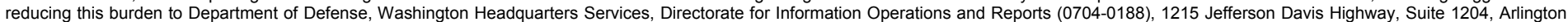

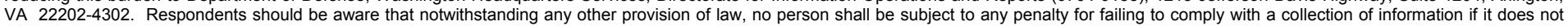
display a currently valid OMB control number. PLEASE DO NOT RETURN YOUR FORM TO THE ABOVE ADDRESS.

\begin{tabular}{l|c}
$\begin{array}{l}\text { 1. REPORT DATE (DD-MM-YYYY) } \\
\text { September } 2002\end{array}$ & $\begin{array}{c}\text { 2. REPORT TYPE } \\
\text { Final report }\end{array}$ \\
\hline
\end{tabular}

4. TITLE AND SUBTITLE

Wave Climate and Wave Response, 2025 Plan, Kahului Harbor, Maui, Hawaii

5a. CONTRACT NUMBER

3. DATES COVERED (From - To)

5a. CONTRACT NUMBER

5b. GRANT NUMBER

5c. PROGRAM ELEMENT NUMBER

6. AUTHOR(S)

5d. PROJECT NUMBER

Edward F. Thompson, Zeki Demirbilek

5e. TASK NUMBER

5f. WORK UNIT NUMBER

7. PERFORMING ORGANIZATION NAME(S) AND ADDRESS(ES)

8. PERFORMING ORGANIZATION REPORT NUMBER

U.S. Army Engineer Research and Development Center

Coastal and Hydraulics Laboratory

ERDC/CHL TR-02-21

3909 Halls Ferry Road

Vicksburg, MS 39180-6199

\section{SPONSORING / MONITORING AGENCY NAME(S) AND ADDRESS(ES)}

10. SPONSOR/MONITOR'S ACRONYM(S)

U.S. Army Engineer District, Honolulu

Building 230

Fort Shaffer, HI 96858-5440

11. SPONSOR/MONITOR'S REPORT NUMBER(S)

\section{DISTRIBUTION / AVAILABILITY STATEMENT}

Approved for public release; distribution is unlimited.

\section{SUPPLEMENTARY NOTES}

\section{ABSTRACT}

Present and projected commercial activities in Kahului Harbor, Maui, HI, indicate that new berths for barge and passenger ship operations will be needed. The U.S. Army Engineer District, Honolulu, in coordination with the Harbors Division, Department of Transportation, State of Hawaii, requested numerical (computer) model studies in support of long-term planning. A numerical model, validated with field measurements for short waves (wind waves and swell) and long waves (harbor oscillations), was used to evaluate the technical feasibility of three alternative modifications to the harbor, including the Kahului Commercial Harbor 2025 Master Plan. Model results were compared to experience in the existing harbor and to general criteria for operational acceptability.

$\begin{array}{ll}\text { 15. SUBJECT TERMS } & \text { Numerical modeling } \\ \text { Harbor resonance } & \text { Wind waves and swell }\end{array}$

Kahului Harbor

16. SECURITY CLASSIFICATION OF:

a. REPORT

UNCLASSIFIED b. ABSTRACT
UNCLASSIFIED

c. THIS PAGE

UNCLASSIFIED

Wind waves and swell

17. LIMITATION OF ABSTRACT
18. NUMBER OF PAGES

75 19a. NAME OF RESPONSIBLE PERSON

19b. TELEPHONE NUMBER (include area code) 